\title{
Projected Climate Change Impact on Hydrology, Bioclimatic Conditions, and Terrestrial Ecosystems in the Asian Highlands
}

Robert Zomer, Antonio Trabucco, Mingcheng Wang, Jianchu Xu 


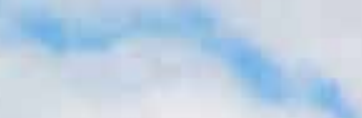
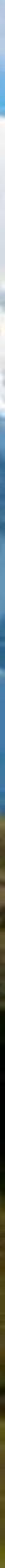


\section{Projected Climate Change Impact on Hydrology, Bioclimatic Conditions, and Terrestrial Ecosystems in the Asian Highlands}

Robert Zomer, Antonio Trabucco, Mingcheng Wang, Jianchu Xu

Working Paper 222 


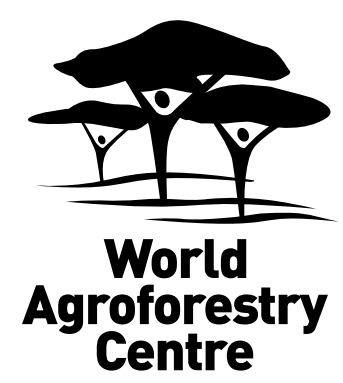

\section{Correct citation:}

Zomer, R.J.; Trabucco, A.; Wang, M.; Xu, J.C., 2016. Projected Climate Change Impact on Hydrology, Bioclimatic Conditions, and Terrestrial Ecosystems in the Asian Highlands. ICRAF Working Paper 222. World Agroforestry Centre East and Central Asia, Kunming, China. 56 pp.

DOI: http://dx.doi.org/10.5716/WP16006.PDF

Titles in the Working Paper Series aim to disseminate interim results on agroforestry research and practices and stimulate feedback from the scientific community. Other publication series from the World Agroforestry Centre include: Agroforestry Perspectives, Technical Manuals and Occasional Papers.

Published by the World Agroforestry Centre

East and Central Asia Regional Programme

\% Kunming Institute of Botany, Chinese Academy of Science

3/F North Research Building

Heilongtan, 650201 Kunming

Yunnan Province, P.R. China

Tel.: +86-871-6522-3014 - Fax: +86-871-6522-3377

Email: icraf-eca@,cgiar.org

Internet: www.worldagroforestry.org/eca

(C) World Agroforestry Centre 2016

Working Paper No. 222

Photos: Robert Zomer, Maya Zomer, Uliana Sotnikova

\section{Disclaimer and copyright}

The views expressed in this publication are those of the author(s) and not necessarily those of the World Agroforestry Centre. Articles appearing in this publication may be quoted or reproduced without charge, provided the source is acknowledged. All images remain the sole property of their source and may not be used for any purpose without written permission of the source. 


\section{About the authors}

Robert J. Zomer, Ph.D. is a landscape ecologist with a broad background in plant community, forest and agricultural ecology. His research in the Asian Highlands region includes environmental modelling and landscape-level spatial analysis to investigate the impact of projected climate change on biodiversity conservation and sustainable development. He is currently a visiting professor at Kunming Institute of Botany and a Senior Landscape Ecologist at the World Agroforestry Centre's East and Central Asia Regional Programme.

Dr Antonio Trabucco, Ph.D. is a landscape ecologist with a strong background in geospatial analysis and wide scientific interest on the interactions between climate, natural/semi-natural ecosystems and human needs. He currently works as a research scientist at the Euro-Mediterranean Center on Climate Change (CMCC) investigating the impact of climate change on ecosystem services and agricultural production at Mediterranean and global scales.

Mingcheng Wang, M.Sc. has a geospatial modelling and remote sensing background, with advanced skills in multi-spectral and multi-resolution satellite remote sensing, geographic information systems (GIS), geospatial analysis, spatial analytical programming and map production, and spatial data analysis and statistics. Special interests include the impacts of climate change on hydrological processes, terrestrial ecosystems, biodiversity conservation, farming systems, and the spatial distribution of natural biodiversity, cropping systems and potentially useful agroforestry species.

Jianchu Xu, Ph.D. is an internationally respected leading ethno-ecologist who works in coupled human environmental systems. His current research includes investigation of early warning signals of global change, trans-boundary water governance, landscape restoration, ecosystem services and their resilience, agriculture, and integrative conservation. Dr Xu leads the World Agroforestry Centre's East and Central Asia regional programme.

\section{Acknowledgements}

Research was part of an IDRC (Canada)-supported project on "Building Effective Water Governance in the Asian Highlands". The field work was also supported by the National Key Basic Research Program of China (Grant No. 2014CB954100), and National Science Foundation China (Grant No. 31270524). Additional support was also provided from the CGIAR Research Programs on Forests, Trees and Agroforestry (CRP6) and Climate Change, Agriculture, and Food Security (CRP 7). Many thanks to Dr Robert Hijmans of the University of California-Davis for providing the down-scaled CIMP5-ESMs. 



\section{Contents}

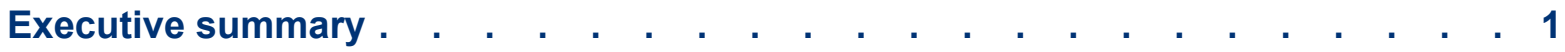

Projected change in bioclimatic indicators . . . . . . . . . . . . . . . . . . . . . . . 1

Projected Change in Spatial Distribution of Bioclimatic Conditions . . . . . . . . . . . . . 3

Introduction .

Overview. . . . . . . . . . . . . . . . . . . . . . 6

Background. . . . . . . . . . . . . . . . . . . . . . . . 6

Regional climate change. . . . . . . . . . . . . . . . . . . . . . . . . . . . . . 8

Climate analysis and modelling of impacts on terrestrial ecosystems: assumptions, sources of uncertainty, and other limitations . . . . . . . . . . . . . . . . . . . . . . . . . . . 10

Methods overview . . . . . . . . . . . . . . . . . . . . . . . . . . . . . . . . . . 13

Projected changes in temperature and precipitation . . . . . . . . . . . . . . . . . . . 13

Projected changes in potential evapotranspiration and aridity-wetness index . . . . . . . . . 15

In-situ soil water balance model . . . . . . . . . . . . . . . . . . . . . . . . . . . 15

Environmental stratification and delineation of bioclimatic zones and strata . . . . . . . . . 15

Modelling of projected future bioclimatic conditions . . . . . . . . . . . . . . . . . . . 17

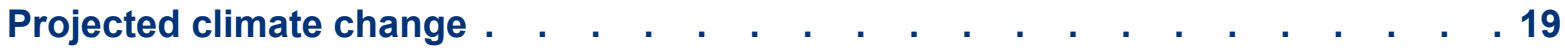

Year of climate departure . . . . . . . . . . . . . . . . . . . . . . . . . . . . . . 19

Mean annual temperature . . . . . . . . . . . . . . . . . . . . . . . . . . . . . 20

Mean annual precipitation . . . . . . . . . . . . . . . . . . . . . . . . . . . . . 22

Mean annual Potential Evapotranspiration (PET) . . . . . . . . . . . . . . . . . . . . . . 24

Mean annual Aridity-Wetness Index (AWI) . . . . . . . . . . . . . . . . . . . . . . 26

In-situ hydrologic status: soil water balance model . . . . . . . . . . . . . . . . . . . . 28

Projected change in spatial distribution of bioclimatic conditions . . . . . . . 32

Bioclimatic stratification. . . . . . . . . . . . . . . . . . . . . . . . . . . . . . 32

Projected change in spatial distribution of bioclimatic zones. . . . . . . . . . . . . . . . 32

Summary and conclusions . . . . . . . . . . . . . . . . . . . . . . . . . . . . . 37

Major findings. . . . . . . . . . . . . . . . . . . . . . . . . . . . . . . . . . 37

Conclusions. . . . . . . . . . . . . . . . . . . . . . . 40

References. . . . . . . . . . . . . . . . . . . . . . . . . . . 43

Appendix . . . . . . . . . . . . . . . . . . . . . . . . . . . . . . . . . 46

Appendix 1: CIMP5 Earth System Models . . . . . . . . . . . . . . . . . . . . . . 46 


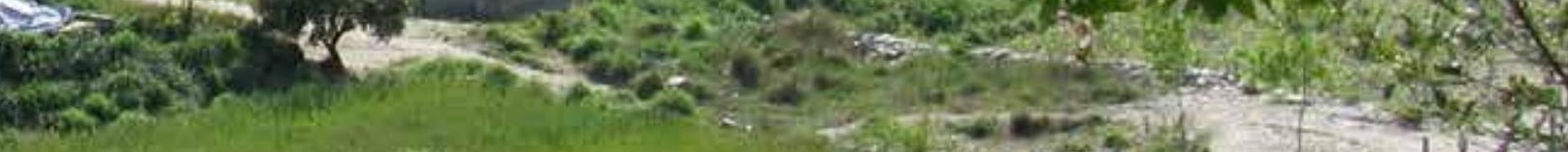
ines.

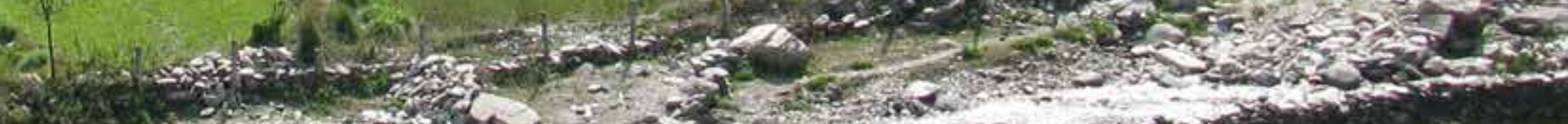

\section{tixis}

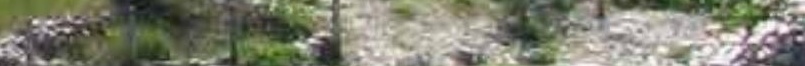

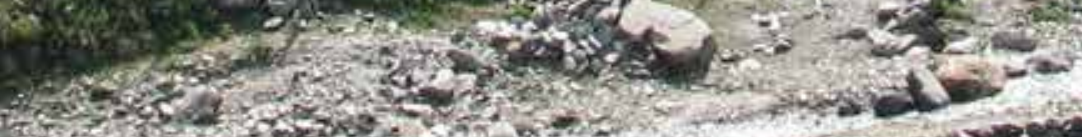

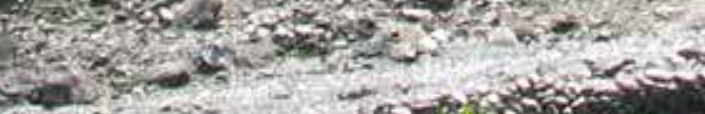

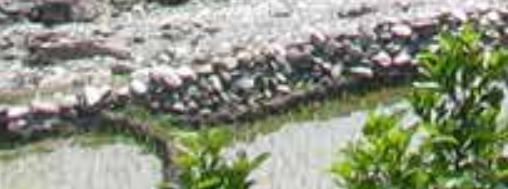

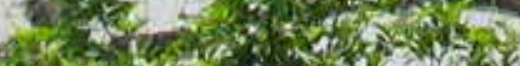

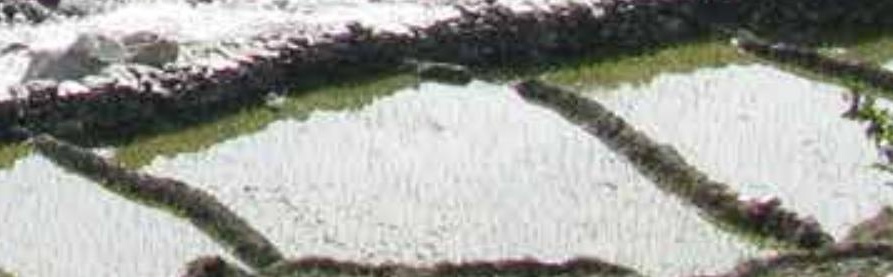
$\sqrt{152}$

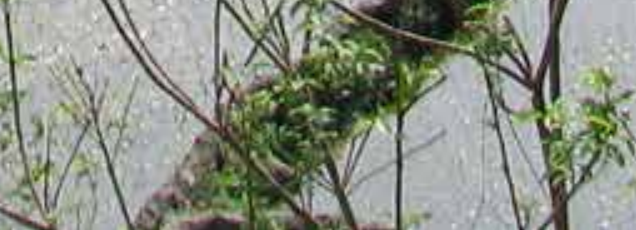

(1) $/ 2$

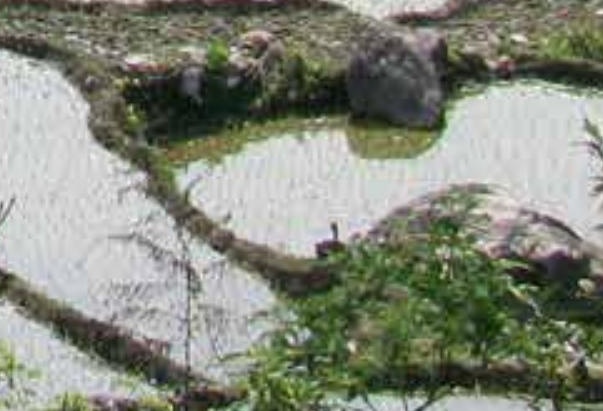

sive of

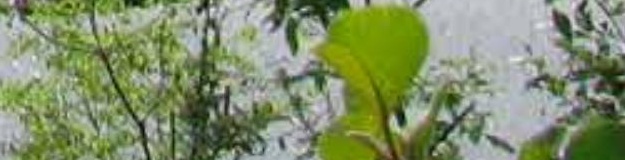

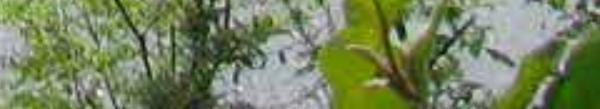

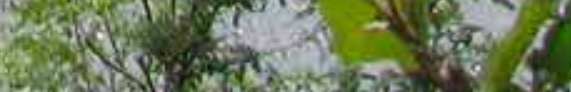




\section{Executive summary}

Understanding and planning for adaptation and mitigation of climate change is crucial to implementation of sustainable development and effective environmental and biological conservation in the Asian Highlands region. Climate change is and has been on-going, and is already evident and widely observed across the region. The results of a spatial analysis, based upon an ensemble of CIMP5 Earth System Model projections, indicate rapid and drastic changes across the Asian Highlands region with significant and increasing spatial displacement of historically "normal" distributions of bioclimatic conditions. As a consequence, significant and increasing biophysical and biological perturbance for biodiversity, ecosystems, ecosystem services, and agricultural and pastoral systems, can be expected to become increasingly prominent in the medium-term future under all of the IPCC-developed Representative Concentration Pathways (RCP), i.e. emission scenarios.

The magnitude of predicted change indicated by our analysis points to a prolonged period of profound impacts on terrestrial ecosystems, biodiversity, hydrological cycles, and ecosystem services across the Asian Highlands. This will be amply evident and well under way by 2050 , as a result of warming and climate disruption, and the shifting of bioclimatic conditions spatially, particularly within highly heterogeneous mountainous terrain and the high elevation highland areas of this region. This change will affect and have increasingly substantial and direct impacts on human health and livelihoods throughout this region as this century progresses. Likewise, effectiveness of both conservation efforts and sustainable development will be affected as ecological conditions across the region change, for example, allowing for newly invasive species or going beyond limits conducive for endangered species currently found within narrow niches or designated protected areas.

There is an overriding necessity to recognize the now central role of a dynamic and rapidly changing climate and bioclimatic conditions across the Asian Highlands region, and a need to incorporate, mainstream and plan for adaptation within most aspects of sustainable development and conservation planning, efforts and policy. The spatial articulation of results from this analysis allow for a detailed and geographically referenced overview of the potential impacts of this projected change on bioclimatic conditions across the region. Results are articulated and summarized by the major river basins comprising the Asian Highlands region.

Among the major findings of this analysis we highlight the following:

\section{Projected change in bioclimatic indicators}

- The highland and mountainous regions of both monsoonal and continental Asia are approaching novel sets of bioclimatic conditions more rapidly than the lowland plains of the region. Regions in the northern and south-eastern portions of the Tibetan Plateau indicate particularly early onset of novel conditions. The estimated year of climate departure (i.e. tipping point for unprecedented climatic conditions) for the countries in the greater Asian Highlands region ranges from the 2051 to 2071 under the more moderate RCP 4.5 emissions scenarios, and ranges from 2036 to 2052 under the worst case RCP 8.5 scenario. This is slightly earlier than for the global average of 2069 for RCP 4.5 and 2047 for RCP 8.5 (Mora et al, 2013).

- By 2050 (i.e. representing a 20-year average between 2041-2060), mean annual temperatures for the Asian Highlands (averaged over all upper basins) are projected to increase from $2.5^{\circ} \mathrm{C}$ to $3.1^{\circ} \mathrm{C}$. All the river basins comprising the region show increases in temperature, with the Indus Basin showing the greatest average increase, from $2.9^{\circ} \mathrm{C}$ to $3.5^{\circ} \mathrm{C}$. 
- Temperature increases are clearly larger at higher elevations across the region, notably over the Tibetan Plateau. Mean annual temperatures over the Tibetan Plateau are projected to rise from $2.8^{\circ} \mathrm{C}$ to $3.4^{\circ} \mathrm{C}$ by 2050 . Notably, the Tibetan Plateau warms from an average mean annual temperature of $-1.5^{\circ} \mathrm{C}$ up to between $1.3^{\circ} \mathrm{C}$ and $1.9^{\circ} \mathrm{C}$, with uncertain implications for impacts on large areas of permafrost and frozen peatlands, and consequently, vast stores of terrestrially sequestered carbon.

- All nine river basins within the Asian Highlands region are projected to experience slight to substantial increases in precipitation by 2050 . Across all basins, annual precipitation is projected to increase by as much as $39 \mathrm{~mm}$ to $48 \mathrm{~mm}$ on average. The Indus River Basin, already fairly arid with $465 \mathrm{~mm} / \mathrm{yr}$ on average under current conditions, is projected to slightly increase by between $8 \mathrm{~mm}$ and $23 \mathrm{~mm}$, whereas the already very wet Meghna River Basin ( $2897 \mathrm{~mm} / \mathrm{yr}$ on average) increases by up to almost 10\% (i.e. projected to increase between $199 \mathrm{~mm}$ to $281 \mathrm{~mm}$ ). Overall, however, we caution that confidence levels for the precipitation projections of the CIMP5 Earth System Models are still, in general, quite low, with variability among models generally higher (i.e. of lower confidence levels) than for temperature projections, which have a higher level of agreement among models and can be considered fairly robust.

- The averaged mean potential evapotranspiration (PET) for the whole Asian Highlands region of $903 \mathrm{~mm} / \mathrm{yr}(1960-2000)$ increases by more than $9 \%$ to over $11 \%$ (between $85 \mathrm{~mm}$ to $103 \mathrm{~mm}$ ) by 2050, indicating significantly high water demand by both natural (unmanaged or lesser managed) ecosystems, and managed agricultural or pastoral systems. Similar to mean annual temperatures, the Tibetan Plateau shows the largest increase in PET, from more than $13 \%$ to almost $17 \%$ increase (from $94 \mathrm{~mm}$ to $117 \mathrm{~mm}$ ). In contrast, PET averaged across the wet Meghna Basin increases by less than 3\%. These results seem to indicate that any benefit derived from increased precipitation in the drier basins will provide little benefit, likely just compensating for the increase in PET (driven by increased temperatures).

- The Aridity-Wetness Index (AWI) is a general indicator of bioclimatic and plant growth conditions. Overall the entire upland Asian Highlands region shows a very slight drying trend. The already dry Indus Basin showed the greatest (though still slight) drying trend, followed by the Yangtze, Mekong, and the Brahmaputra Basins. The Meghna is projected to become even wetter with a substantial increase in an already saturated AWI, along with the Irrawaddy to a lesser extent.

- The spatially articulated soil water balance approach, used to model in-situ hydrological status, indicated that Annual Vapor Flow or Actual Evapotranspiration (AET) for the upland Asian Highlands region increases by more than 5\%. However, the Tibetan Plateau sees large increases in AET, from 9\% to 11\%, along with the Salween, the Brahmaputra, and Yangtze Rivers. Only the Meghna Basin shows decreased AET.

- All basins showed a slight drying trend in Soil Water Content (SWC), with the overall average SWC for the upland Asian Highlands region projected to decrease 5\% by 2050 . The Tibetan Plateau showed the largest decrease in SWC (9\% to 13\%), along with the Indus (almost 9\%), noting the already dry state of the soil in these basins.

- In general, for the upper Asian Highlands region as a whole, the water balance model indicates a slight increase in in-situ excess water (ROF). This is an estimation of water from precipitation that is left over after AET and SWC changes are accounted for. The Ganges Basin increases its ROF by $13 \%$ to $15 \%$, while the Salween Basin increases from $10 \%$ to $15 \%$. The Indus Basin sees only a very slight increase, along with the Mekong. The Meghna Basin, with increases from $9 \%$ to $13 \%$, also sees the largest absolute increase in ROF (192 $\mathrm{mm}$ to $263 \mathrm{~mm}$ ). 


\section{Projected Change in Spatial Distribution of Bioclimatic Conditions}

- Sixteen major bioclimatic zones, comprised of 102 strata, were identified through this study as currently found within the upper basins of the Asian Highlands region, ranging from the Extremely Hot and Moist strata at low elevations in the south and southeast, to Extremely Cold and Wet zones at the higher elevations. Warm tropical strata are found along the lower elevations and southern slopes of the mountains, and in the southeast, e.g. the tropical mountains of Yunnan, Laos, and Myanmar, with vast areas of Extremely Cold, Cold and Cool zones covering the high elevation regions of the Tibetan Plateau.

- Mean annual temperatures for bioclimatic zones are generally inversely correlated with their average elevation, however the zonal distribution of bioclimatic conditions also reflects a strong influence of latitudinal, altitudinal and moisture gradients, and the influence (and confluence) of continental and oceanic (monsoonal) climatic regimes.

- Cold and Extremely Cold zones are found stretched across high elevation portions of the Asian Highlands, notably covering much of the Tibetan Plateau. Together these Cold zones comprise more than half of the total combined region (55\%). Of the 16 zones found within the Asian Highlands, only 10 zones individually cover $1 \%$ or more of the total regional area, with the five most extensive zones together comprising more than $85 \%$ of the total area.

- By 2050, substantial shifting and spatial displacement of the bioclimatic zones is seen across the region. Zones shift both upslope along elevational gradients and northward along the latitudinal gradient. Between $38 \%$ and $47 \%$ of the entire region is projected to shift to another bioclimatic zone by 2050, that is, can expect a major shift to a novel set of bioclimatic conditions to be prevalent by then. Between $75 \%$ to $84 \%$ of the entire region shifts to a different bioclimatic stratum (indicating a more marginal incremental shift but still novel conditions).

- The largest zone in areal extent (Extremely Cold and Mesic), covering more than 2 million $\mathrm{km}^{2}$, decreases substantially $(22 \%-29 \%)$ by 2050 , with these areas warming to become Cold to Cool Temperate strata. Medium elevation Warm Temperate and Mesic zones decrease in area, while Extremely Hot zones at lower elevations increase substantially.

- The average mean elevation of all the bioclimatic zones shifts upward, on average across the entire upland Asian Highlands region, by $279 \mathrm{~m}$ to $345 \mathrm{~m}$. Almost all the zones shift upward substantially in their highest elevational extent, and most also shift upward in their lowest elevational extent (or at least stay approximately at the same minimum elevation). Many of the zones, especially the warmer zones, increase the extent of their elevational range substantially.

These impacts on the spatial distribution of bioclimatic strata within the Asian Highlands will lead to substantial, although regionally distinctive, impact on agricultural production across the Asian Highlands, particularly affecting traditional mountain agricultural and pastoral systems which may be adapted to highly specific climatic niches ( $\mathrm{Li}$ and Fox, 2012). Traditional agricultural systems, which have been shown to conserve and maintain in-situ high levels of agricultural biodiversity, may in some cases benefit from improved growing conditions, however this potential may be offset by increased climate variability.

Additionally, the spatial displacement of bioclimatic conditions analysed in this study suggests that these mountain farming and pastoral systems will be forced to adapt to rapidly changing conditions, either by modifying their agricultural or pastoral management practices, selecting new cultivars, species, livestock breeds or farming systems, or migrating to areas of better opportunities or newly 
improved conditions, for example as higher elevation slopes warm sufficiently for crop production. Global and regional processes, notably infrastructure development, commercialization, globalization of agriculture, but also cultural and socio-economic change in the Asian Highlands, have already undermined the viability of many of these subsistence systems across the region. These diverse and in many cases cyclic land use systems enhance biodiversity at genetic, species, landscape, and cultural levels. Supporting these farmers, herders and mountain communities to adapt to changing conditions requires efforts to enhance socio-ecological resilience of ecosystems and mountain communities. The results of this analysis provide the foundation for a spatially georeferenced knowledge base embracing the impacts and opportunities of future climate conditions for mountain communities, farming systems, and for supporting localized adaptation planning and strategy development.

In terms of biodiversity and its conservation, results of this analysis forewarn of a prolonged period of climate perturbation and of ecological disruption and potentially widespread spatial dislocation with the potential of extinctions for already endangered or threatened species, especially those which are narrowly adapted to highly specific niches. Without concerted conservation efforts to mitigate habitat loss, species ranges may shift beyond current habitat or extent of existing vegetation type, or fragment through lack of connectivity. In particular, the terrain, topography, land cover, and human settlement patterns within mountains create highly specific conditions which affect the ability of species and ecosystems to adapt to climate change. Likewise, the velocity of climatic change (La Sorte and Jetz, 2012; Corlett and Westcott, 2013) and the potential vegetation dispersal rates in the landscape create highly specific conditions for adaptation capacity, which varies both by species and/or ecosystem, and by very regional or site-specific considerations.

The highly differentiated and diverse micro-climatic conditions found in a mosaic of patterns across mountain landscapes means that there will be inherent resilience within mountain ecosystems to adapt to rapidly changing conditions, however, in general, mountains and mountain biodiversity are considered highly fragile and vulnerable to the projected change and spatial displacement of bioclimatic conditions. This set of fairly rapid and drastic change processes will increasingly impact upon the conservation effectiveness of the many protected areas and biodiversity reserves across the Asian Highlands region (Zomer et al, 2015a; Pu et al, 2007; La Sorte and Jetz, 2010), as ecological conditions within these protected areas change beyond limits conducive for species currently found there. Impacts on specific vegetation types, particular species, or wildlife, are more difficult to predict, as the spatial distribution of life forms cannot be defined in purely abiotic terms (Barbour et al, 1987). In general, however, it is possible to define the climatic envelopes of most types of vegetation, and to a large extent associated fauna, on the basis of correlations between their distribution, annual temperature, and precipitation (Holdridge, 1947, 1967; Whittaker, 1970; Leith, 1974; Box, 1981; Woodward, 1991).

It is likely that the responses to changing climate conditions will be closely correlated with the more critical ecological limiting factors (Woodward and Williams, 1987). Although species ranges will shift, the ability to survive, adapt or benefit from these changes is species and site specific, and depends on factors such as population dynamics, seed dispersal mechanisms, habitat fragmentation, and physiological adaptability (Corlett and Westcott, 2013). Improving our understanding of these responses, while maintaining as much habitat and landscape connectivity as possible, is imperative if conservation strategies and policies, designed to meet these challenges, have to be effective within rapidly changing bioclimatic conditions.

Climate change and adaptation has now become a widespread and urgent issue for almost all sectors across the Asian Highlands region. Opportunities to anticipate, and to some extent mitigate expected impacts of climate change may exist if the nature and magnitude of changing bioclimatic conditions can be better understood. The results of the analysis presented in this report provide an overview and a spatial mapping of trends and impacts on bioclimatic conditions across the region by 2050 . 
In conclusion, we stress the need to incorporate a fundamental awareness of on-going and projected rapid climatic change at all levels of planning and policy. In response to anticipated effects of climate change, organizations and government agencies throughout the region, and global institutions, are developing "adaptation strategies" at various scales to facilitate the adjustment of human society and ecological systems to altered climate regimes. As evident from this analysis, the Asian Highlands region is, and will be for some time, at the forefront of this change, and the challenge of our times.

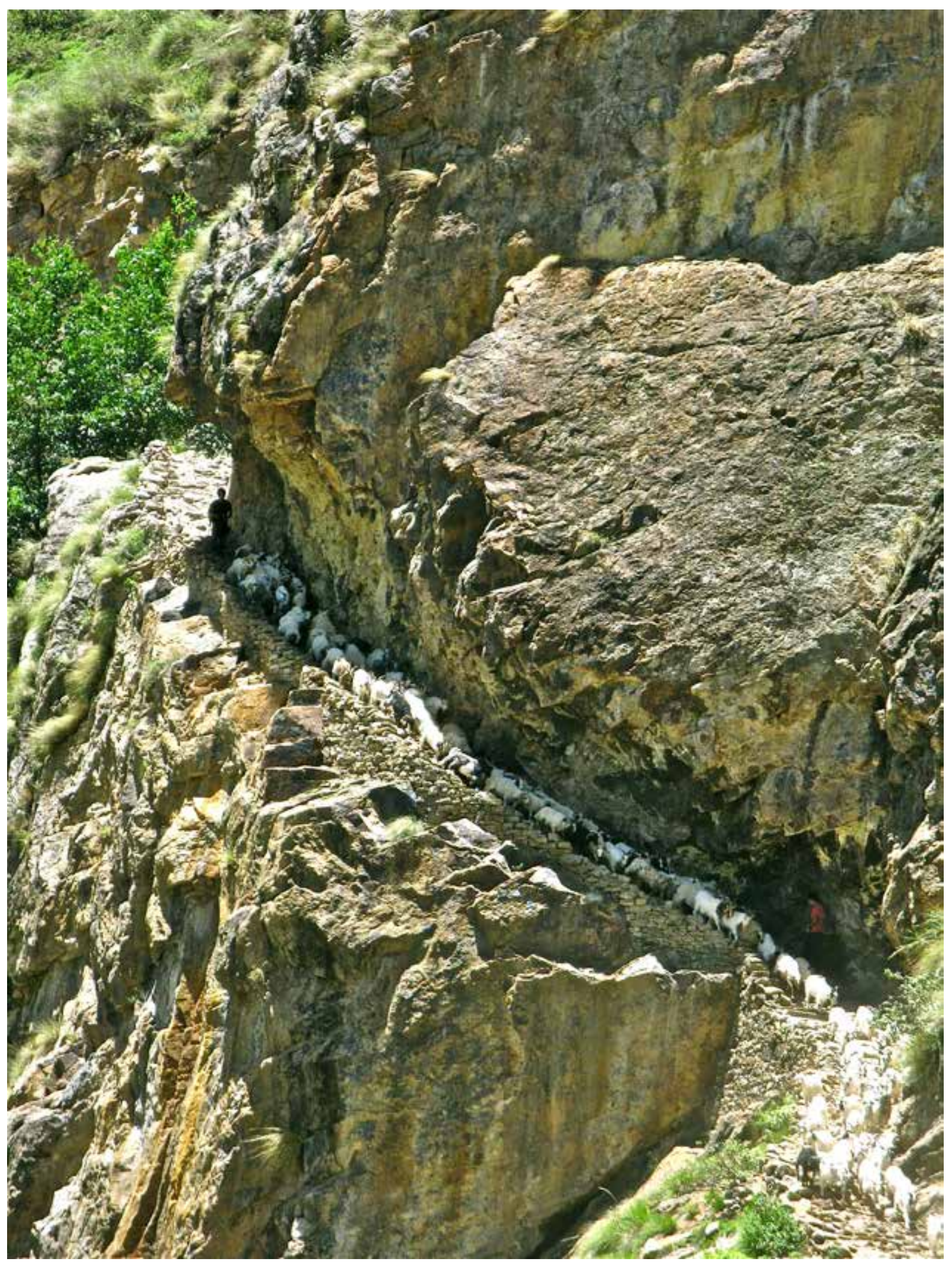




\section{Introduction}

\section{Overview}

In this report, we summarize the current and future projected status of a set of bioclimatic indicators, and the expected impacts of climate change on the spatial distribution of bioclimatic conditions and hydrological cycles across the Asian Highlands region (Figure 1). The Asian Highlands project target region covers the upland, mountainous highland region of the Hindu-Kush and Himalaya mountain ranges, including the Tibetan Plateau, and is comprised of nine major upper river basins. Results and conclusions are presented for the combined region as a whole, and individually by the nine river basins comprising this vast mountainous and highly heterogeneous remote and rugged region.

The analyses and results presented here are based upon a geospatial analysis using spatially interpolated weather station data averaged over 40 years, from 1960 to 2000 (referred to below as "2000" or "current conditions") as baseline for the estimation of climatic and other environmental change. A multi-model ensemble ( $n=63$ ) of future (i.e. average over 20 years, from 2041 to 2060, and referred below as 2050) climate projections available through the Coupled Inter-Comparison Model Project - Phase 5 (CIMP-5), and downscaled to $1 \mathrm{~km}^{2}$ (Hijmans et al, 2015), has been analysed across the range of all four IPCC AR-5 Representative Concentration Pathways (RCP) or emission scenarios, to describe the general consensus and uncertainty among these models on the trend, direction and magnitude of projected changes in annual temperature and precipitation.

Using these same downscaled climate data, a modelling approach based on a soil water balance (Trabucco et al, 2008; Zomer et al, 2006; 2008), and a statistically derived environmental stratification (Metzger et al, 2013; Zomer et al, 2014, 2015a) are used to delineate and describe the nature and magnitude of projected changes in the spatial distribution of hydrologic and bioclimatic conditions across the Asian Highlands and its various river basins by 2050 .

This overview and analysis are intended to provide a basis for, and a first step towards, understanding the potential impacts of climate change across the Asian Highlands in the near to medium term (i.e. 2050, represented as a 20-year average of the period 2041 to 2060) on terrestrial ecosystems, biodiversity, agricultural production, and pastoral systems. Both the regional Asian Highlands Environmental Stratification (AH_EnS), and the analysis of projected change in spatial distribution of bioclimatic conditions are intended to provide important inputs and a knowledge base for climate change adaptation planning and policies, and in particular, for the design and implementation of agroforestry practices, environmental conservation efforts, and sustainable development across this magnificent but highly vulnerable and fragile mountainous region. All geospatial results for Asian Highlands described in this report are available, by request.

\section{Background}

Although there are great uncertainties in our understanding of future climate and climate change, it is generally recognized that the Asian Highlands region, like other mountainous regions of the world, and like other economically less-developed areas, is highly vulnerable to on-going and future anticipated climatic change and associated ecological perturbations (Beniston, 2003; Sharma et al, 2009; Xu et al, 2009a, 2009b). Improving our understanding of the nature of the changes in bioclimatic conditions, both in the near to medium term, as this study focuses on (i.e. 2050), and/or in the longer term (i.e. by the end of the century), is essential to provide the knowledge base that allows for science/evidence-based decision-making for adaptation, biodiversity conservation, environmental planning, and sustainable development. 
Regional vulnerability and adaptation to changing climatic conditions include both biophysical and socio-economic dimensions, with climate change being one of many factors within a complex matrix of on-going change processes, including globalization, market integration, and regional socioeconomic and cultural change. Nevertheless, climate change will have increasingly substantial and direct impacts on socio-ecological systems and a range of ecosystem services, including biodiversity, agricultural crops, pastoral systems, water resources, as well as human health and livelihoods, throughout this region, as this century progresses (Xu et al, 2007b).

The Asian Highlands exhibit great heterogeneity, both geographically and culturally. The landscape's bioclimatic zones range from hot tropical moist, and semi-arid regions in the south and southwest, to lush green and humid valleys in the mid-hills along the Hindu Kush-Himalaya ranges, extensive mountain forests, moist alpine meadows, remote and arid trans-Himalayan valleys, unto the cold Tibetan Plateau and vast areas of high altitude grasslands and steppes, as well as extensive areas of permanent snow and ice. This geographic heterogeneity has given rise to a high level of biodiversity including an array of forest types (ranging from moist tropical broadleaf to temperate oak forests, alpine conifers, and high altitude krumholz and alpine pastures) and wildlife (including tigers, Asian elephant, musk deer, blue sheep, snow leopard, Tibetan antelopes, and many other rare and endangered species).

The Asian Highlands region is rich in biological and cultural diversity, water resources, and plays an important role in both atmospheric circulation and the global hydrological cycle (Bandyopadhyay and Gyawali, 1994). Notably, these mountains are the source of the nine largest rivers in Asia, the basins of which are home to over 1.3 billion people (Xu et al, 2009). Environmental change in the Asian Highlands affects much of inland China, Central and South Asia, and the mainland of Southeast Asia. These mountains are some of the world's poorest regions, and their downstream basins are among the most densely populated. Within these populations and communities, the impacts of climate change will not be evenly distributed either in intensity within the region, or among various sectors of society.

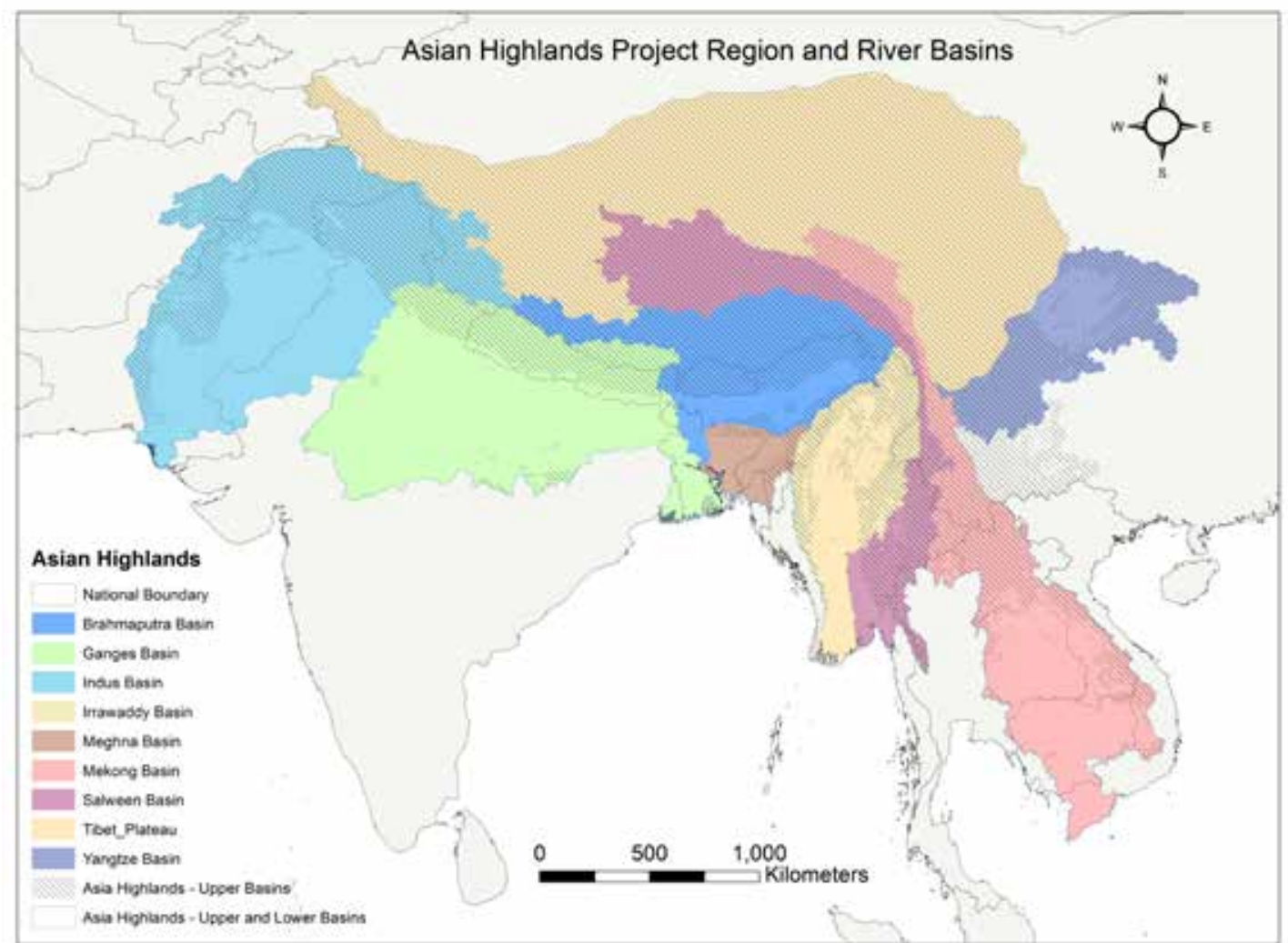

Figure 1: Map of the Asian Highlands, showing the nine river basins which comprise the full project region, and the extent of the upper basins (mountainous and upland regions) which are the main focus of the study. 
More fragile environments and ecosystems, and poorer and more marginalised human communities are likely to be more exposed to earlier and greater impacts (Xu et al, 2007b). The impacts of climate change across this vast and highly diverse region are superimposed on a complex matrix of poverty and other on-going environmental and social stresses. It is generally agreed that geographic regions and socio-economic groups that are already vulnerable to contemporary climate variability and extreme weather events are very likely to become more vulnerable in the future. However, a long historical experience of indigenous ecological knowledge, adaptive strategies and coping skills, developed within the context of, and specifically in response to highly variable precipitation and other bioclimatic conditions may provide a basis for adaptation strategies and local responses. Likewise, high levels of local and indigenous agro-biodiversity, particularly fruit and nut trees, and local livestock landraces, provide important genetic resources for future adaptive responses and potentially offer economic opportunities which may result from changed bioclimatic conditions.

\section{Regional climate change}

Although there has been significant progress and a growing understanding of global climate change, a substantial level of uncertainty still exists in the prediction of future climate conditions, and of ecosystem responses, particularly within mountainous regions, to global and regional climate change. Rapidly accelerating climate change across the Asian Highlands region (Shrestha et al 2012; Singh et al, 2011) is predicted to have major implications for this vast mountainous area (Xu et al, 2009a).

As the effects of climate change are expected to be early, evident and pronounced within mountainous areas, they are considered to be uniquely useful areas for detection of climate change and related impacts (Beniston, 2003). In general, regional climate change processes in this remote and rugged region are poorly understood (Xu et al, 2007a), sparsely monitored, and generally under-researched (Schild, 2008; Xu et al, 2007b). However, climate change impacts are becoming increasingly evident within this highly vulnerable and fragile region (Ramesh and Goswami, 2007; Shrestha et al, 2012; Zomer et al, 2014), with potentially profound implications for mountain communities (Ebi et al, 2007), water resources (Immerzeel et al, 2010; Shrestha et al, 2012), agricultural production systems (Maikhuri et al, 2001), biodiversity, ecosystem services (Beniston, 2003), and both regional and global climate processes.

Regional temperatures are rising at rates substantially higher than the global average, and significantly more so in higher altitude areas (Liu, 2000; Liu et al, 2009; Shrestha et al, 2012). Large-scale climatic and phenological changes have been documented across the Himalayan region. Between 1982 and 2006 , average annual mean temperature increased $1.5^{\circ} \mathrm{C}$, annual mean precipitation by $163 \mathrm{~mm}$, and the average start of the growing season advanced by 4.7 days (Shrestha et al, 2012). In higher altitude areas, a greater proportion of total annual precipitation is falling as rain, rather than snow (Sharma et al, 2009), resulting in earlier snowmelt and shorter winters. This affects river regimes and impacts on water supply (Immerzeel et al, 2010), agro-ecological adaptations, livelihoods, and causes natural disasters, notably increasing glacial lake outburst flows (Xu et al, 2007a, 2009b).

Climate change will increase temperatures, but also changes in precipitation, evapotranspiration, soil and air moisture, runoff, and river flow as well as groundwater through water cycles. Regionally, intensification of the Asian monsoon is predicted by most climate models. On the regional scale this could result in increased precipitation in monsoon influenced locales (southern slopes, eastern Himalayas), with increasing water availability, although local effects are poorly understood. Melting glaciers will increase stream flow in the near to medium term, but will eventually, in the longer term have a negative effect on downstream water (Barnett et al, 2005) with drastically reduced meltwater contribution to regional river flows (Immerzeel, 2013). The highest mountains, or those facing or funnelling the prevailing winds, may retain a substantial, if diminished, glacial cover, whereas lower or less favourably oriented watersheds eventually may be completely de-glaciated. 
Montane biodiversity, species, and ecosystems, because of their geographical isolation, limited range, and highly specific environmental adaptations, are among the most vulnerable to climate change (La Sorte and Jetz, 2010). Consequently, changing climate will have major implications for biodiversity conservation efforts (Beniston, 2003; La Sorte and Jetz, 2010; Myers et al, 2000) and the many protected areas established over the last fifty years across the region (Chettri et al, 2008; Sharma et al, 2010), as well as on the important agro-biodiversity and crop genetic resources found here. It is anticipated that species ranges will shift along altitudinal gradients (Chen et al, 2009; La Sorte and Jetz, 2012; Tingley et al, 2009), as much as they are able to within a challenging and complex matrix of biological and physical constraints (La Sorte and Jetz, 2010).

The range of some species may shift beyond the boundaries of protected areas established for their conservation. Climate change may exacerbate other ongoing environmental change processes (Thuiller, 2007), for example, expansion of fire-adapted or invasive species. Climate change impacts on the structure, processes, and resilience of ecosystems and socio-ecological adaptation of mountain communities are equally complex. Human adaptations to harsh, rugged and remote mountain landscapes have created both a high diversity of highly specialized and specific mountain farming and pastoral systems, and a wealth of local indigenous ecological knowledge, as well as flexible and innovative coping skills to adapt to highly variable and dynamic mountain environments. However, in many areas within the Asian Highlands, both ecosystems and humans are possibly already stressed, both by adaptation to topoclimatic diversity (Xu et al, 2007b), and on-going regional and global change. In general, local impacts of climate are highly specific and are followed up by single or simple adaptation pathways, whether in terms of biodiversity or wildlife habitat, plant ecology, stream hydrology, erosion and sedimentation, or other human activities like crop production or transhumance pastoralism.

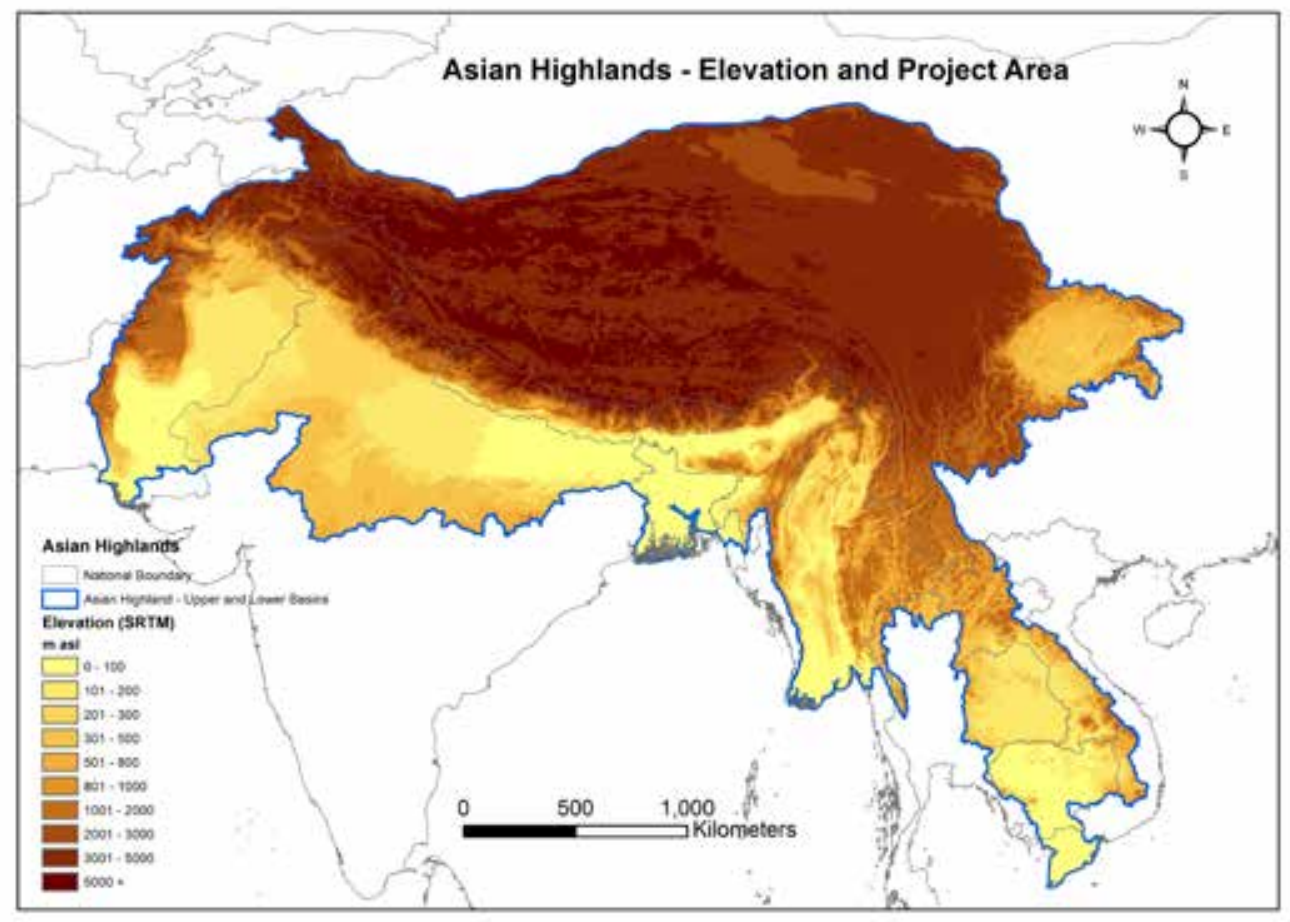

Figure 2: Map of the Asian Highlands, showing the nine river basins which comprise the full project region, and the extent of the upper basins (mountainous and upland regions) which are the main focus of the study. 


\section{Climate analysis and modelling of impacts on terrestrial ecosystems: assumptions, sources of uncertainty, and other limitations}

There are significant implications derived from the projected levels of climatic change which will drive a spatial redistribution and shifting of bioclimatic conditions across the landscape. This is especially prevalent and relevant within mountainous and upland regions where topographic and elevation gradients create highly variable conditions with a wide range across short distances. The impact on terrestrial ecosystems, vegetation types, wildlife habitat, growing conditions, agricultural and pastoral production systems, and mountain peoples and communities are likely to be unmistakeable and drastic (Zomer et al, 2014).

Due to a scarcity of environmental and historical climate data, absence of systematic monitoring, and political sensitivities within the region (Schild, 2008), the knowledge base for developing scientifically-based adaptation strategies to mitigate these potentially severe implications is lacking. In this regard, an ever-improving estimation of the nature and magnitude of regional climatic change is essential to provide for informed decision making, risk and vulnerability mapping, sustainable "climate-proof" development, the delineation and development of climate change adaptation and mitigation strategies, and effective biodiversity and conservation management. A better, deeper understanding of the potential impacts of climate change on food security, livelihoods, and local economies of the region is urgently required to inform regional planning and adaptation strategies. An improved understanding of the impacts of climate change is essential for sustainable development, effective conservation, and mitigation and adaptation planning within the context of rapidly changing biophysical conditions.

Our study uses a methodology developed to provide informed climate projections and allow assessment of projected impacts on terrestrial ecosystems in data-scarce regions, i.e. the Asian Highlands, based upon available global datasets. As such, it has limitations in detail and accuracy associated with the original resolution of the models, and the downscaling approach. In mountains, climatic conditions can vary sharply across elevation and other gradients, with slope, aspect, orographic rain shadow effects, and terrain ruggedness creating a large range of micro-climatic niches and a high level of landscape diversity. Broad predictions of global climate change may not take into account important regional complexities in the mountains related to the effects of topography and elevation.

Although the climate change analysis presented here primarily involves shifts in precipitation and temperature (bioclimatic) conditions, in mountainous and highland regions it is local terrain, ruggedness, elevation, and orientation that modify the significance of regional and local changes. These local effects are poorly understood and no attempt is made to predict these. In particular, whereas temperature changes have a predominantly regional character, precipitation changes are more locally determined and very difficult to analyse and predict in mountainous areas (Jian et al, 2006). For small-scale farming, rain-fed agriculture, pastoral systems, and the assessment of human vulnerability, and to some extent natural ecosystems as well, the changes in the spatial and temporal distribution of precipitation, and inter- and intra-annual variability may be more relevant than absolute precipitation values (Lioubimtseva and Henebry, 2009). However, these important dimensions of year-to-year variability and the intra-annual nuances of climate change are also more difficult to model and project. 
In this analysis, we report the mean annual results for a set of bioclimatic indicators which include the basic climatic parameters of annual mean temperature, precipitation, potential evapotranspiration, and an aridity-wetness index. In-situ soil-water balance modelling is done on a monthly basis, and provides a simple overview of the hydrological status of a spatially referenced and delineated area, dividing the input of precipitation into three compartments, namely vapour flow or actual evapotranspiration (AET), soil-water content (SWC), and excess in-situ water or runoff (ROF). It does not account for overland flow or ground water recharge, and as such is most relevant to rainfed agricultural, pastoral and natural ecosystems. However, although downscaling issues increase uncertainties at more local scales, this approach provides an informed (or in this case, best-guess consensus among many model projections) spatial delineation of projected climate trends, as per a multi-model ensemble result of the latest state of the art earth system model (ESM) projections (CIMP-5).

Likewise, we employ this dataset of bioclimatic indicators to stratify the region into a set of distinct, broadly homogenous bioclimatic zones (strata). These zones can be interpreted as bioclimatic envelopes, distributed across the landscape and representing a unique combination of bioclimatic conditions, which are a major factor and in many cases the primary determinant of the spatial distribution of biomes, vegetation types, forest types, species, and mountain agricultural systems. Due to high terrain diversity, topographic ruggedness, and steep elevation, temperature and moisture gradients, the spatial distribution of these bioclimatic envelopes, or strata, are likely to significantly shift as bioclimatic conditions change. In particular, as temperatures rise, the various strata associated with altitudinal zonation in mountain ecosystems are likely to shift upslope, or in highland plateau areas such as the Tibetan Plateau or the steppes of Central Asia (Zomer et al, 2015b), to move northward latitudinally. In this analysis, we use the shift in spatial distribution of these bioclimatic envelopes as a surrogate for climate change impacts, allowing us to provide a set of modelled indicators for the Asian Highlands and their various river basins, which delineate an outline of expected impacts on bioclimatic conditions, and by extension, terrestrial ecosystems, vegetation cover, species abundance, wildlife habitat, biodiversity conservation, agricultural and pastoral ecosystems, and various ecosystems services.

There are significant limitations associated with the models, the downscaling and interpolation of weather data and CIMP-5 ESM model results, and the assumptions in the models we have developed and which we use in this analysis (see Zomer et al, 2009; 2014; 2015a; 2015b). In particular, although the analysis was conducted, and results are presented at a resolution of $1 \mathrm{~km}^{2}$, we cannot expect that any particular grid cell will be correctly classified and accurately predicted when compared with ground-based data. However, in terms of mapping the spatial distribution of a fairly homogenous set of similar bioclimatic conditions, and then projecting these strata into the future by mapping the spatial redistribution of these sets of unique homogenous conditions under future projected climate conditions, these results synthesize an accounting of the current state of the projections for changes in climatic variables for the Asian Highlands region by 2050. These results allow for an integrative and holistic interpretation of climatic change to be visualized and interpreted quantitatively. As such, it provides a basis for understanding and assessing trends and directions of change, and can be summarized in terms of more contextual bioclimatic stratification references, for example as agroeco-zones, and can be used as extrapolation domains which can spatially reference analogous future climatic conditions (e.g. currently existing in a nearby similar place). 


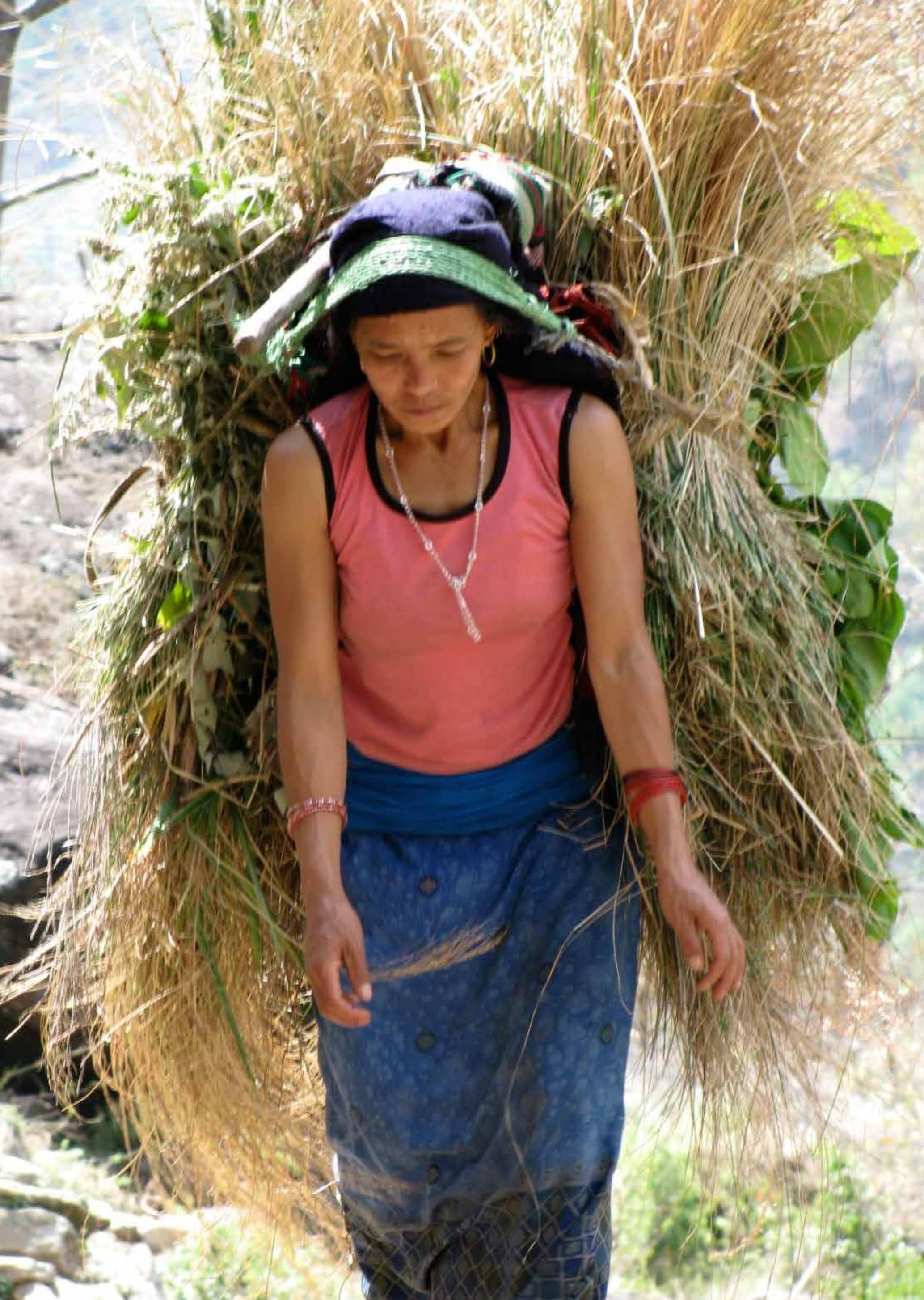




\section{Methods overview}

This report provides an overview of a geospatial analysis of projected climate change across the nine upper river basins (including the Tibetan Plateau), that comprise the Asian Highlands region. Results have been articulated for the whole of this region, and for each of the nine river basins. Although all four of the IPCC AR5 future emission scenarios (Representative Concentration Pathways-RCP) have been modelled and analysed, for clarity of presentation, maps and tables mostly only show results for RCP 4.5 and RCP 8.5 (i.e. not all four RCPs), in keeping with common practice in the literature. All statistics for all RCPs are given in the appendix summary tables. In this regard, it is generally agreed that RCP 2.6 (the best case scenario) is unlikely, given current global trends (IPCC, 2013). In general, comparing RCP 4.5 and 8.5 should provide the full realistic range of future climate projections (Figure 3). The emissions trajectory for RCP 6.0 does not diverge above RCP 4.5 until after 2060, and before then (i.e. 2050) is relatively similar to RCP 4.5.

\section{Year of climate departure}

Most ecological and sociological systems can adapt to climate change over time, although this might not be the case for all species. However, the time frame in which climates will reach unprecedented states (i.e. climatic conditions not seen before in that location) may strongly determine the magnitude of disruption in ecosystems and the ability of species to adapt and avoid extinction. We use data provided by Mora et al (2013) to give an indication of the projected timing of climate departure. This index gives an estimate of the year when the climate (i.e. near-surface air temperature) exceeds the bounds of historical variability for a particular location, as determined by all consecutive years after that date being outside the bounds of variability over the past 140 years (Figure 4). Although this index gives a date in the future for unprecedented climatic conditions, this does not mean that change is not already occurring. Mora et al (2013) provide estimates for RCP 4.5 and RCP 8.5, based upon all 39 available CIMP5 models, at a resolution of $100 \mathrm{~km}^{2}$. When compared spatially, i.e. over the whole of the Asian Highlands, it can give an indication of the relative rate of warming by region and locally: the earlier the date of departure, the more rapid the rate of warming in that locale.

\section{Projected changes in temperature and precipitation}

An analysis, using a multi-model downscaled ensemble (n=63) of CIMP5 Earth System Models (ESM) applied across four representative concentration pathways (RCP), has been used to assess climate change and its impact on temperature and growing conditions by 2050 . We give the results of all models within each RCP. A table of all CIMP 5 ESMs used in the analysis is given in Appendix 1. The RCPs represent the range of approved IPCC AR5 $\mathrm{CO}_{2}$-emission scenarios, with RCP 2.6 representing aggressive mitigation, and RCP 8.5 following a trajectory of "worse-case scenario" (Figure 4). We have used the Worldclim meteorological dataset (Hijmans et al, 2005), which gives spatially interpolated climate values (i.e. temperature and precipitation) based on data averaged from 1960 through 2000, as the current conditions (2000) baseline. 


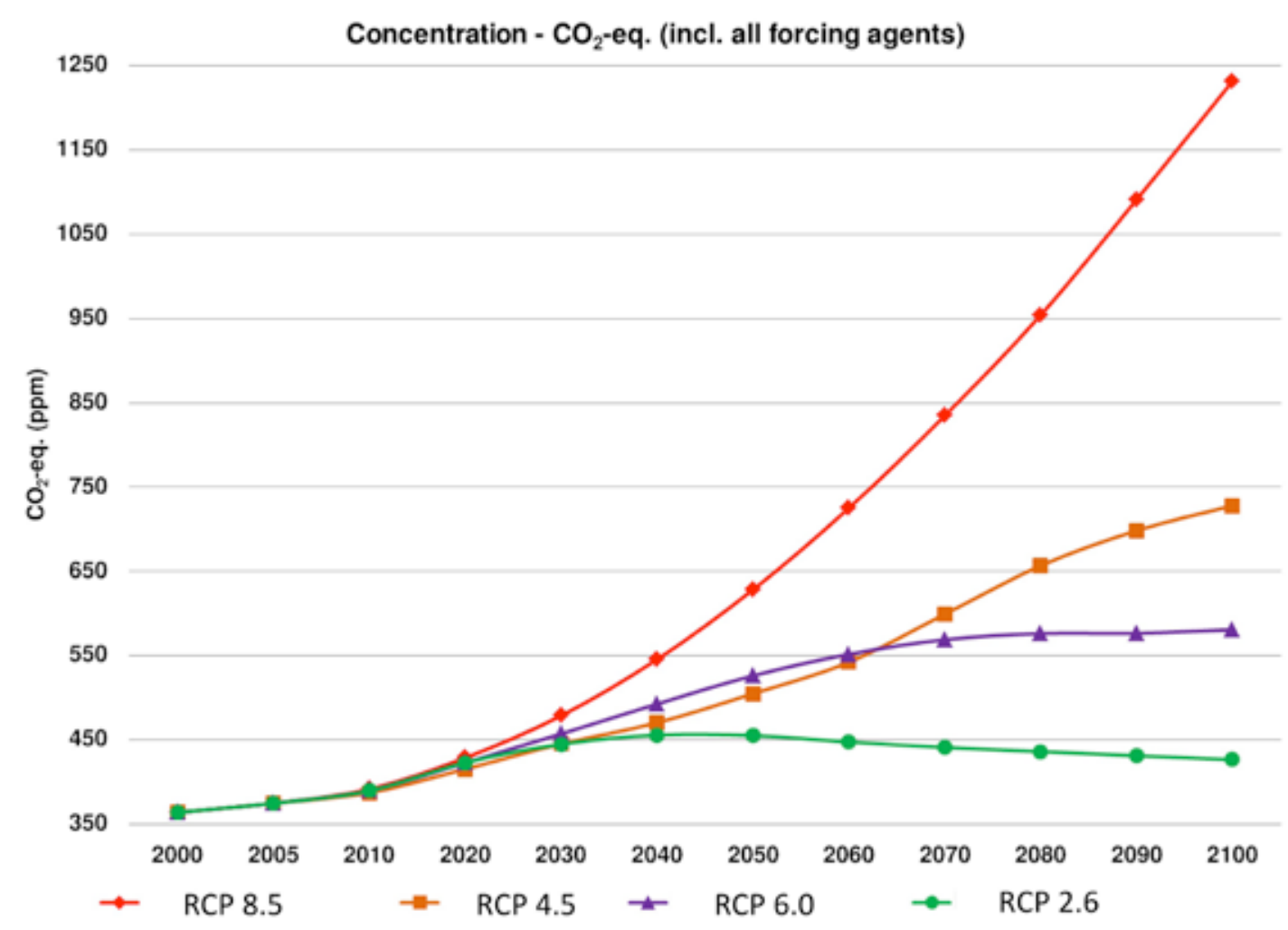

Figure 3: IPCC AR5 Representative Concentration Pathways (emission scenarios) (Source: IPCC, 2013, WikiCommons)

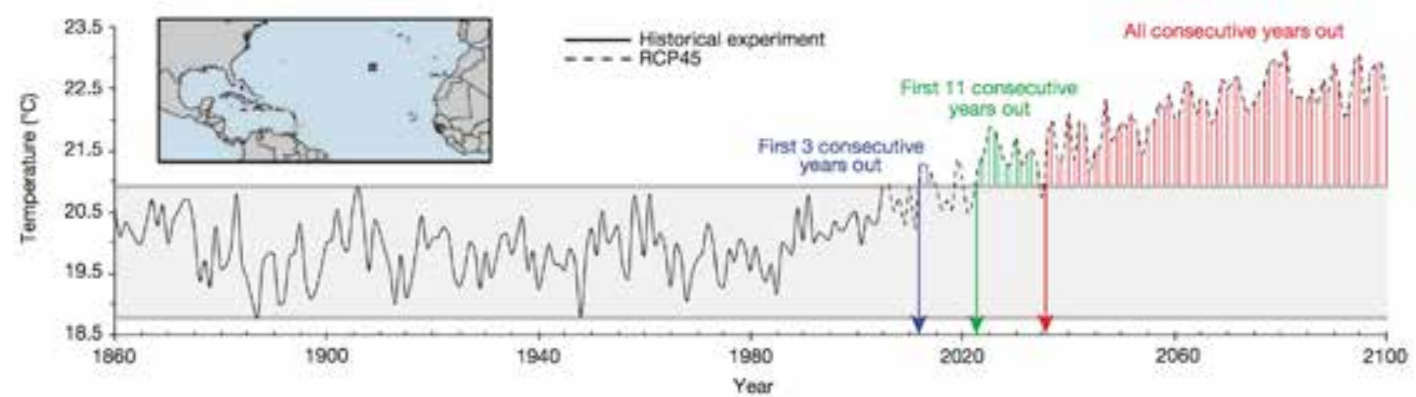

Figure 4: Illustration of the analysis used in determining the year of climate departure (Source: Mora et al, 2013, with permission by Nature Publishing Group). 


\section{Projected changes in potential evapotranspiration and aridity-wetness index}

We provide an overview of the expected change in mean annual temperature, mean annual precipitation, mean annual potential evapotranspiration (PET), and the mean annual aridity-wetness index (AWI). The aridity-wetness index (AWI) is an integrative measure applicable to assess the moisture (precipitation) available for plant growth, i.e. after evapotranspiration. The higher the value of AWI, the more moisture is available. In general, 1.0 represents saturated conditions, i.e. more than enough water for most types of agriculture, and .65 is approximately a threshold for adequate moisture to support rain-fed agriculture under semi-arid conditions. It is based on a ratio of the amount of annual precipitation compared to the PET. The PET, which we have modelled for the entire Asian Highlands region, is a measure of the total potential amount of atmospheric water demand expected under existing (or projected) temperature and relative humidity conditions, that induce transpiration (from plants) and evaporation (from soil). PET is a measure of the ability of the atmosphere to remove water through ET processes, that is, transpiration by plants, and evaporation from soil and other water sources, such as interception of precipitation by the canopy. The AWI is calculated as the ratio of mean annual precipitation to the mean annual PET. A complete explanation of the methodology used to calculate PET and AWI is given in Zomer et al (2008).

\section{In-situ soil water balance model}

A simple water balance approach, using the ensemble of future climate scenarios, is used to estimate impacts on hydrological cycles at the regional scale, at a resolution of $1 \mathrm{~km}$. Hydrologic impacts of climate change are modelled and analysed in terms of in-situ (i.e. one-dimensional) soil water balance and vapour flow response. The model is applied on a per-pixel basis to estimate spatially disaggregated biophysical conditions, and to predict hydrologic changes with change in future climate conditions. The spatially distributed water balance model is used to examine hydrological differences in actual evapotranspiration, soil water content and runoff. This model uses the average spatially distributed values of monthly precipitation and monthly potential evapotranspiration (PET), land-use classes, soil depth and soil water holding capacity, and returns monthly spatially distributed raster data representing actual evapotranspiration (AET), surface runoff (ROF) and soil water content (SWC). All the results are computed on a monthly basis throughout an average year for current climate and future projected scenarios, and the results are aggregated into yearly figures.

\section{Environmental stratification and delineation of bioclimatic zones and strata}

The Global Environmental Stratification classification (GEnS: Metzger et al, 2013), used as a taxonomic basis for our analysis, is a statistical stratification of the world's land surface into 125 homogeneous bioclimatic strata. The development of this approach has been facilitated by recent availability of high-resolution global climate datasets, and represents a considerable advance (Metzger et al, 2013, 2012) over earlier global attempts at bioclimatic or ecosystems mapping (Holdridge, 1947; Thornthwaite, 1948; Peel et al, 2007). Based on a statistical clustering of significant climate variables, the GEnS provides a global stratification that can a) quantitatively relate the spatial distribution of ecosystems to an identified set of bioclimatic parameters; b) provide a consistent methodology across landscapes and countries that have so far mostly been studied using different protocols, approaches and taxonomies; and c) allow for a statistical modelling of bioclimatic zonal shifts that can be used to estimate the direction and magnitude of impacts on ecosystems due to climatic changes (Zomer et al, 2012, 2014, 2015a). 
The original GEnS, based on a high-resolution dataset of geospatial monthly climate datasets averaged from 1960 to 2000 (Hijmans et al, 2005), characterizes recent conditions to stratify the globe into 125 bioclimatic strata, which have been aggregated into 18 broad bioclimatic zones. This quantitative approach allows using an identified geodataset of statistically significant variables and the variable statistical profiles of the various strata to reconstruct the stratification based on projected future conditions (i.e. using the variable values derived from modelled climate scenarios). This environmental stratification reconstructed for the Asian Highlands project region is below referred to as the Asian Highlands Environmental Stratification (AH_EnS). The strata continue to represent bioclimatic conditions similar to the original strata (i.e. recent climatic conditions), but may shift in areal extent or location according to changing climate.

The change in distribution of the bioclimatic strata is analysed and used as a surrogate measure to describe the potential projected macro-level impacts of climate change on terrestrial ecosystems (Metzger et al, 2008; Zomer et al, 2013, 2014). When combined with other ecosystem, vegetation, or land-use data, these shifts in spatial distribution can be interpreted in terms of projected impacts on ecosystems services, land use, wildlife habitats, risks to endemic or threatened species, or the risks and opportunities associated with future agricultural production. As both strata and zones are labelled by unique alpha-numeric identifiers, the ability to use these for comparative purposes across the highly diverse landscapes of the Asian Highlands region remains, even though there is a flexibility to label specific local or regional conditions spatially corresponding to bioclimatic strata with local bioclimatic and/or ecosystem classifications and nomenclature.

The geospatial analysis and environmental stratification was performed in ArcGIS 10.2 (ESRI 2013) using the global datasets listed below, along with various national and local secondary datasets and information collected on land use and biodiversity, and a remote-sensing based land-use change analysis described below, to corroborate and interpret results:

- GEnS: Global Environmental Stratification v. 3 (Metzger et al, 2013)

- WorldClim v. 1.4: Global high-resolution climate surfaces in 1960-2000 (Hijmans et al, 2005)

- CIMP-5: Ensemble of downscaled CIMP5 ESM models (Meehl and Bony, 2011)

○ Available from Hijmans (2015)

- CGIAR-CSI Global Aridity and PET database (Zomer et al, 2008)

- SRTM: CGIAR-CSI SRTM Digital Elevation Model Database v. 4.1 (Jarvis et al, 2008) 


\section{Modelling of projected future bioclimatic conditions}

Metzger et al (2013) identified a set of significant bioclimatic parameters, based on a statistical screening of the various global climate datasets. Principal Component Analysis (PCA) of the global dataset revealed that $99.9 \%$ of the total variation was determined by four variables:

- Mean Temperature Growing Degree Days is defined as the annual sum of daily mean temperature degrees of days with a mean temperature above $0^{\circ} \mathrm{C}$, reflecting latitudinal and altitudinal temperature gradients, and plant growth periods (Hijmans et al, 2005);

- Aridity Wetness Index (AWI), is defined as the ratio of annual precipitation over annual potential evapotranspiration (PET) and forms an expression of plant available moisture (Zomer et al, 2008);

- Monthly Mean Temperature Seasonality is defined as the standard deviation of the monthly temperature means, and is a measure of temperature seasonality (Hijmans et al, 2005); and

- PET Seasonality is defined as the standard deviation of the monthly PET means, and is a measure of seasonality of plant available moisture (Zomer et al, 2008).

These four bioclimatic variables were used as the input to the ISODATA clustering routine in ArcGIS to classify the GEnS environmental strata (Metzger et al, 2013). Projected impacts are modelled by reconstructing the stratification based upon current and future climate conditions, as modelled by an ensemble of 19 Earth System Models (ESM) provided through the Coupled Model Intercomparison Project - Phase 5 (CIMP5; (Meehl and Bony, 2011)), using the same set of significant bioclimatic variables. The statistical signature profiles of the strata have been reconstructed for the Asian Highlands region, based upon a multivariate analysis (maximum likelihood classification) of these four bioclimatic variables. These signature profiles were then used to project the future spatial distribution of the EnS strata based upon the CIMP5-modelled future climate conditions in 2050.

Four emission scenarios, or representative concentration pathways (RCP) (Vuuren et al, 2011) were analysed using the CIMP5 model predictions for 2050 (average of 2041-2060), ranging from RCP 2.6 (aggressive mitigation/lowest emissions) to RCP 8.5 (highest emission scenario). CIMP5 model results were downscaled using the Delta method (Ramirez-Villegas and Jarvis, 2010) to 30 arc secresolution (equivalent to $\sim 1 \mathrm{~km}^{2}$ at the equator). The Maximum Likelihood Classification algorithm in ArcGIS 10.2 helped to construct the projected future spatial distribution of strata and zones, using the modelled future climate conditions as predicted by each of the emission scenario/ESM combinations $(\mathrm{n}=63)$ as input variable.

All models within each RCP were combined into a majority ensemble result, using the class with the majority of occurrence within any particular grid cell as the class for that location. The rate of occurrence of other classes is used as a measure of the uncertainty among models. Mora et al (2013) tested the robustness of the CIMP5 model ensemble based on historical observation data (1985-2005) and found a high correlation when using multi-model averages. Other sources of uncertainty in our analysis include the difficulties associated with model predictions in highly heterogeneous terrain and landscape, such as the mountainous areas of the Asian Highlands region. 
1528

nes

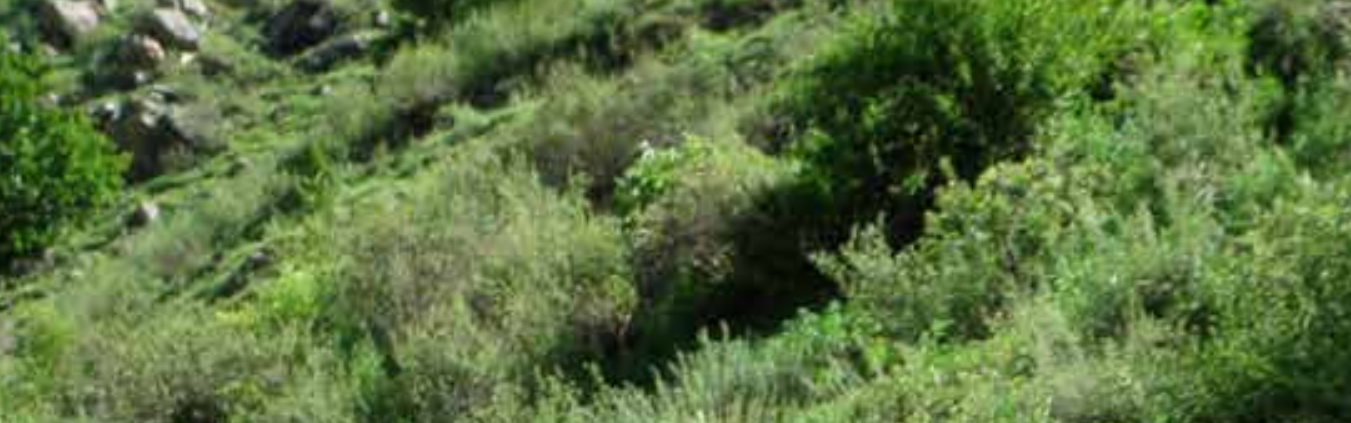

num anceses

$\sin ^{2}(3)(3)^{2}$

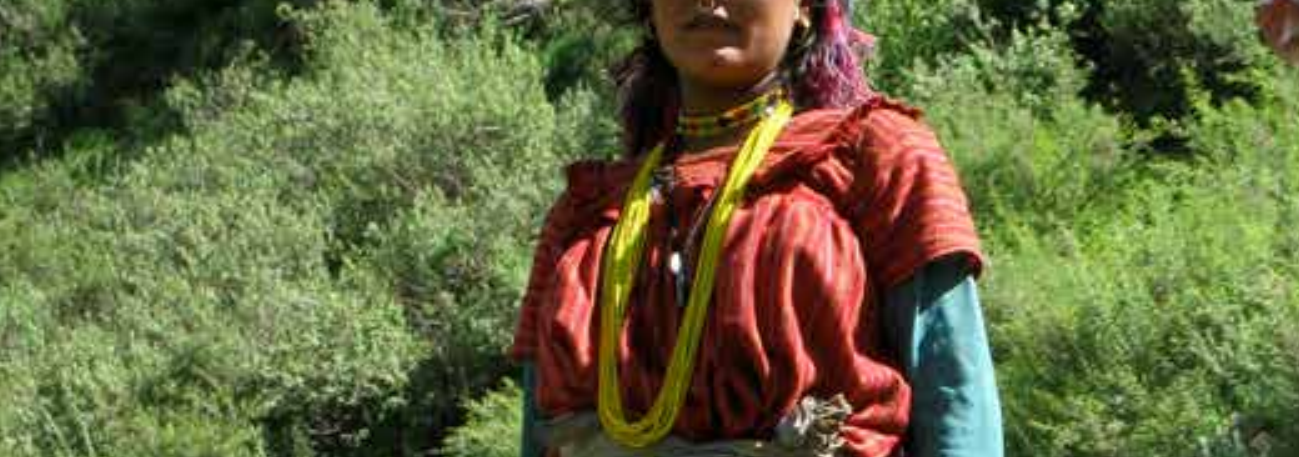

$+124 \times 5$

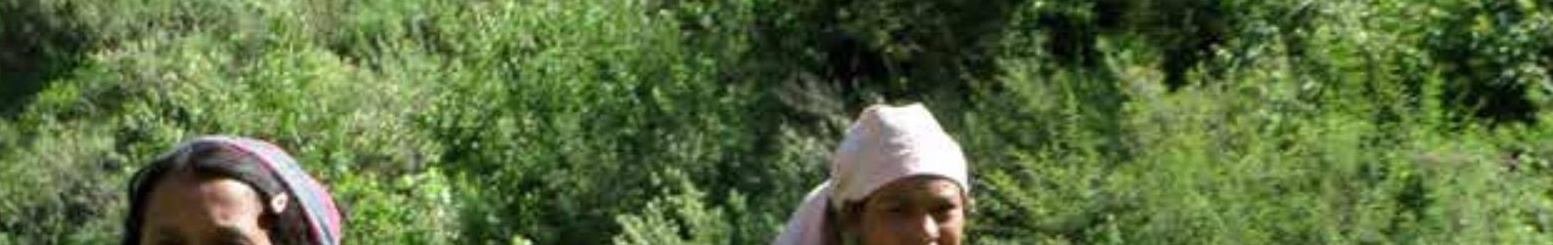

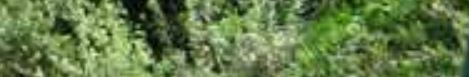

40.

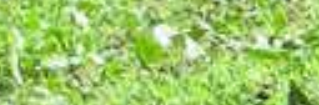 \\ $12 x$}
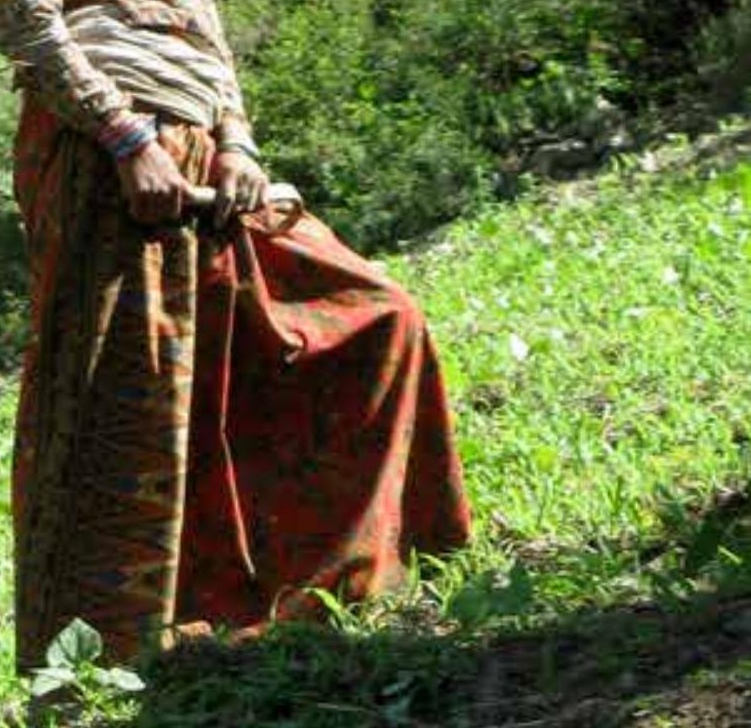

5.

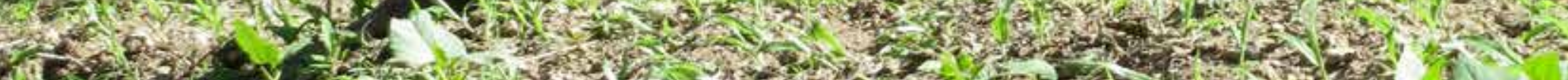

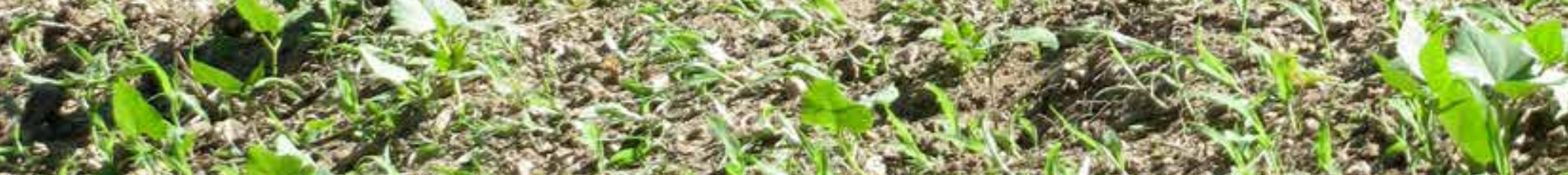

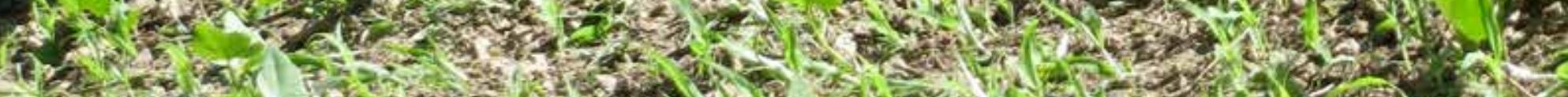
4 4.

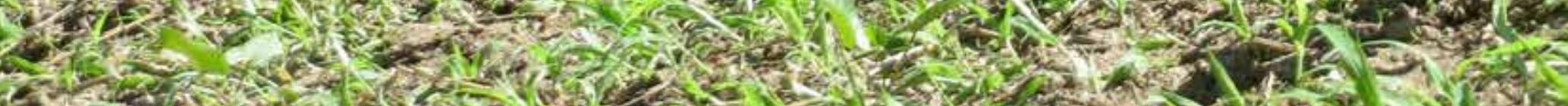

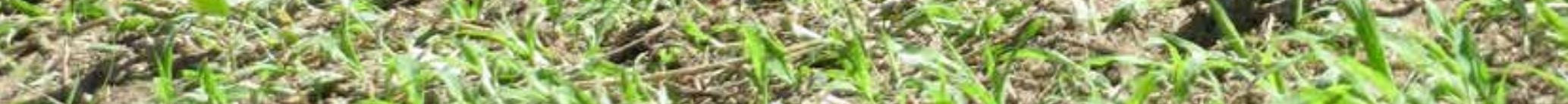

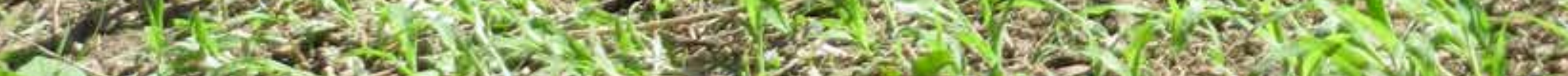

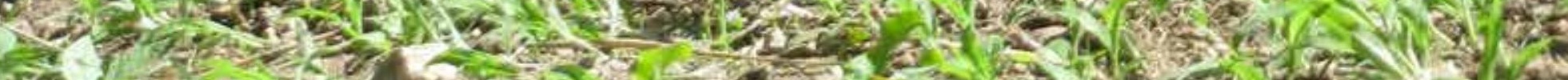
5 kares erestis $500^{2}, 634=0$

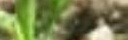




\section{Projected climate change}

\section{Year of climate departure}

The mapping of the year of climate departure (Mora et al, 2013) for the region (Figure 3) clearly shows that the highland and mountainous regions of both monsoonal and continental Asia are approaching novel sets of bioclimatic conditions more rapidly than the lowland plains of the region (Figure 5). The estimated year of climate departure for the various countries of the greater Asian Highlands region ranges from the 2041 to 2071 under the more moderate RCP 4.5 emissions scenarios, and ranges from 2036 to 2052 under the "worst case" RCP 8.5 scenario. This is slightly earlier than for the global average of 2069 for RCP 4.5 and 2047 for RCP 8.5 (Mora et al, 2013).
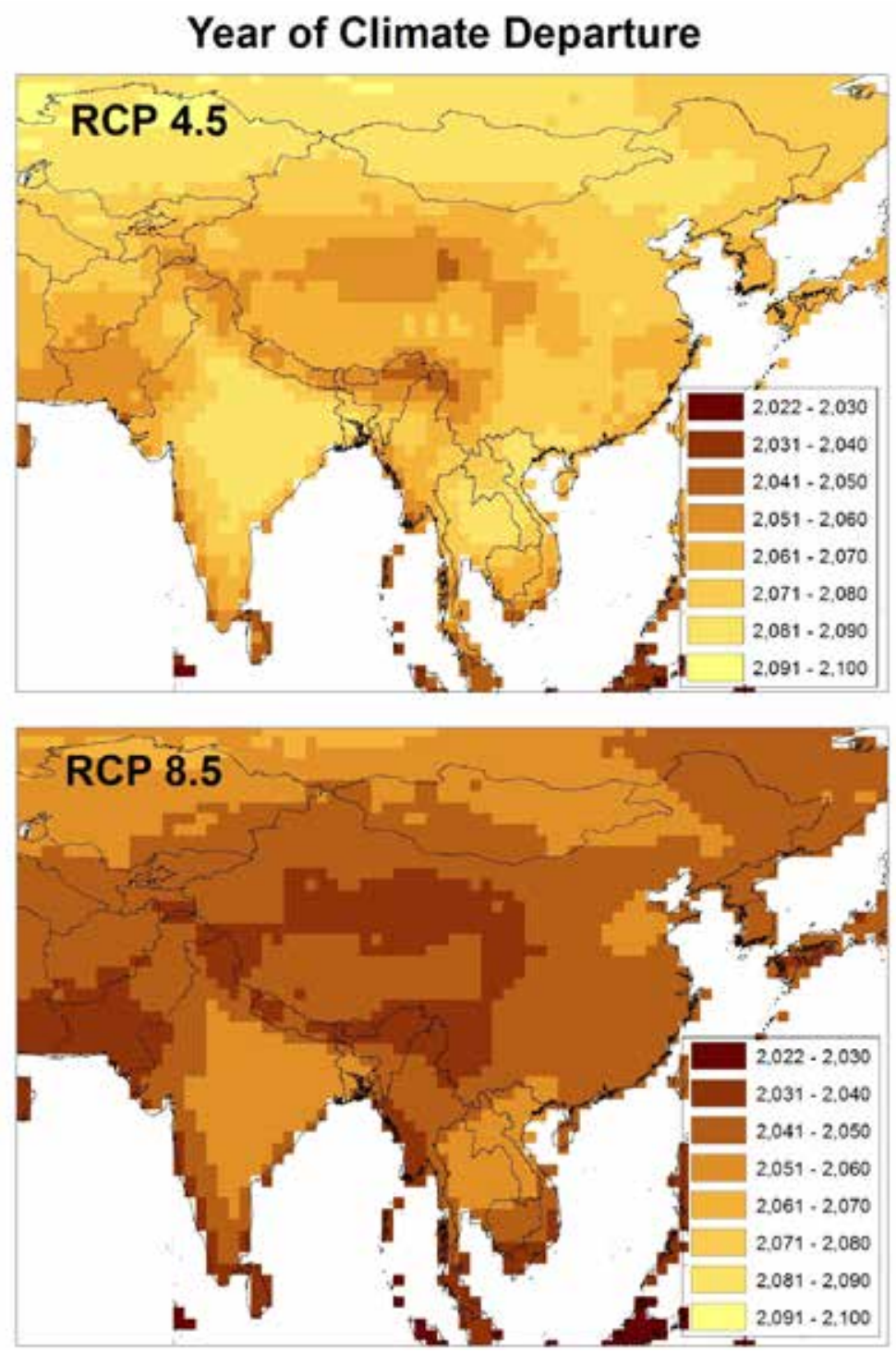

Figure 5: Year of climate departure showing the greater Asian Highlands region. Darker colors are approaching the onset of novel climatic conditions relatively more rapidly than areas with lighter colors (Data source: Mora et al, 2013). 


\section{Mean annual temperature}

The spatial distribution of current mean annual temperatures for the region highlights the cooler temperatures of the highland, mostly continental Tibetan Plateau (Figure 6), and the relatively warm tropical and sub-tropical conditions of the monsoon-influenced lower hills and southeastern ranges. The very high elevations of the Hindu-Kush and Himalayan mountain ranges create a barrier to warmer ocean airflows going north, and cold continental winter winds from the north. This is reflected by a prominent rain shadow effect along the crest of these mountains.

Temperature increases are clearly larger at the higher elevations across the region, notably over the Tibetan Plateau (Figure 7). Projected temperature changes are evident in all basins across the region (Figure 8), ranging across the different ensemble projections from $2.5^{\circ} \mathrm{C}$ to $3.1^{\circ} \mathrm{C}$ on average over the entire Asian Highlands region, with colder areas noticeably retreating, mountain tops warming, and a general warming trend concentrated in the high elevations, with a marked expansion of warmer areas upslope.

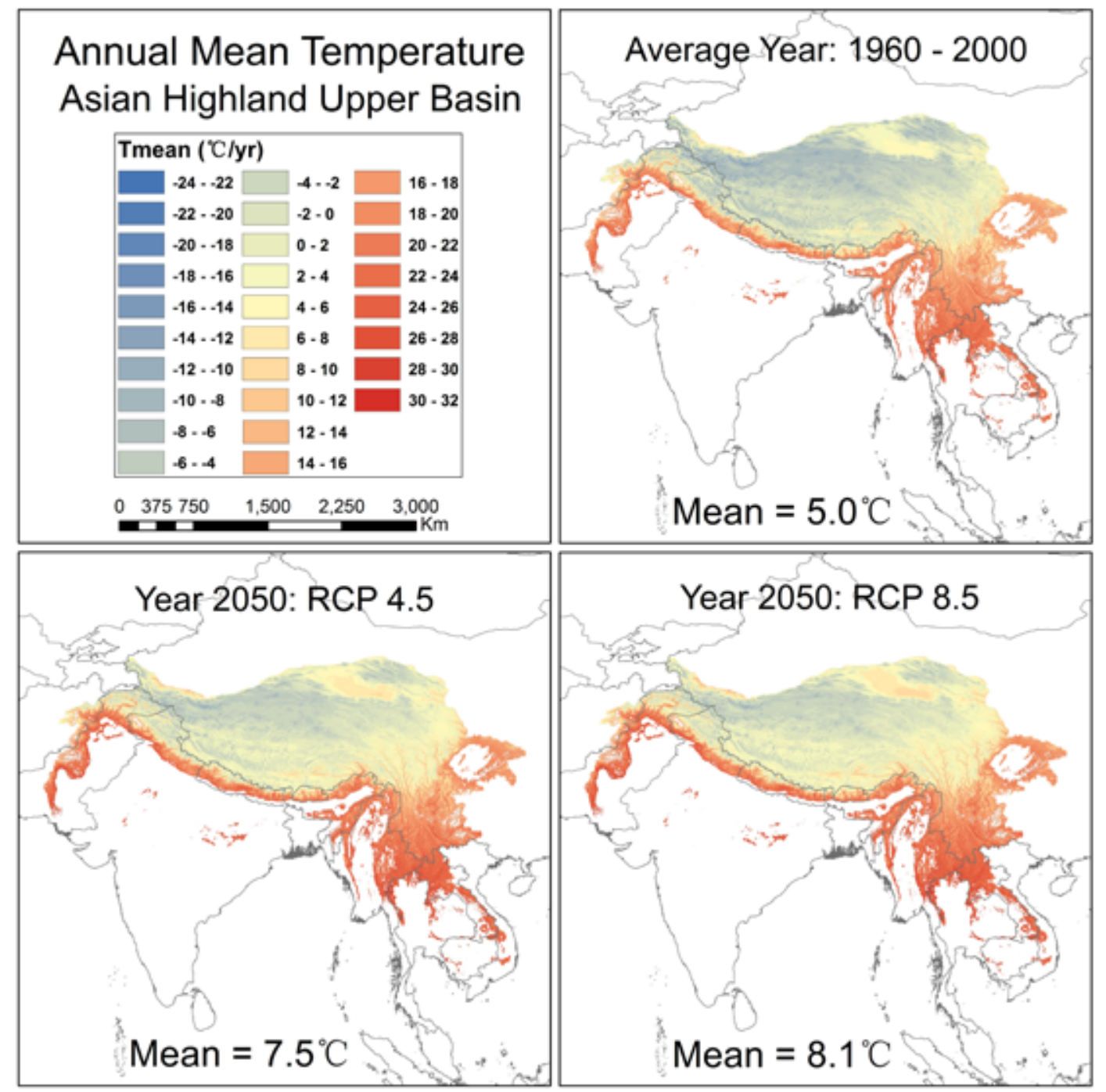

Figure 6: Mean annual temperature across the Asian Highlands region, showing current conditions (2000), based on spatially interpolated weather station data, averaged between 1960-2000, and as projected for 2050 under the RCP 4.5 and RCP 8.5 emission scenarios. 


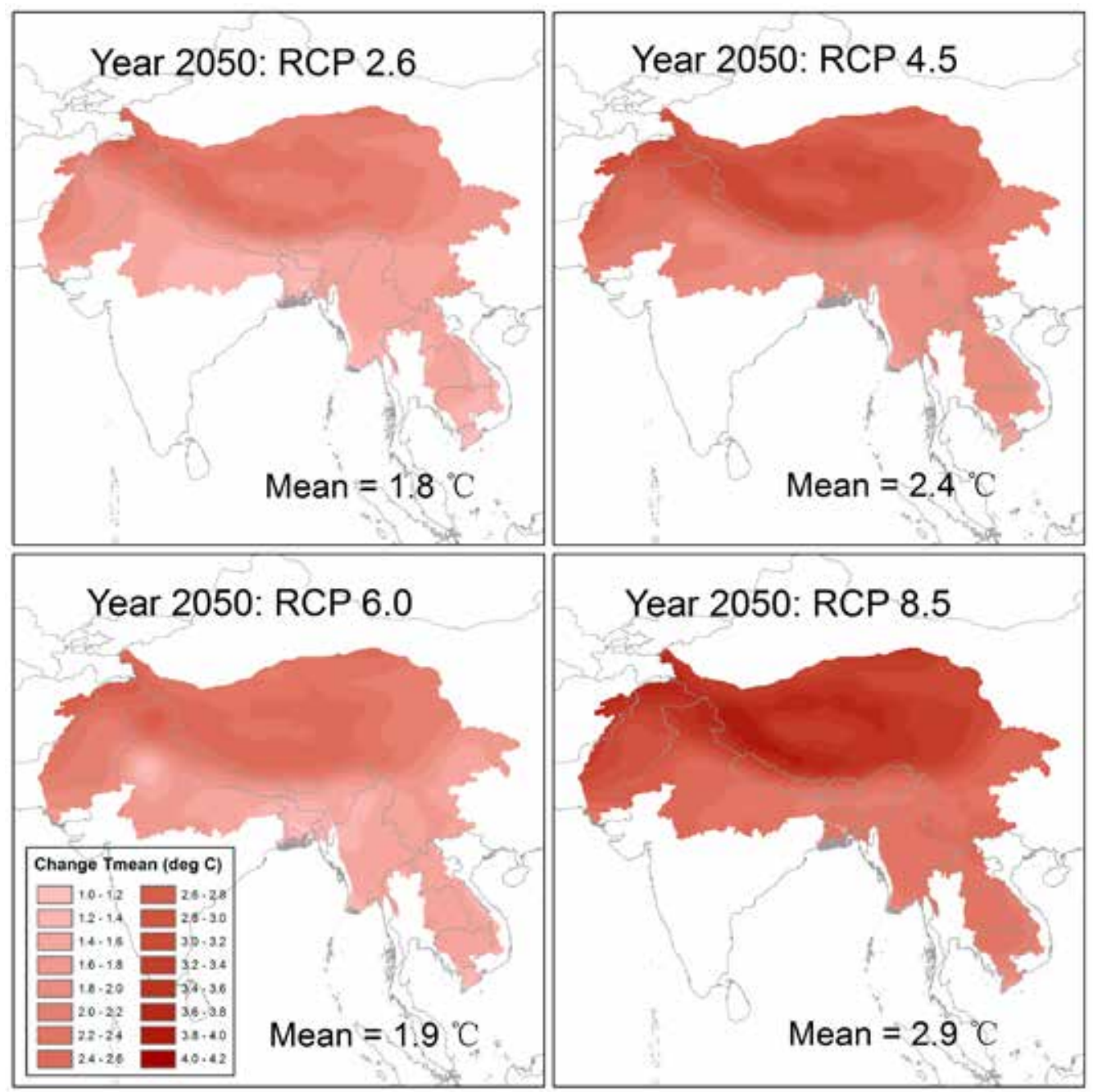

Figure 7: The projected change in mean annual temperature across the Asian Highlands region (and associated lowland basins), showing current conditions (2000), based on spatially interpolated weather station data, averaged over 1960-2000, and as projected for 2050 under all four of the resource concentration pathways $(R C P)$.

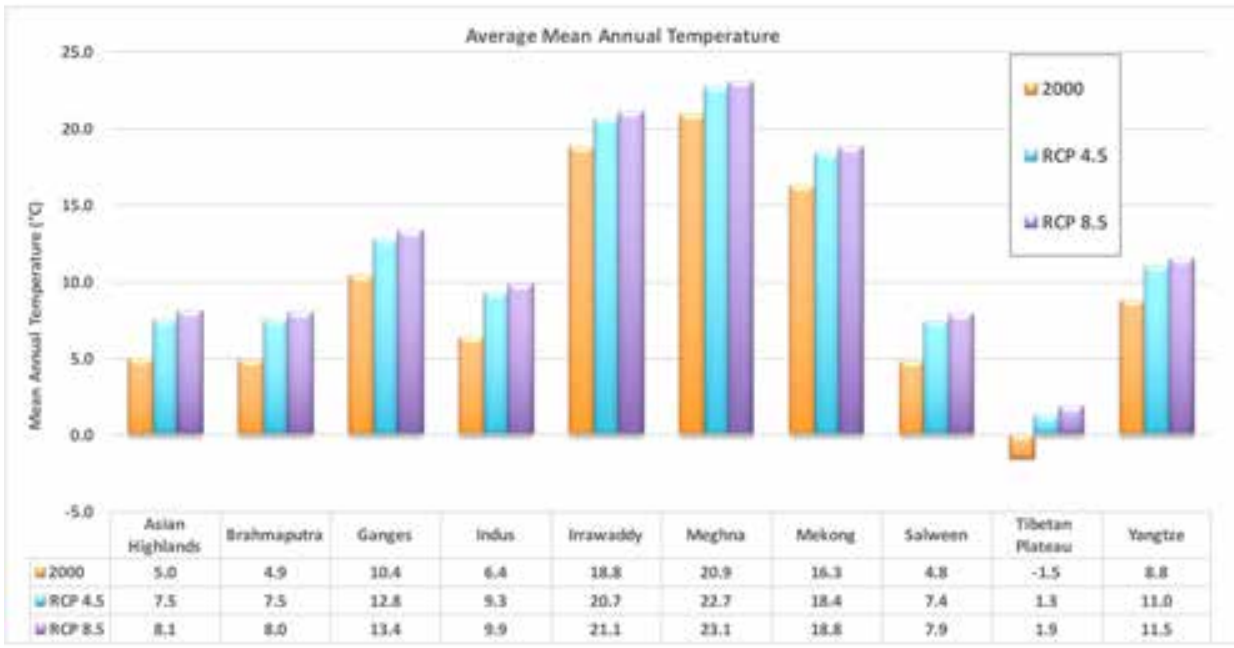

Figure 8: The projected change in mean annual temperature across the Asian Highlands region (upper basins), showing current conditions (2000), based on spatially interpolated weather station data, averaged over 1960-2000, and as projected for 2050 under two Representative Concentration Pathways scenarios (RCP 4.5 and RCP 8.5). 


\section{Mean annual precipitation}

The very high elevations of the Hindu-Kush and Himalayan mountain ranges create a barrier to warmer ocean airflows going north, and cold continental winter winds from the north. This is reflected by a prominent rain shadow effect along the crest of these mountain ranges. Arid conditions are found to the north on the high elevation Tibetan Plateau, while southern Himalayan slopes exposed to the Asian monsoon are some of the rainiest places in the world (Figure 9). An overview of the spatial distribution of annual precipitation reveals the important role of the relatively wet southern slopes of mountainous areas as water towers for a vast and highly populated downstream region.

Overall, confidence levels in the precipitation projections of the CIMP5 Earth System Models are still, in general, quite low, with the variability among models higher than for temperature projections. In our case, we have used the multi-model ensemble to aggregate, on average, and to generally present a consensus view of the model results $(n=63)$. Although variability within the various results for precipitation may be higher, there does, however, seem to be a convergence indicating wetter conditions on the southern slopes and monsoon influenced regions, and some drying of conditions in both the far west and the southeast of the Asia Highland region (Figure 10).

In general, the Asian Highlands region exhibits a moisture gradient from drier in the west to wetter in the east, wetter in the south and drier in the north, and wetter at lower elevations. The Meghna and Irrawaddy basins receive by far the most precipitation, with the Indus and Tibetan Plateau being the most arid (Figure 11). The wetter Irrawaddy and Meghna, and to a certain extent also the Ganges and Mekong, are projected to have substantial increases of annual precipitation by 2050, while most other basins can expect more moderate to minimal increases.

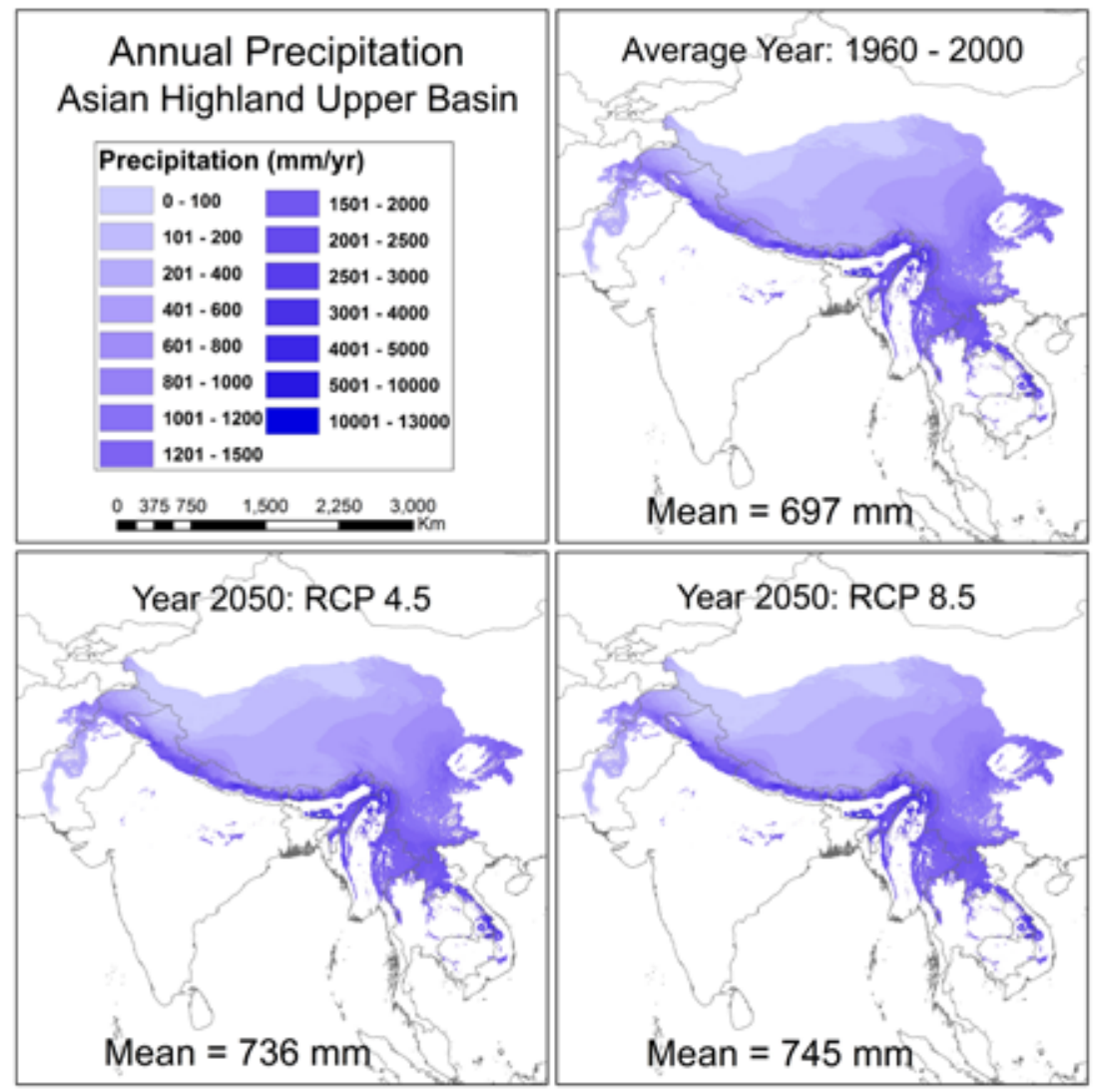

Figure 9: Mean annual precipitation across the Asian Highlands region, showing current conditions (2000), based on spatially interpolated weather station data, averaged over 1960-2000, and as projected for 2050 under the RCP 4.5 and RCP 8.5 emission scenarios. 


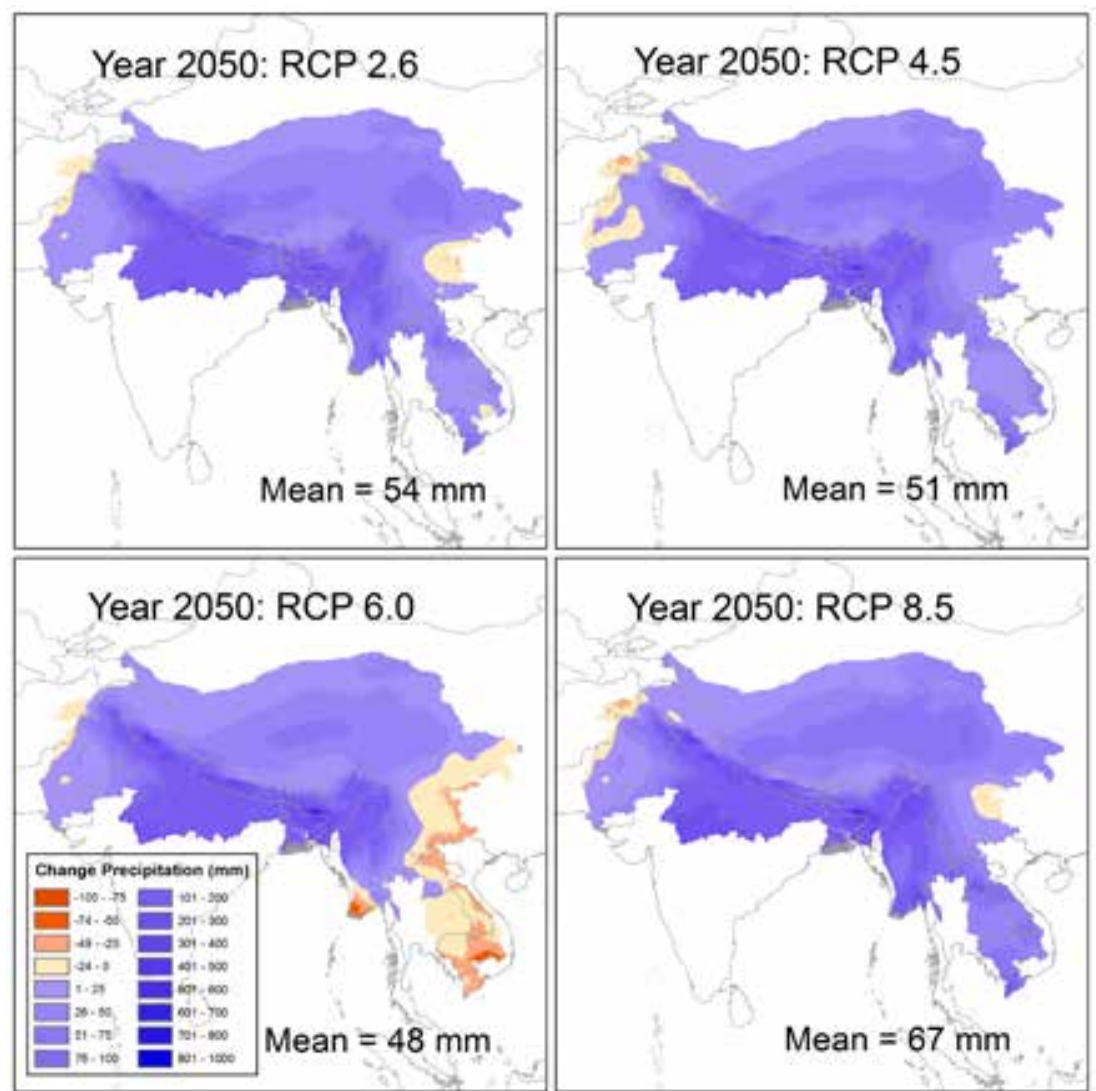

Figure 10: The projected change in mean annual precipitation $(\mathrm{mm} / \mathrm{yr})$ across the Asian Highlands region (and associated lowland basins), showing current conditions (2000), based on spatially interpolated weather station data, averaged over 1960-2000, and as projected for the year 2050 under all four of the Representative Concentration Pathways $(R C P)$.

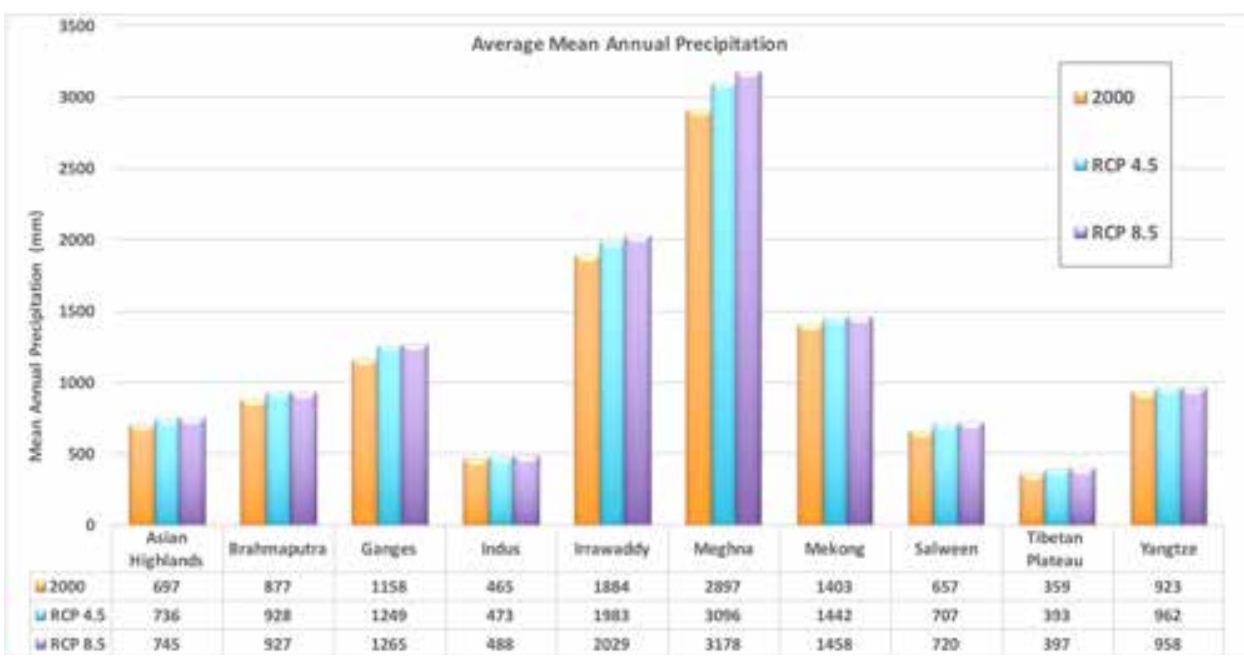

Figure 11: Mean annual precipitation for each of the river basins in the Asian Highlands region, and the region as a whole, showing current conditions, based on spatially interpolated weather station data, averaged over 1960-2000 (2000), and as projected for 2050, shown for two Representative Concentration Pathways (RCP). 


\section{Mean annual Potential Evapotranspiration (PET)}

Relatively high levels of PET are evident across the region, with the highest PET found in the south-eastern portions of the Himalayas, and markedly decreasing along the latitudinal gradient while moving north. Lower values are found in the colder high altitude zones. Overall, annual PET is projected to increase due to higher temperatures, on average over the region between $85 \mathrm{~mm}$ to $100 \mathrm{~mm}$ by 2050 .

The averaged mean PET for the whole Asian Highlands region of $903 \mathrm{~mm}$ (1960-2000) increases by almost $10 \%$ by 2050 , indicating potentially higher water demand by both managed agricultural and pastoral systems, and natural (unmanaged or lesser managed) ecosystems. All nine basins within the Asian Highlands region show a similar increase in PET, i.e. of approx. 9-10\% or just less than $100 \mathrm{~mm}$ on average. These results seem to indicate that any benefit derived from increased precipitation will just compensate for the increase in PET (driven by increasing temperatures).

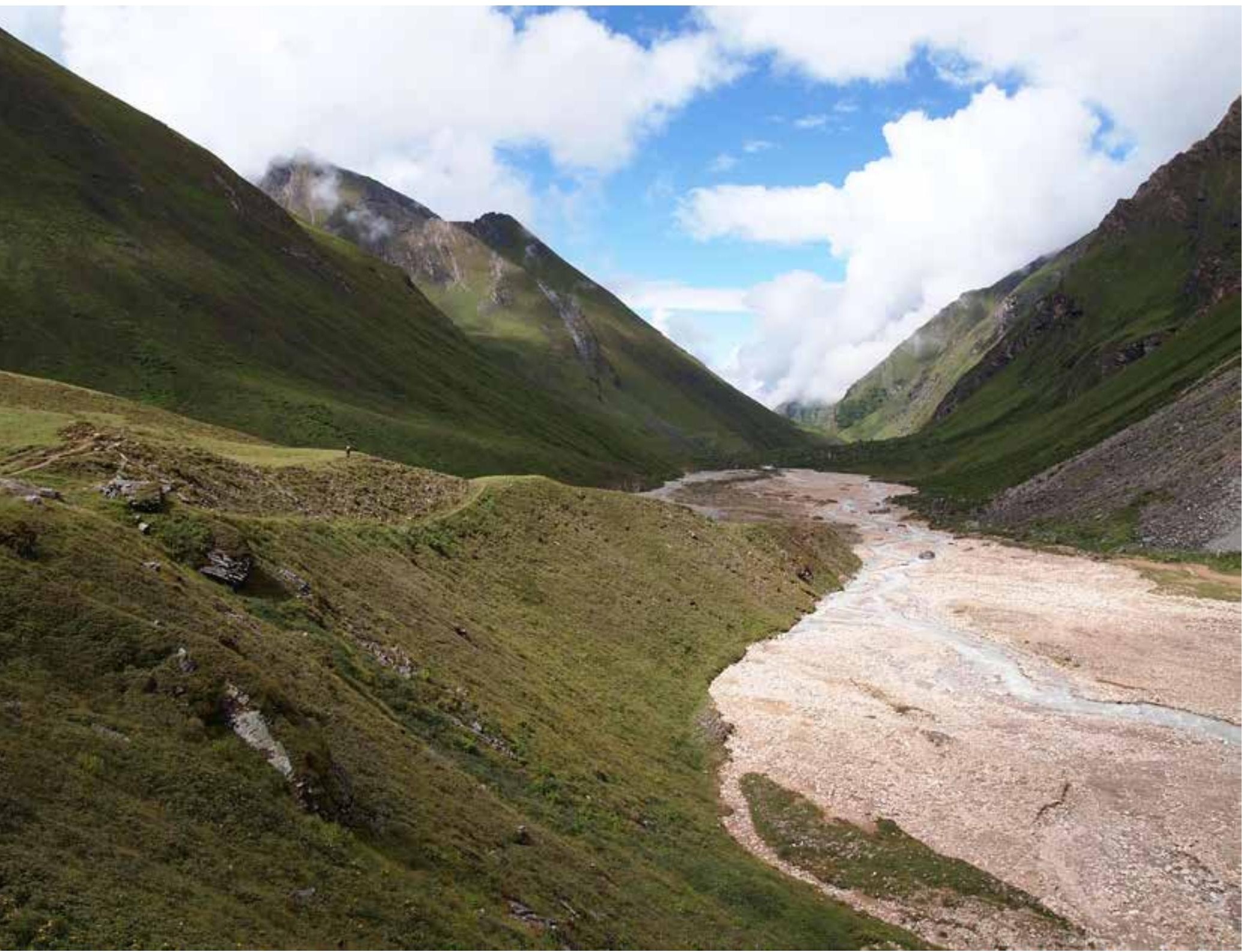




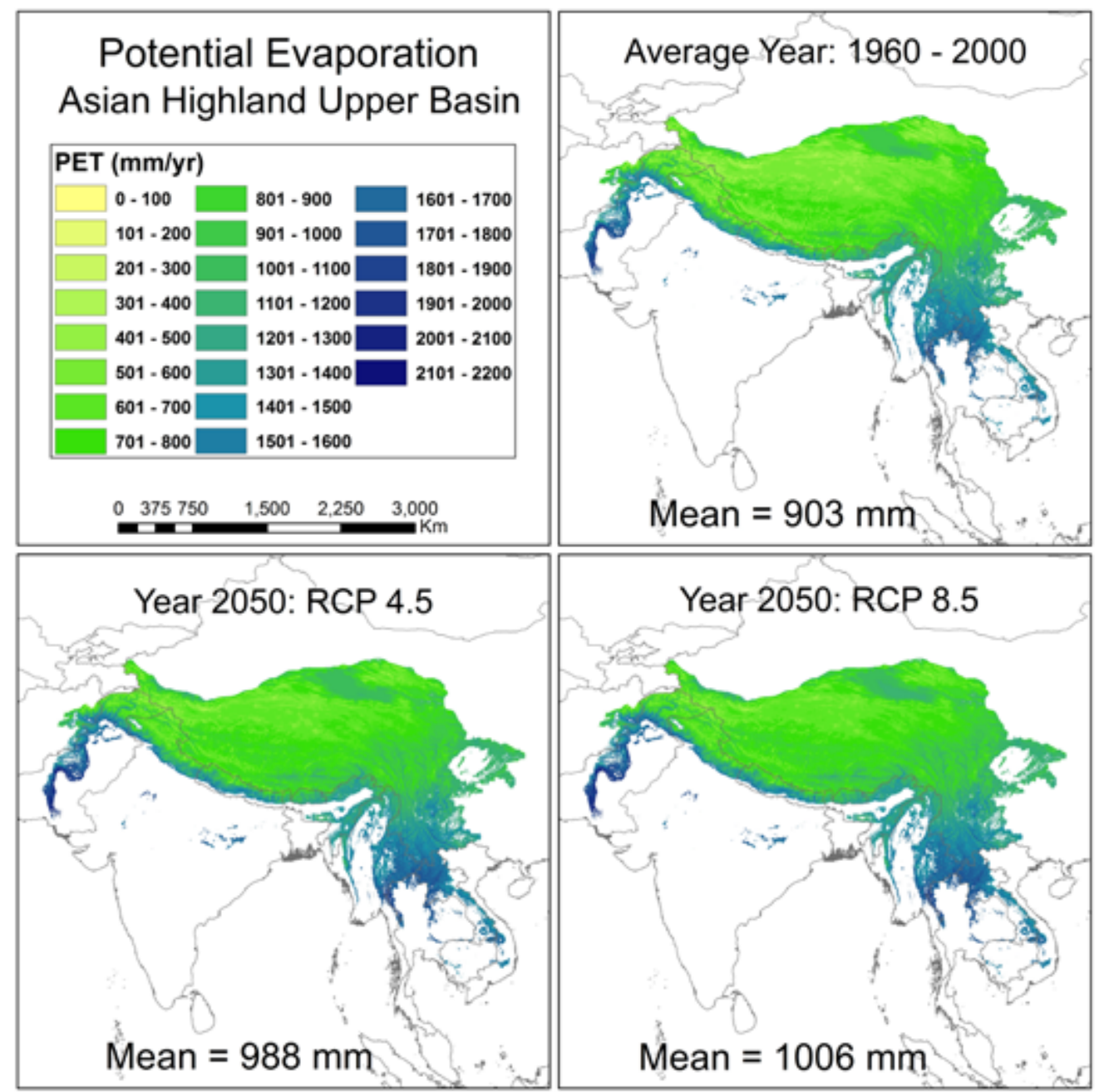

Figure 12: Mean annual potential evapotranspiration (PET) across the Asia Highlands region, showing current conditions (2000), based on spatially interpolated weather station data, averaged over 19602000, and as projected for 2050 under the RCP 4.5 and RCP 8.5 emission scenarios.

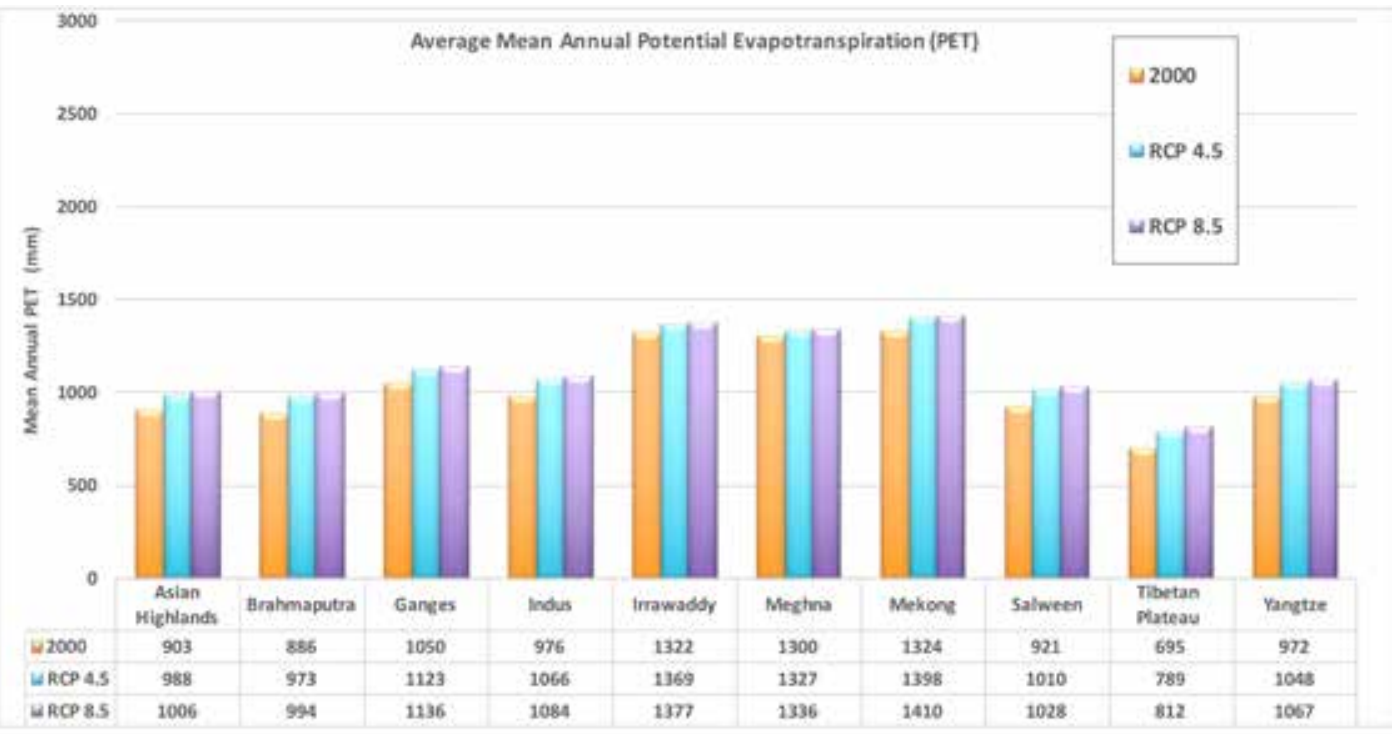

Figure 13: Mean annual potential evapotranspiration (PET) for each of the upper river basins comprising the Asian Highlands region, and the region as a whole, showing current conditions, based on spatially interpolated weather station data, averaged over 1960-2000 (2000), and as projected for 2050, shown as average of the four $R C P$ emission scenarios. 


\section{Mean annual Aridity-Wetness Index (AWI)}

The Aridity-Wetness Index (AWI; as a unit-less measure) is a general indicator of humid bioclimate levels regulating plant growth, and is essentially a ratio of the amount of precipitation any one spot receives over the total PET, i.e. how much of the total PET requirement is satisfied by precipitation. Using this measure, 1.0 would indicate that the PET requirement was fully met, with 0.65 often used as a threshold for semi-arid conditions. Within this context, the mean AWI of 0.69 for the region indicates that taking into account the extremes of terrain, elevation, and bioclimatic conditions across the region, there should be at least enough precipitation for semi-arid rainfall agriculture.

Although vegetation water requirements are in general limited over cold highland areas and could be easily balanced by precipitations, limited crop yields are obtained, which may increase with temperature, and consequently PET will increase. However, in the mountainous regions there are concentrated high AWI values (AWI $>1.0$ ), underscoring the important role of these areas as water towers for the region. AWI increases along the southern slopes and southeastern portions of the region. Overall, there is a very slight drying trend by 2050 .

The Meghna, Ganges and Mekong Basins all have relatively high AWI ( $>1.0)$, however, the Irrawaddy Basin has by far the highest AWI (2.3), which is also projected to increase substantially by 2050. Most other basins expect slight decreases in AWI, indicating slightly less conducive conditions for plants growth. It is thus assumed that expected growth benefits of increased precipitation have been more than balanced out by an increase in PET, leaving the more integrated measure of the AWI to decrease, both regionally, and for most of the individual basins.

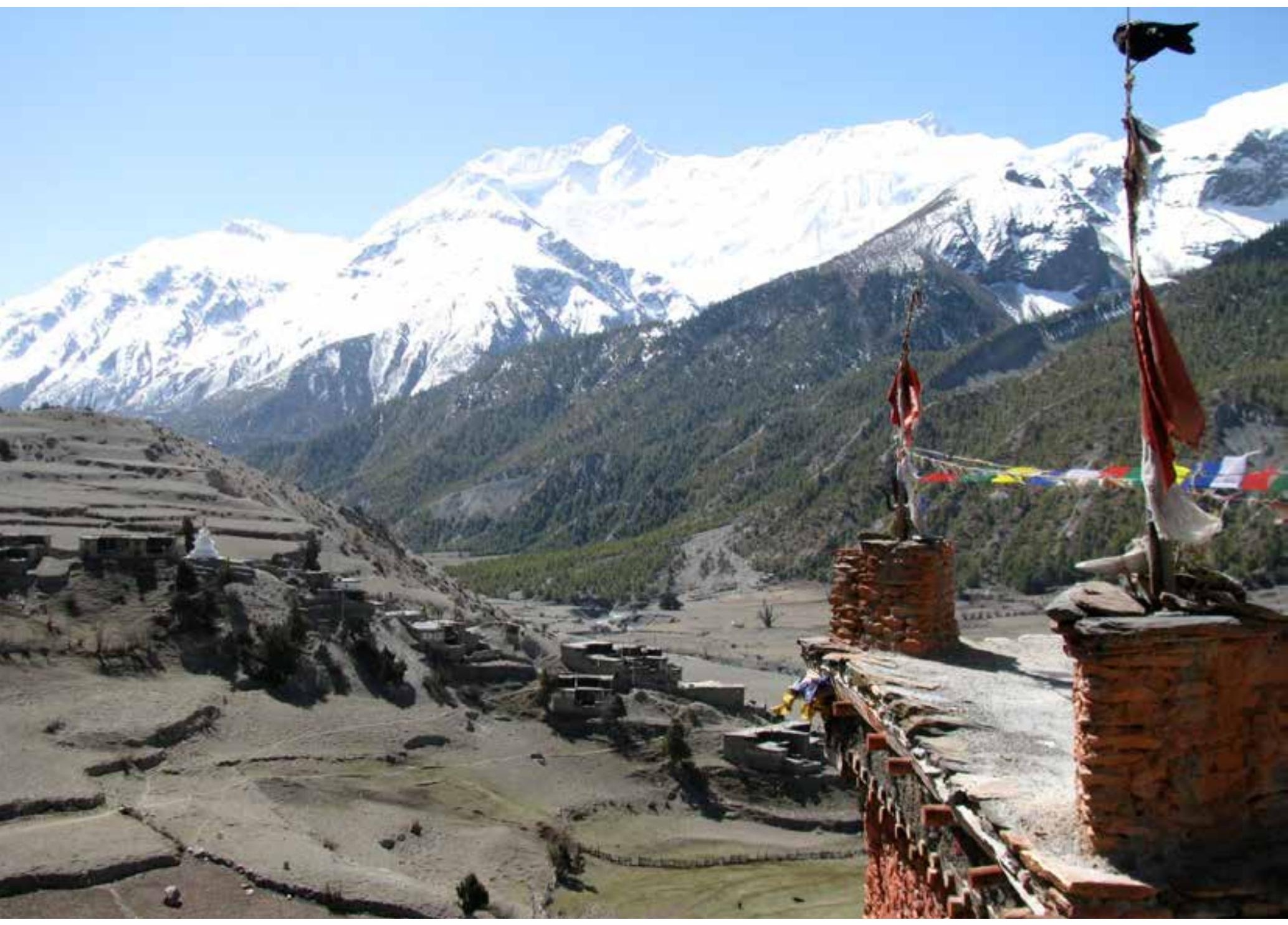




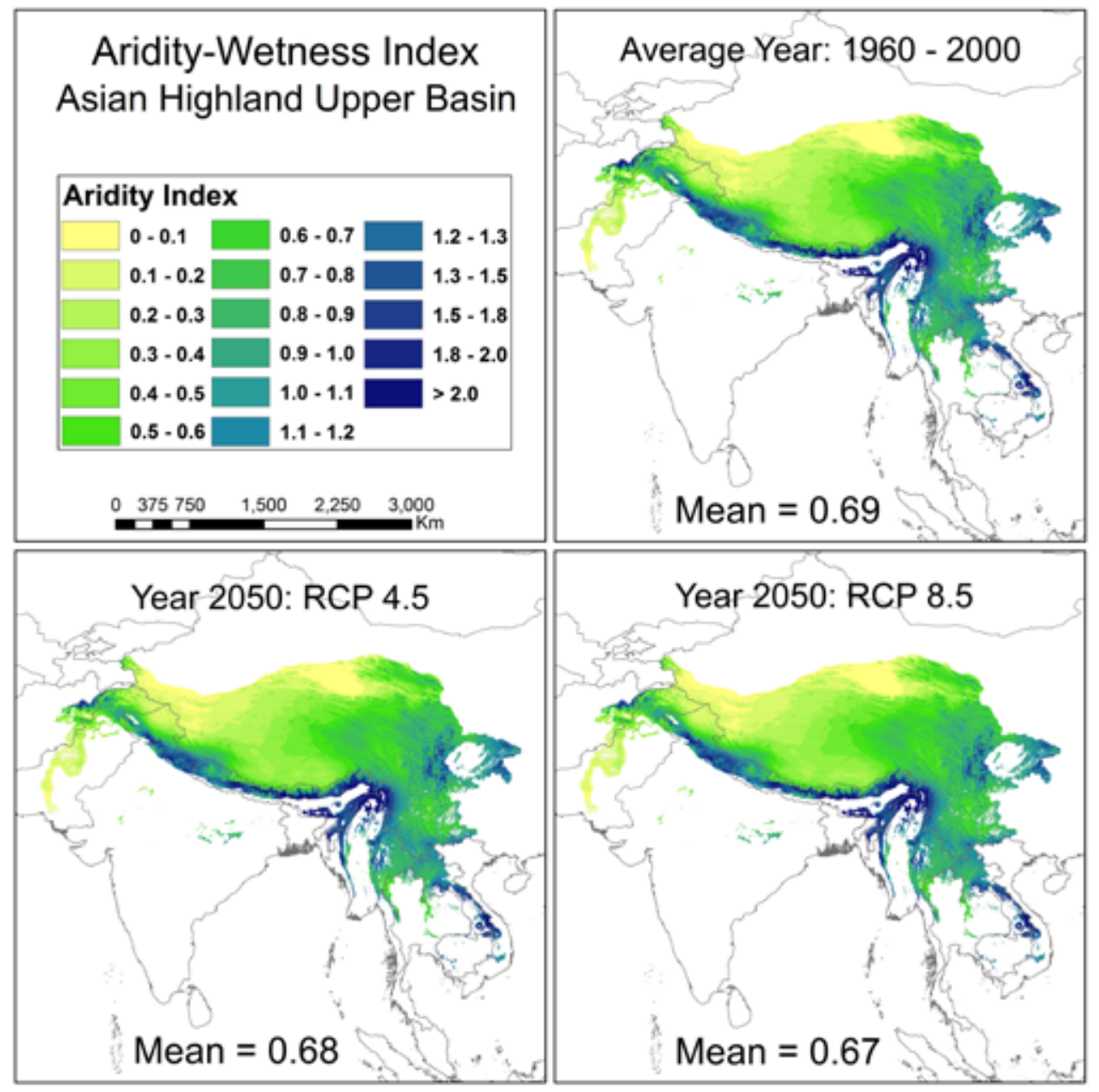

Figure 14: Mean annual Aridity-Wetness Index (AWI) across the Asian Highlands region, showing current conditions (2000), based on spatially interpolated weather station data, averaged over 19602000, and as projected for 2050 under the RCP 4.5 and RCP 8.5 emission scenarios.

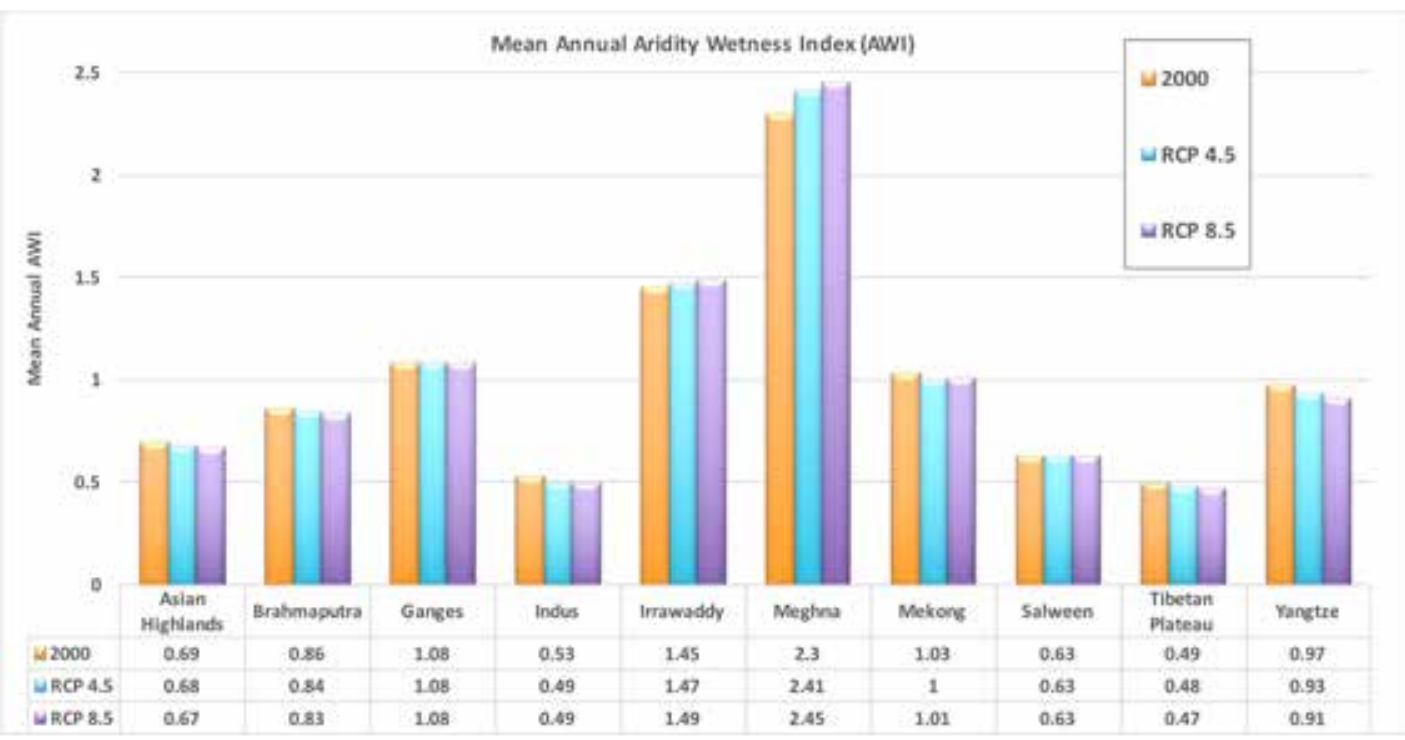

Figure 15: Mean Annual Aridity-Wetness Index (AWI) for each of the upper river basins comprising the Asian Highlands region, and the region as a whole, showing current conditions, based on spatially interpolated weather station data, averaged over 1960-2000 (2000), and as projected for 2050, shown as an average of the four RCP emission scenarios. 


\section{In-situ hydrologic status: soil water balance model}

A simple and spatially-distributed soil water balance approach has been used to model insitu hydrological status, divided into three basic components, namely vapour flow (actual evapotranspiration or AET), soil water content (SWC), and excess in-situ water, similar to "runoff". Since the model only calculates in-situ (i.e. one-dimensional) processes and precipitation as the only water input into the system, without accounting for overland flow, we use excess water as the term for that portion of the input into the grid cell (i.e. precipitation), left over after actual evapotranspiration (AET), and accounting for water changes within the soil matrix (SWC). Annual vapour flow, or AET, differs from PET in that it takes land use and its specific evaporation and transpiration characteristics into account, providing an estimate of the actual amount of water evaporated and transpired, that is, a value substantially lower than PET in water-limited environments, such as much of the Asian Highlands region.

As with PET, we see a slight increase in AET over the entire Asian Highlands region, averaging about $5 \%(18 \mathrm{~mm}-20 \mathrm{~mm})$ for the region as a whole (Figure 12). Irrawaddy, Meghna and Mekong Basins had the highest AET values, with very low values across the Tibetan Plateau, especially toward the northeast portions.

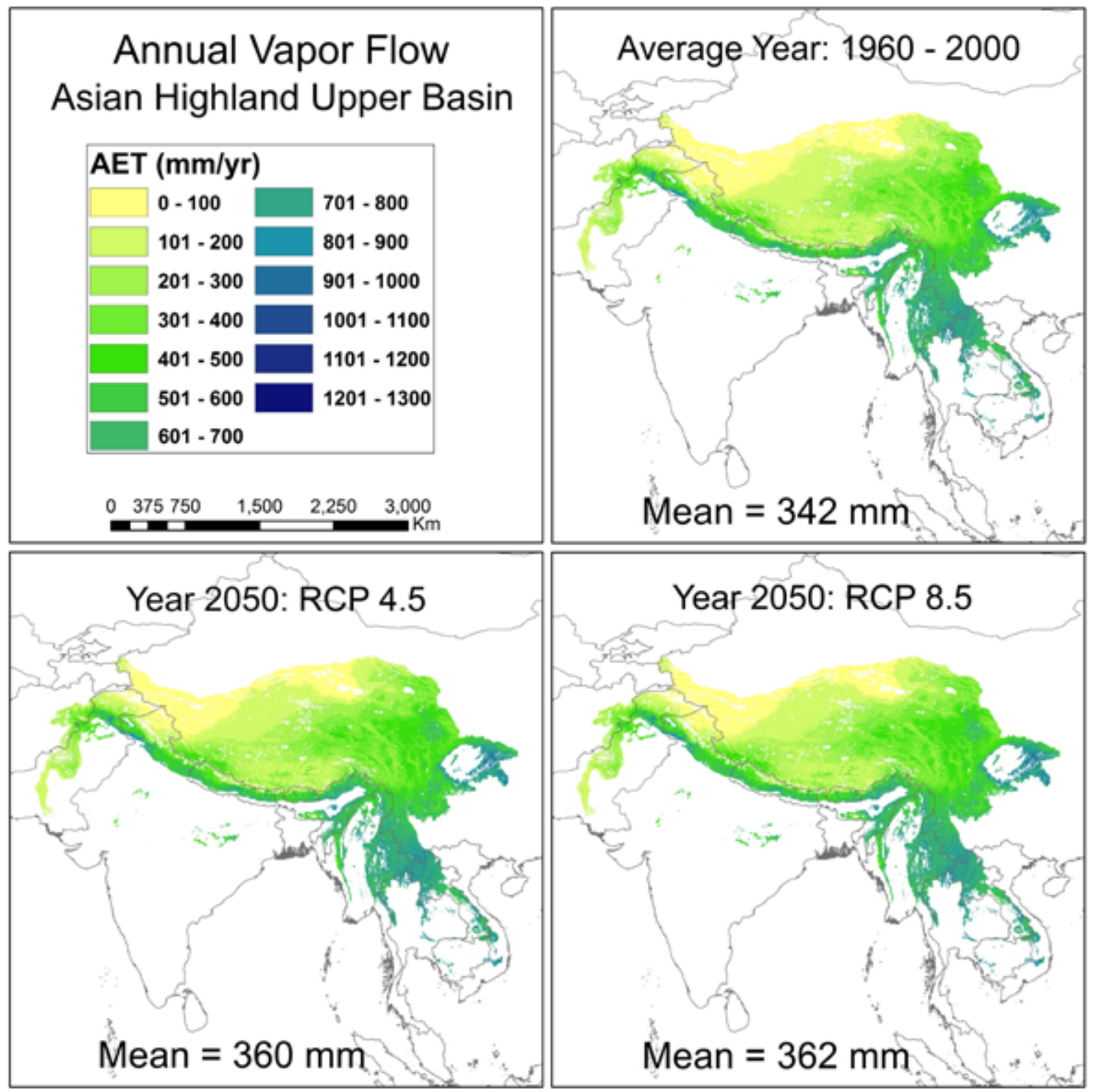

Figure 16: Mean annual vapour flow (AET) across the Asian Highlands region, showing current conditions (2000), based on spatially interpolated weather station data, averaged over 1960-2000, and as projected for 2050 under the RCP 4.5 and RCP 8.5 emission scenarios. 
The spatial modelling of the SWC component revealed that northern portions of the region and the high elevation Tibetan Plateau have generally dry soil conditions. In general, however, soil conditions are moister towards the southeast and along the southern slopes of the mountain ranges. SWC is projected to decrease slightly by 2050 , however, this could be a balance in the model dynamics where larger vapour flows neutralize increasing precipitation, leaving soil moisture conditions less sensitive to changes than other parameters.

Meghna Basin has the highest excess in-situ water (ROF) in the region, followed by the Irrawaddy and the Ganges, with the Indus Basin and the Tibetan Plateau having the lowest and least favourable environment for streamflow disposal. For the region as the whole, the average is $303 \mathrm{~mm}$, reflecting the large expanse of the arid Tibetan Plateau. By 2050 almost all basins show a slight increase in ROF under both RCP 4.5 and 8.5, with an average increase of $19 \mathrm{~mm}$ to $25 \mathrm{~mm}$ for the Asian Highlands region as a whole.

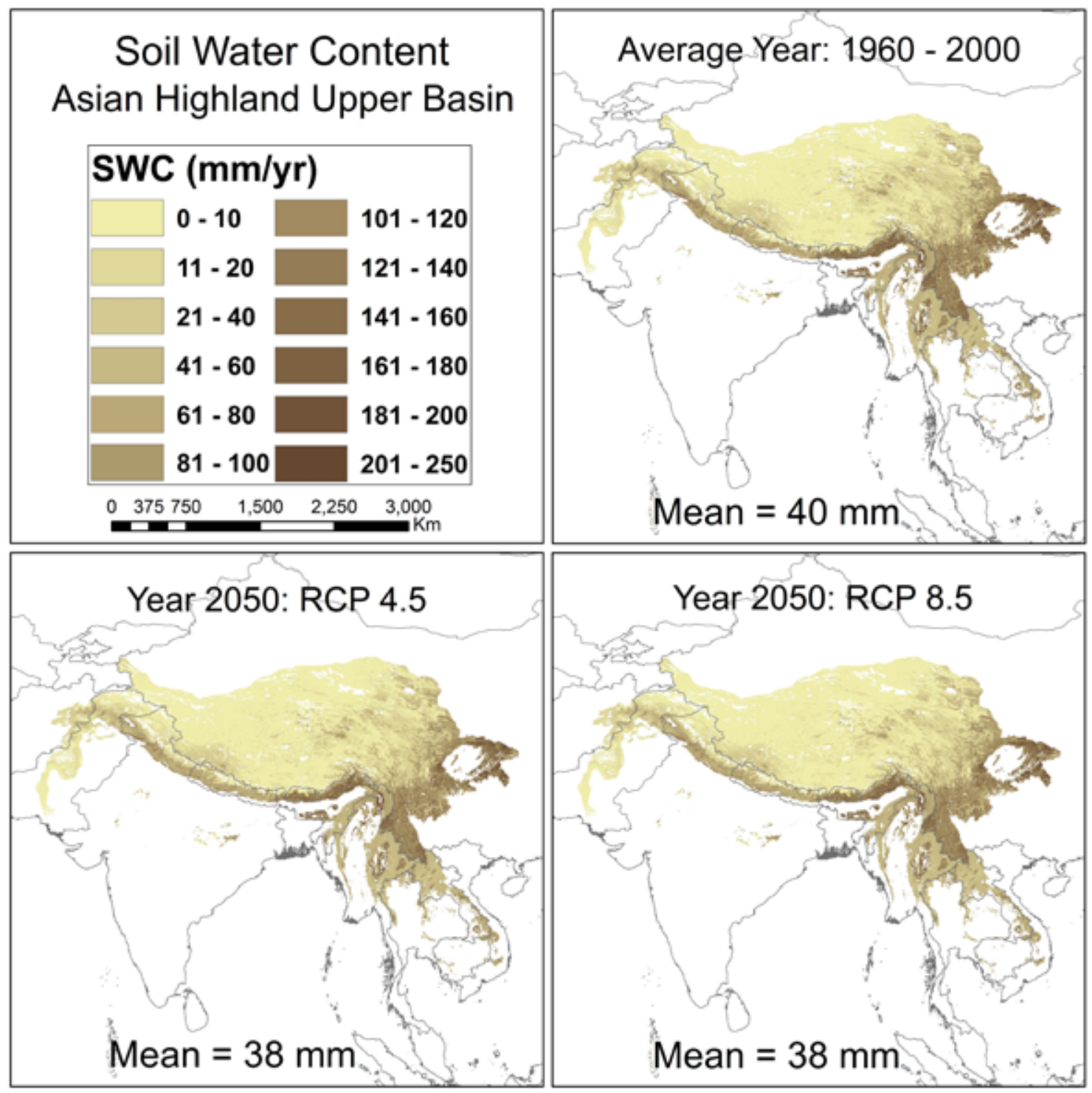

Figure 17: Mean annual soil water content (SWC) across the Asian Highlands region, showing current conditions (2000), based on spatially interpolated weather station data, averaged over 1960-2000, and as projected for 2050 under the RCP 4.5 and RCP 8.5 emission scenarios. 


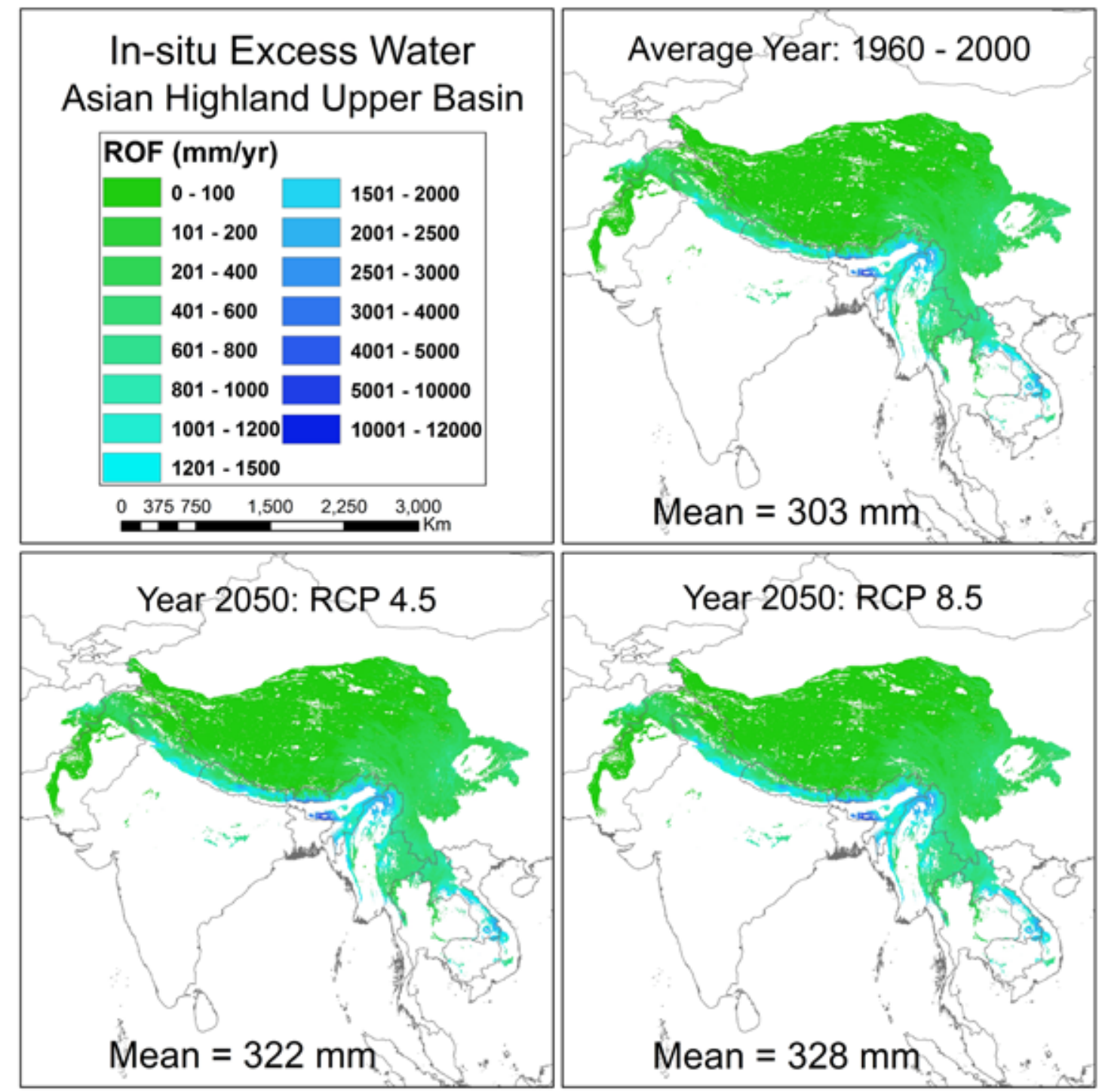

Figure 18: Mean annual in-situ excess water (ROF) across the Asian Highlands region, showing current conditions (2000), based on spatially interpolated weather station data, averaged over 1960-2000, and as projected for 2050 under the RCP 4.5 and RCP 8.5 emission scenarios.

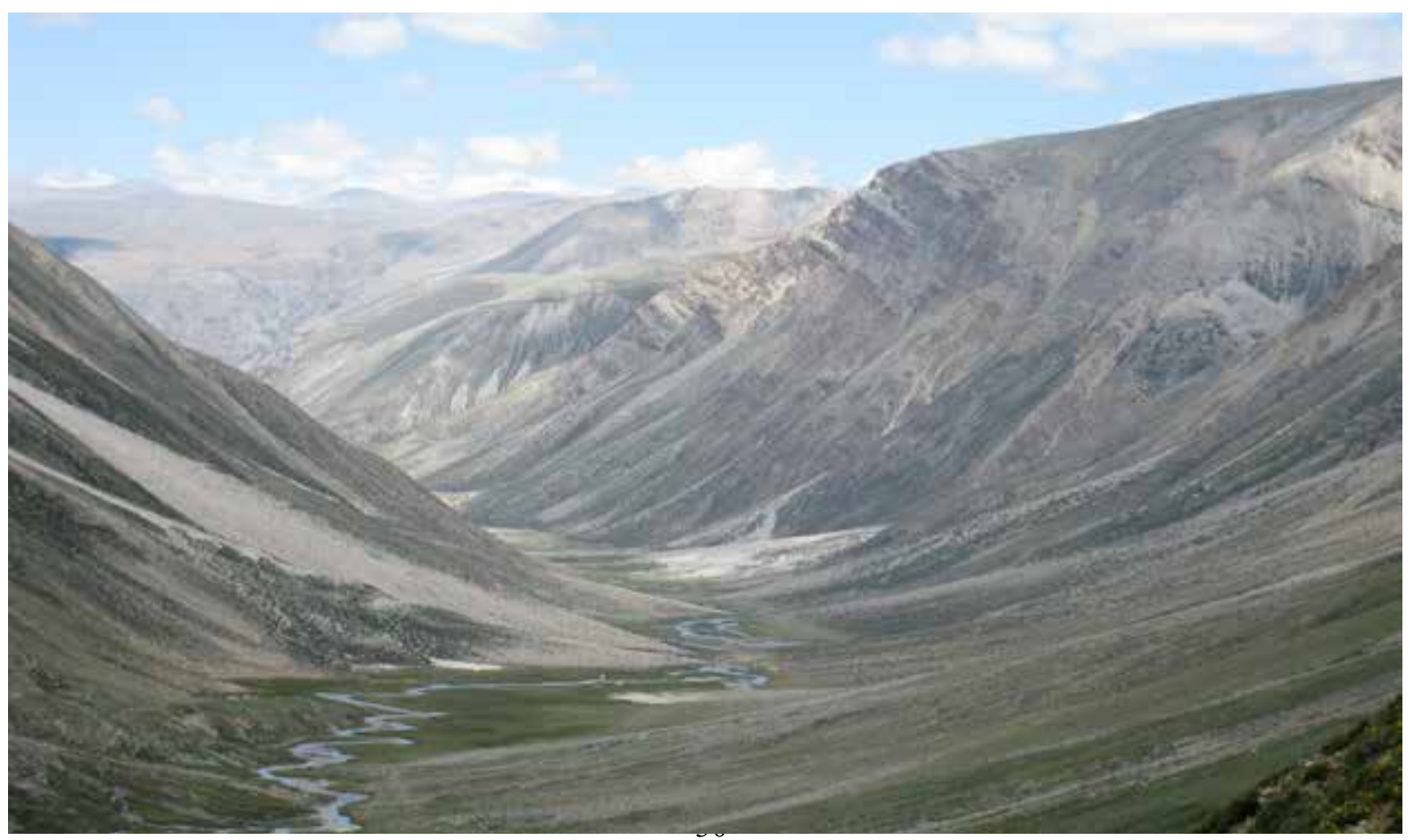



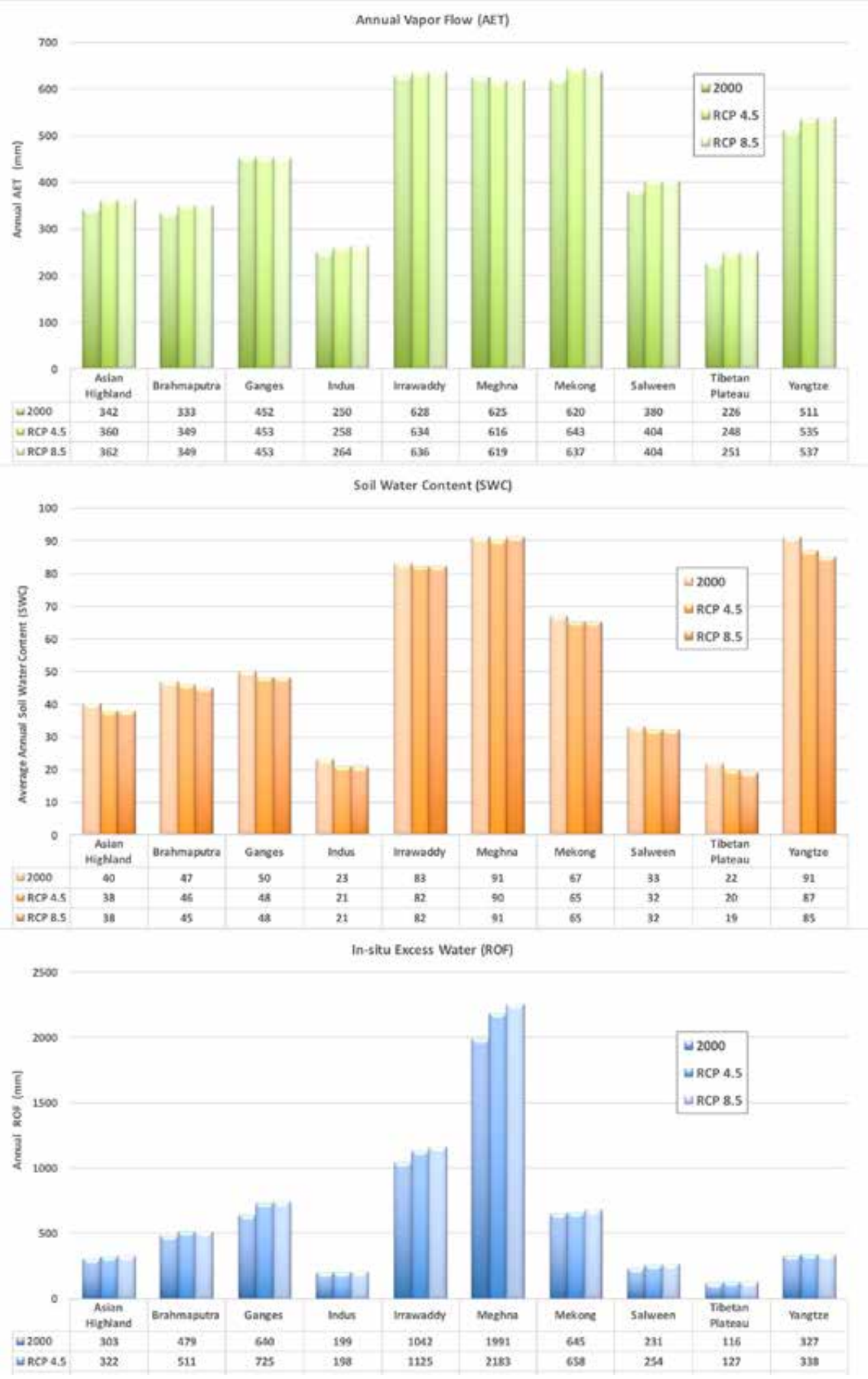

Figure 19: Mean annual vapour flow (AET), soil water content (SWC), and excess in-situ water (ROF) for each of the basins across the Asian Highlands region, and the region as a whole, showing current conditions, based on spatially interpolated weather station data, averaged over 1960-2000, and as projected for 2050, shown for two RCP emission scenarios. 


\section{Projected change in spatial distribution of bioclimatic conditions}

\section{Bioclimatic stratification}

Sixteen major bioclimatic zones, comprised of 102 strata, were identified through this study as currently found within the upper basins of the Asian Highlands project region (Figure 20), ranging from the Extremely Hot and Moist zone at low elevations in the south, to Extremely Cold and Wet zones at the higher elevations (Table 1). Mean annual temperatures for these zones are generally inversely correlated with their average elevation, however the zonal distribution of bioclimatic conditions also reflects a strong influence of the regionally predominant latitudinal and moisture gradients. Warm tropical zones are found along the lower elevations and base of the mountains, and in the southeast, e.g. the tropical mountains of Yunnan, Laos, and Myanmar.

The Extremely Cold and Mesic zone lying across much of the Tibetan Plateau, with a relatively high mean elevation of over 4700 m.a.s.l. comprises nearly half of the total Asian Highlands region (Table 1). Of the 16 zones, only 10 zones individually cover $1 \%$ or more of the total regional area, with the five most extensive zones (i.e. the Cold and Mesic and the Warm Temperate) together comprising $85 \%$ of the total area. Zones with smaller overall areal extent nevertheless cover thousands of square kilometres and may be important, for example as glaciated environments or water source regions, or provide distinct bioclimatic conditions and niche habitat for biodiversity, specialized mountain agricultural systems, or transhumance pastoral systems.

\section{Projected change in spatial distribution of bioclimatic zones}

By 2050, substantial shifting and spatial displacement of the bioclimatic zones is seen across the region under all RCP (Figure 21). Zones shift both upslope along elevation gradients, and northward along the latitudinal gradient. Approximately $38 \%$ to $47 \%$ of the total area of the upland Asian Highlands region (Table 2) shifts to a different bioclimatic zone (indicating a major shift to a completely novel set of bioclimatic conditions), while $75 \%$ to $84 \%$ of the region shifts to a different bioclimatic stratum (indicating a more marginal incremental shift but still novel conditions). The largest zone in areal extent (Extremely Cold and Mesic), covering more than 2 million $\mathrm{km}^{2}$, decreases substantially (between $22 \%$ and $29 \%$ ) by 2050 under both reported RCP projections, with these areas warming to become Cold and Mesic to Cool Temperate and Dry. Medium elevation Warm Temperate and Mesic zones decrease in area, while Extremely Hot zones at lower elevations increase substantially.

On average, the mean elevation of all the bioclimatic zones shifts upward from $279 \mathrm{~m}$ to $345 \mathrm{~m}$ (Table 3). All zones shift upward, several of which shift in excess of 500 meters upward in mean elevation. Almost all the zones shift upward substantially in their maximum elevation extent (Figure 22), and most also shift upward in their minimum elevation extent (or at least stay approximately at the same minimum elevation). The warmer zones all increase the extent of their elevation range substantially. 


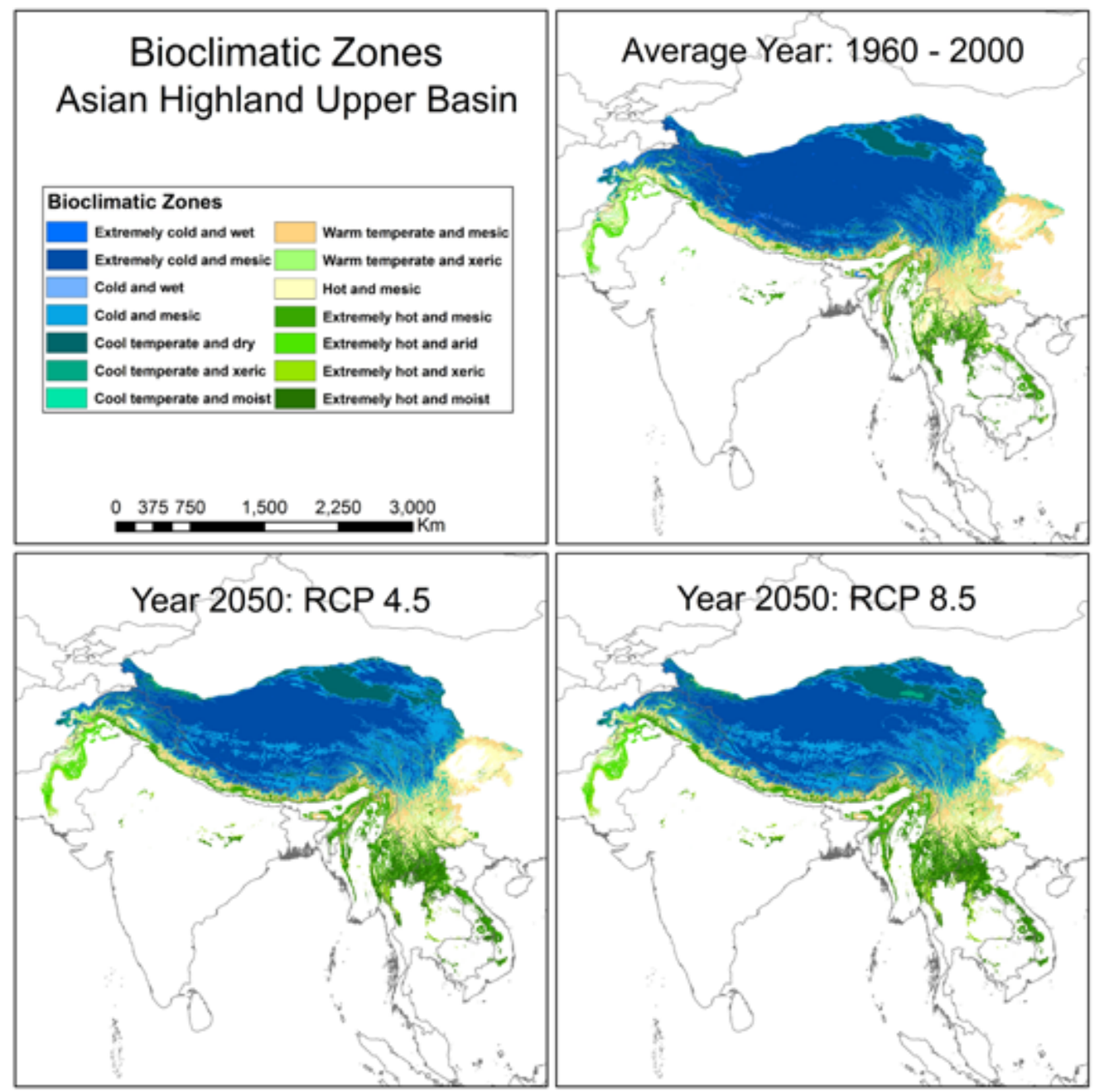

Figure 20: Bioclimatic stratification of the Asian Highlands region based on spatially interpolated weather station data averaged over 1960-2000, and two projected climate change scenarios for 2050.

Asia Highlands - Upper Basins

\begin{tabular}{|c|c|c|c|c|c|c|c|c|}
\hline Bioclimatic Zone & Zone & Are & & Elevation & Temperature & Precipitation & PET & AWI \\
\hline & & $\mathbf{k m}^{2}$ & $\%$ & $\mathrm{~m}$ asl & ${ }^{\circ} \mathrm{C}$ & $\mathbf{m m}$ & $\mathbf{m m}$ & \\
\hline Extremely cold and wet & $\mathrm{C}$ & 17,276 & 0.4 & 5219 & $(6.7)$ & 1156 & 465 & 1.36 \\
\hline Extremely cold and wet & $\mathrm{D}$ & 29,891 & 0.7 & 5277 & $(5.1)$ & 633 & 494 & 1.31 \\
\hline Cold and wet & $E$ & 15,776 & 0.4 & 5441 & $(5.9)$ & 531 & 469 & 1.16 \\
\hline Extremely cold and mesic & $\mathrm{F}$ & $2,081,610$ & 48.1 & 4737 & (3.6) & 307 & 614 & 0.49 \\
\hline Cold and mesic & G & 482,681 & 11.1 & 3628 & 2.9 & 506 & 842 & 0.60 \\
\hline Cool temperate and dry & $\mathrm{H}$ & 220,309 & 5.1 & 2902 & 5.0 & 260 & 965 & 0.26 \\
\hline Cool temperate and xeric & I & 30,379 & 0.7 & 2331 & 10.0 & 346 & 1133 & 0.31 \\
\hline Cool temperate and moist & $\mathrm{J}$ & 109,558 & 2.5 & 2610 & 10.1 & 1124 & 997 & 1.14 \\
\hline Warm temperate and mesic & $\mathrm{K}$ & 444,551 & 10.3 & 1675 & 14.9 & 1419 & 1159 & 1.23 \\
\hline Warm temperate and xeric & L & 62,281 & 1.4 & 1593 & 16.9 & 565 & 1405 & 0.42 \\
\hline Extremely hot and mesic & M & 348,213 & 8.0 & 717 & 22.2 & 1945 & 1490 & 1.34 \\
\hline Hot and dry & $\mathrm{N}$ & 315,706 & 7.3 & 1088 & 19.3 & 1343 & 1392 & 0.98 \\
\hline Extremely hot and arid & $\mathrm{O}$ & 44,751 & 1.0 & 749 & 22.2 & 300 & 1707 & 0.18 \\
\hline Extremely hot and arid & $P$ & 13,434 & 0.3 & 433 & 24.8 & 258 & 1861 & 0.14 \\
\hline Extremely hot and xeric & Q & 3,602 & 0.1 & 431 & 26.5 & 975 & 1792 & 0.55 \\
\hline Extremely hot and moist & $\mathrm{R}$ & 112,045 & 2.6 & 495 & 24.7 & 1461 & 1659 & 0.89 \\
\hline
\end{tabular}

Table 1: Basic climatic characteristic of the $A H$ EnS bioclimatic zones under current conditions (2000) as found in the Asia Highlands region, including the areal extent of the zone (Area), both as $\mathrm{km}^{2}$ and as a percentage of the total area of the whole Asia Highlands region, the mean elevation (Elevation), mean annual temperature (Temperature), mean annual potential evapotranspiration (PET), and the mean annual aridity-wetness index (AWI). Red parentheses signify negative values. 


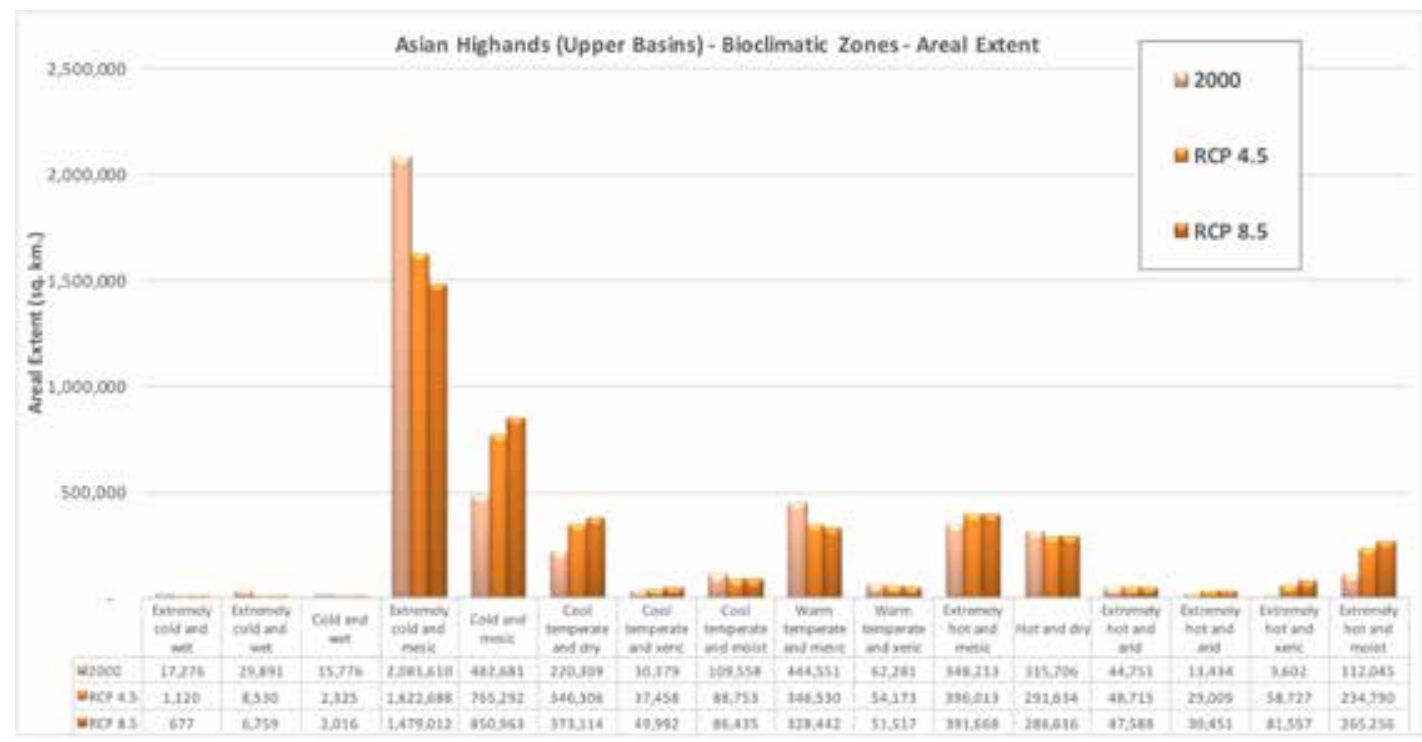

Figure 21: Areal extent of the AH_EnS bioclimatic zones under current (averaged 1960-2000) bioclimatic conditions, and by 2050, showing results for two RCP emission scenarios.

Percent of Area Shifted

\begin{tabular}{|l|cc|c|c|}
\hline & \multicolumn{2}{|c|}{ Bioclimatic Zones } & \multicolumn{2}{c|}{ Bioclimatic Strata } \\
\hline Basin & RCP 4.5 & RCP 8.5 & RCP 4.5 & RCP 8.5 \\
\hline & $\%$ & $\%$ & $\%$ & $\%$ \\
\hline Asian Highlands & 37.9 & 46.9 & 75.1 & 84 \\
Brahmaputra & 38.9 & 46.5 & 68.8 & 76.8 \\
Ganges & 47.3 & 55.3 & 82.7 & 88 \\
Indus & 56.1 & 65.3 & 84.7 & 90.4 \\
Irrawaddy & 45.2 & 55.5 & 83.1 & 90.4 \\
Meghna & 43.4 & 50.3 & 66.2 & 74.7 \\
Mekong & 56 & 67.4 & 89.9 & 94.3 \\
Salween & 37.1 & 47.1 & 75.3 & 84.3 \\
Tibetan Plateau & 27.7 & 35.8 & 66.4 & 78.4 \\
Yangtze & 48.2 & 60.3 & 92.2 & 96.1 \\
\hline
\end{tabular}

Table 2: The percent of the total area of each upland river basin (and the Asian Highlands as a whole) which have shifted to a completely different $A H \_E n S$ bioclimatic zone, or strata, indicating the likelihood of a novel set of bioclimatic conditions prevailing in that area by the year 2050. 


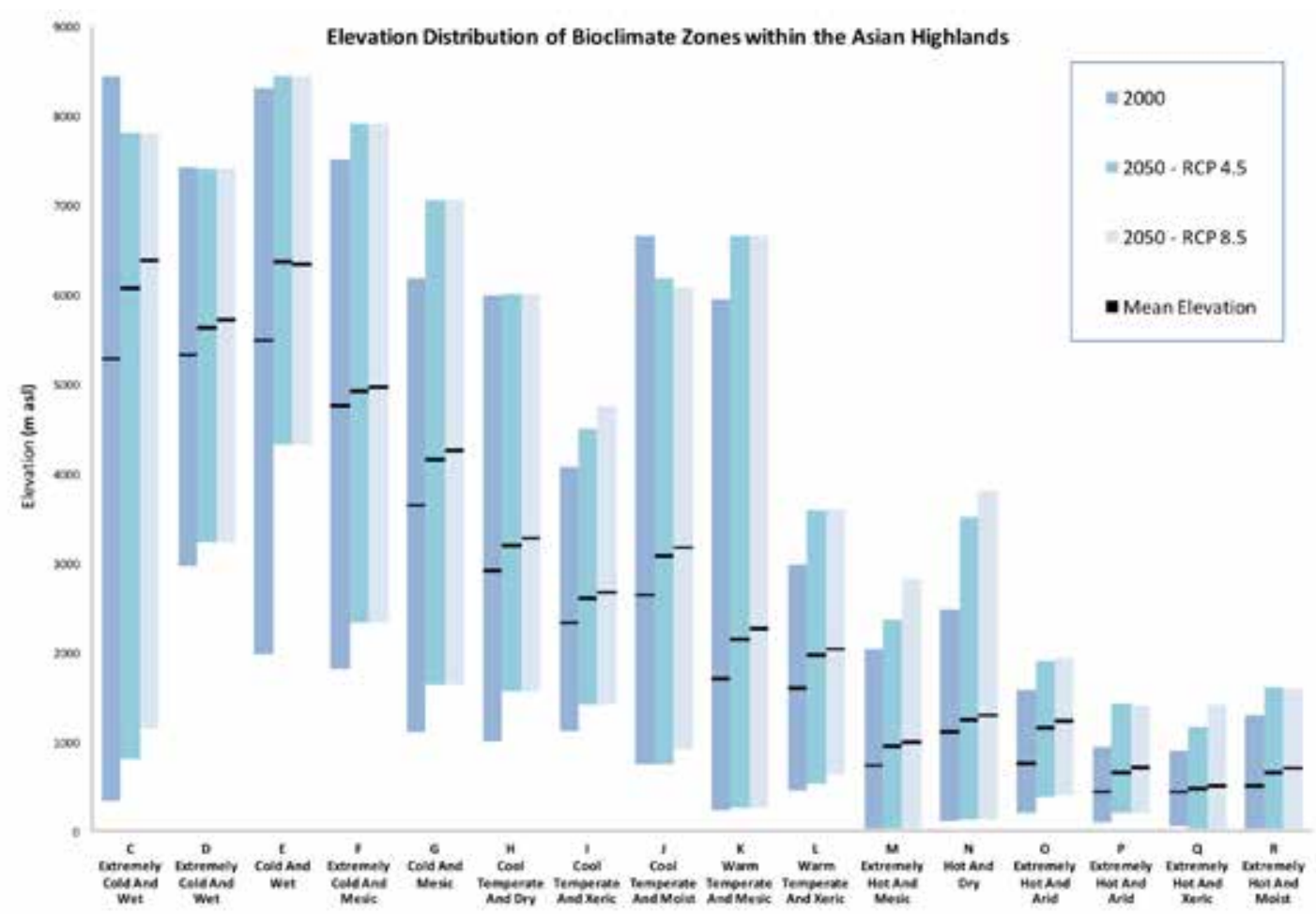

Figure 22: Maximum, mean, and minimum elevation of the $A H \_$EnS bioclimatic zones within the Asian Highlands, under current (averaged over 1960-2000) bioclimatic conditions, and by 2050, as show for two RCP emission scenarios (RCP 4.5 and 8.5). The dark bar in the middle of the column indicates the mean elevation.

Asian Highlands - Upper Basins

\begin{tabular}{|c|c|c|c|c|c|c|}
\hline \multirow[b]{2}{*}{ Bioclimatic Zone } & \multirow[b]{2}{*}{ Zone } & \multicolumn{3}{|c|}{ Mean Elevation (m asl) } & \multicolumn{2}{|c|}{ Upward Shift (m) } \\
\hline & & Year 2000 & RCP 4.5 & RCP 8.5 & RCP 4.5 & RCP 8.5 \\
\hline & & $\mathrm{m}$ asl & $\mathrm{m}$ asl & $\mathrm{m}$ asl & m & m \\
\hline Extremely cold and wet & C & 5219 & 5985 & 6286 & 766 & 1067 \\
\hline Extremely cold and wet & D & 5277 & 5569 & 5648 & 292 & 371 \\
\hline Cold and wet & $E$ & 5441 & 6293 & 6267 & 852 & 826 \\
\hline Extremely cold and mesic & $\mathrm{F}$ & 4737 & 4898 & 4936 & 161 & 199 \\
\hline Cold and mesic & G & 3628 & 4131 & 4238 & 503 & 610 \\
\hline Cool temperate and dry & $\mathrm{H}$ & 2902 & 3186 & 3264 & 284 & 362 \\
\hline Cool temperate and xeric & 1 & 2331 & 2602 & 2667 & 271 & 336 \\
\hline Cool temperate and moist & $\mathrm{J}$ & 2610 & 3054 & 3147 & 444 & 537 \\
\hline Warm temperate and mesic & K & 1675 & 2126 & 2245 & 451 & 570 \\
\hline Warm temperate and xeric & L & 1593 & 1961 & 2024 & 368 & 431 \\
\hline Extremely hot and mesic & M & 717 & 932 & 969 & 215 & 252 \\
\hline Hot and dry & $\mathrm{N}$ & 1088 & 1230 & 1280 & 142 & 192 \\
\hline Extremely hot and arid & $\mathrm{O}$ & 749 & 1146 & 1219 & 397 & 470 \\
\hline Extremely hot and arid & $P$ & 433 & 649 & 707 & 216 & 274 \\
\hline Extremely hot and xeric & Q & 431 & 465 & 490 & 34 & 59 \\
\hline Extremely hot and moist & $\mathrm{R}$ & 495 & 642 & 688 & 147 & 193 \\
\hline & & & & & 279 & 345 \\
\hline
\end{tabular}

${ }^{* * *}$ Zones $C, D, E$ not included in average

Table 3: Mean elevation of the AH EnS bioclimatic zones under current (averaged over 1960-2000) bioclimatic conditions, and mean upward shift under 2 RCP scenarios, by 2050. 


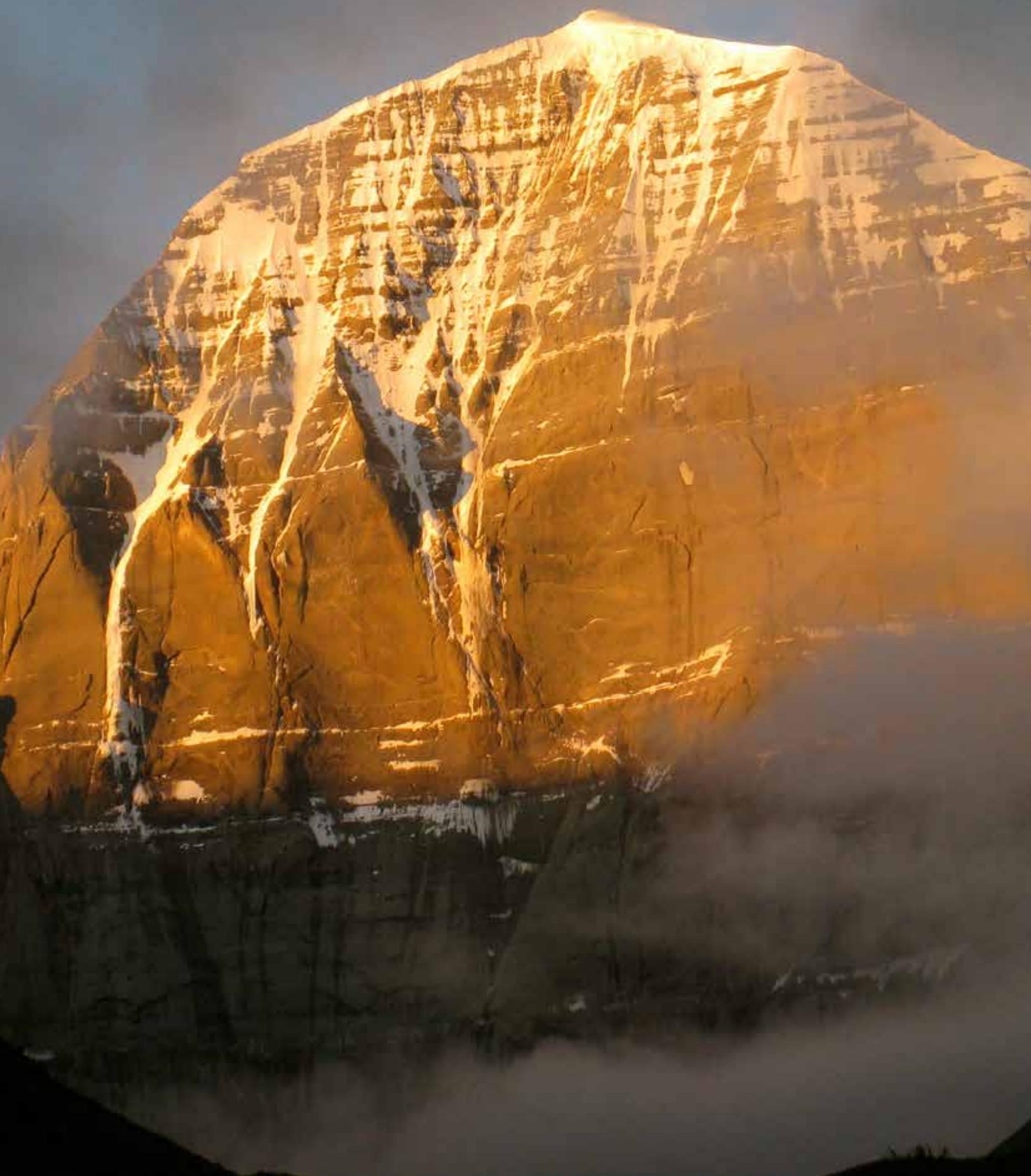




\section{Summary and conclusions}

Understanding and planning for adaptation and mitigation of climate change is crucial to the implementation of sustainable development and effective environmental and biological conservation in the Asian Highlands region. Climate change is and has been on-going, and is already evident and widely observed across the region. Meteorological data series for the Asian Highlands region have shown a steady increase of annual and winter temperatures since the beginning of the $20^{\text {th }}$ century. In line with predictions by global climate change models generally, the frequency of droughts has been observed to increase over the last few decades, highlighting the predicted increase in inter-annual, as well as intra-annual variability and frequency of extreme events.

Overall, the results of our spatial analysis based on the CIMP5 Earth System Model projections indicate rapid and drastic change in the spatially and historically "normal" distribution of bioclimatic conditions across the Asian Highlands region. As a consequence, significant and increasing biophysical and biological perturbance for biodiversity, ecosystems, ecosystem services, and agricultural and pastoral production systems, can be expected to become increasingly important in the near- to medium-term future under all RCP scenarios. The magnitude of predicted change indicated by our analysis points to a prolonged period of profound impacts on terrestrial ecosystems, biodiversity, and ecosystem services across the Asian Highlands, well under way by 2050 as a result of warming and climate disruption, and the shifting of bioclimatic conditions spatially, particularly within the highly diverse mountainous terrain and the high elevation highland areas. This change will impact upon and have increasingly substantial and direct impacts on ecosystems, biodiversity, agricultural crops, pastoral systems, water resources, as well as human health and livelihoods, throughout this region as this century progresses. Likewise, effectiveness of both conservation efforts and sustainable development will be affected, as ecological conditions across the region change, for example, allow for newly invasive species or going beyond limits conducive for endangered species currently found within narrow niches or designated protected areas.

A major conclusion to be drawn from this report is the overriding necessity to recognize the now central role of a rapidly changing climate and environment across the Asian Highlands region, and the need to incorporate, mainstream and plan for adaptation within most aspects of sustainable development and conservation planning, efforts and policy. The spatial articulation of results from this analysis allows for a detailed and geographically referenced overview of the potential impacts of change on bioclimatic conditions across the region.

Below we list the major findings of this analysis and report.

\section{Major findings}

\section{Projected change in bioclimatic indicators}

- The highland and mountainous regions of both monsoonal and continental Asia are approaching novel sets of bioclimatic conditions more rapidly than the lowland plains of the region. In particular, the northern and south-eastern portions of the Tibetan Plateau indicate early onset of novel conditions. The estimated year of climate departure for the various countries of the greater Asian Highlands region ranges from the 2051 to 2071 under the more moderate RCP 4.5 emissions scenarios, and ranges from 2036 to 2052 under the "worst case" RCP 8.5 scenario. This is slightly earlier than for the global average of 2069 for RCP 4.5 and 2047 for RCP 8.5 (Mora et al, 2013). 
- By 2050, mean annual temperatures for the Asian Highlands region (averaged over all upper basins) are projected to increase from $2.5^{\circ} \mathrm{C}$ to $3.1^{\circ} \mathrm{C}$. All the river basins comprising the region show increases in temperature, with the Indus Basin showing the greatest increases, ranging from $2.9^{\circ} \mathrm{C}$ to $3.5^{\circ} \mathrm{C}$.

- Temperature increase is greater at the higher elevations across the region, notably over the Tibetan Plateau. Mean annual temperatures over the Tibetan Plateau are projected to rise between $2.8^{\circ} \mathrm{C}$ to $3.4^{\circ} \mathrm{C}$ by 2050 . Notably, the Tibetan Plateau warms from an average of $-1.5^{\circ} \mathrm{C}$ up to between $1.3^{\circ} \mathrm{C}$ and $1.9^{\circ} \mathrm{C}$, with uncertain implications for impacts on large areas of permafrost, and consequently, vast stores of terrestrially sequestered carbon.

- All basins within the Asian Highlands region are projected to experience slight to moderate to substantial increases in precipitation by 2050 . Across all basins, annual precipitation is projected to increase as much as $39 \mathrm{~mm}$ to $48 \mathrm{~mm}$ on average. The Indus River Basin, already fairly arid with $465 \mathrm{~mm}$ on average under current conditions, is projected to slightly increase by between $8 \mathrm{~mm}$ to $23 \mathrm{~mm}$, whereas the already very wet Meghna River Basin (2897 mm on average) increases by up to almost $10 \%$ (i.e. projected to increase between $199 \mathrm{~mm}$ to $281 \mathrm{~mm}$ ). Overall, however, we caution that confidence levels for the precipitation projections of the CIMP5 Earth System Models are still, in general, quite low, with the variability among models generally higher (i.e. of lower confidence levels) than for the temperature projections, which has a higher level of agreement among models and can be considered fairly robust.

- The mean PET for the whole Asian Highlands region, on average $903 \mathrm{~mm}$ (1960-2000), increases by more than $9 \%$ to over $11 \%$ (between $85 \mathrm{~mm}$ to $103 \mathrm{~mm}$ ) by 2050, indicating significantly high water demand by both natural (unmanaged or lesser managed) ecosystems, and managed agricultural or pastoral systems. The Tibetan Plateau shows the largest increase in PET, from more than $13 \%$ to almost $17 \%$ increase (from $94 \mathrm{~mm}$ to $117 \mathrm{~mm}$ ). By contrast, PET averaged across the wet Meghna Basin increases by less than 3\%. These results seem to indicate that any benefit derived from increased precipitation in the drier basins will likely just compensate for the increase in PET (driven by increased temperatures).

- The Aridity-Wetness Index (AWI) is a general indicator of bioclimatic and plant growth conditions. The entire upland Asian Highlands region shows a very slight drying trend. The already dry Indus Basin showed the greatest (though still slight) drying trend, followed by the Yangtze, Mekong, and Brahmaputra Basins. The Meghna is projected to become wetter with a substantial increase in an already saturated AWI, along with the Irrawaddy to a lesser extent.

- A simple, spatially distributed soil water balance approach, used to model in-situ hydrological status, indicated that Annual Vapour Flow or Actual Evapotranspiration (AET) for the upland Asian Highlands region increases by more than $5 \%$. However, the Tibetan Plateau sees larger increases in AET, from $9 \%$ to $11 \%$, along with the Salween, the Brahmaputra, and Yangtze. Only the Meghna Basin shows decreased AET.

- All basins showed a slight drying trend in Soil Water Content (SWC), with the overall average SWC for the upland Asian Highlands region projected to decrease $5 \%$ by 2050 . The Tibetan Plateau showed the largest decrease in SWC (9\% to 13\%), along with the Indus (almost 9\%).

- In general, for the upper Asian Highlands region as a whole, the water balance model shows a slight increase in in-situ excess water (ROF), that is, an estimation of water from precipitation that is left over after AET and SWC changes are accounted for. The Ganges Basin increases its ROF by $13 \%$ to $15 \%$, while the Salween Basin increases from $10 \%$ to $15 \%$. The Indus Basin sees only a very slight increase, along with the Mekong. The Meghna Basin, with from $9 \%$ to $13 \%$ increase, also sees the largest absolute increase in ROF (192 mm to $262 \mathrm{~mm}$ ). 


\section{Projected change in spatial distribution of bioclimatic conditions}

- Sixteen major bioclimatic zones, comprised of 102 strata, were identified through this study as currently found within the upper basins of the Asian Highlands project region, ranging from the Extremely Hot and Moist strata at low elevations in the south and southeast, to Extremely Cold and Wet zones at the higher elevations. Warm tropical strata are found along the lower elevations and southern slopes of the mountains, and in the southeast, e.g. the tropical mountains of Yunnan, Laos, and Myanmar, with vast areas Extremely Cold, Cold and Cool zones covering the high elevation regions of the Tibetan Plateau.

- Mean annual temperatures for bioclimatic zones are generally inversely correlated with their average elevation, however the zonal distribution of bioclimatic conditions also reflects a strong influence of latitudinal and moisture gradients, and the influence (and confluence) of continental and oceanic (monsoonal) climatic regimes.

- Cold and Extremely Cold zones stretched across high elevation portions of Asian Highlands, notably covering much of the Tibetan Plateau, together comprise more than half of the total combined region (55\%). Of the 16 zones found within the Asian Highlands, only 10 zones individually cover $1 \%$ or more of the total regional area, with the five most extensive zones together comprising more than $85 \%$ of the total area.

- By 2050, substantial shifting and spatial displacement of the bioclimatic zones is seen across the region. Zones shift both upslope along elevation gradients and northward along the latitudinal gradient. From $38 \%$ to $47 \%$ of the entire regional is projected to shift to another bioclimatic zone by 2050 , that is, can expect a major shift to a novel set of bioclimatic conditions to be prevalent by then. Between $75 \%$ and $84 \%$ of the entire region shifts to a different bioclimatic stratum (indicating a more marginal incremental shift but still novel conditions).

- The largest zone in areal extent (Extremely Cold and Mesic), covering more than 2 million $\mathrm{km}^{2}$, decreases substantially (between $22 \%$ and $29 \%$ ) by 2050 , with these areas warming to become Cold to Cool Temperate strata. Medium elevation Warm Temperate and Mesic zones decrease in area, while Extremely Hot zones at lower elevations increase substantially.

- The average mean elevation of all the bioclimatic zones shifts upward, on average across the entire upland Asian Highlands region by $279 \mathrm{~m}$ to $345 \mathrm{~m}$. Almost all of the zones shift upward substantially in their maximum elevation extent, and most also shift upward in their minimum elevation extent (or at least stay approximately at the same minimum elevation). Many of the zones, especially the warmer zones, increase the extent of their elevation range substantially.

Impacts on specific ecosystems, ecosystem function, ecosystem services, vegetation types, wildlife or wildlife habitat, and/or agricultural and pastoral production systems, are difficult to predict, as the spatial distribution of life forms and ecosystems cannot be determined purely by general biophysical terms, and are likewise subject to other secondary change processes, for example disruption of pest or pollinator cycles, or invasive species. In general, although ranges of ecosystems and agricultural/ pastoral systems may shift, the ability to survive, adapt or benefit from these changes is system- and to a certain extent, site-specific, and depends on many factors as to the degree of vulnerability. In the case of mountain communities or agricultural and pastoral systems, that vulnerability is to a great extent dependent upon the biophysical and socio-ecological resilience of that system, and along with its cultural and socio-economic capacity for adaptation. Improving our understanding of biophysical 
and ecological responses to warming and climate disruption is among many important efforts that must be regionally implemented to provide a knowledge base useful for adaptation planning and implementation. Integrating spatially georeferenced modelled climate projections articulated in terms that are operationally usable can provide the input for climate-smart and sustainable development, supporting adaptation strategies and policies that can be effective within the context of the rapidly changing climate of the Asian Highlands.

\section{Conclusions}

Large scale vegetation distribution patterns are mainly controlled by climate (Barbour et al, 1987; Woodward and Williams, 1987), and in high elevation mountainous terrain, such as found in the Asian Highlands region, these can be delineated by the altitudinal zonation associated with steep elevation gradients. As a result of these steep elevation gradients and the accelerated warming evident over the region, projected wide-spread and large-scale spatial displacement of bioclimatic strata (i.e. sets of bioclimatic conditions, or "envelopes") indicates an increasingly dynamic ecological landscape in a process of change to new equilibriums in biophysical and ecological systems. The magnitude of projected change indicated by our multi-model ensemble analysis of the CIMP-5 Earth System Models points to profound impacts on terrestrial ecosystems, biodiversity, ecosystem services and mountain communities as a result of warming and changing climatic conditions in the near to medium-term, that is, these impacts and processes are expected to be amply evident across the region and well under way by 2050 .

These impacts on the spatial distribution of bioclimatic strata within the Asian Highlands region will similarly have a substantial although regionally differentiated impact on agricultural production across the Asian Highlands, particularly traditional mountain agricultural and pastoral systems which may be adapted to highly specific climatic niches (Li and Fox, 2012). Traditional agricultural systems, which have been shown to conserve and maintain in-situ high levels of agricultural biodiversity, may benefit from improved growing conditions in some locales, however this potential may be offset by increased variability. Additionally, the spatial displacement of bioclimatic conditions projected and analysed in this study suggests that these mountain farming and pastoral systems will be forced to adapt to rapidly changing conditions, either through modifying their agricultural or pastoral management practices, selecting new cultivars, species, livestock breeds or farming systems, or migrating to areas of better opportunities or newly improved conditions, for example as higher elevation slopes warm sufficiently for crop production.

Global and regional processes, notably infrastructure development, commercialization, globalization of agriculture, but also cultural and socio-economic change in the Asian Highlands, have already undermined the viability of many of these subsistence systems across the region. These diverse and in many cases cyclic land use systems enhance biodiversity at genetic, species, landscape, and cultural levels (Guo et al, 2002). Supporting these farmers, herders and mountain communities to adapt to changing conditions requires efforts to enhance socio-ecological resilience of ecosystems and mountain communities. The results of this analysis provide the basis for a spatially georeferenced knowledge base that takes into account the impacts and opportunities of future conditions for mountain communities, farming systems, and for supporting localized adaptation planning and strategy development. 
In terms of biodiversity and its conservation, results of this analysis forewarn of a prolonged period of climate perturbation, ecological disruption, and potentially widespread spatial dislocation with the potential of extinctions for already endangered or threatened species, especially those that are narrowly adapted to highly specific niches. Without concerted efforts to mitigate habitat loss, species ranges may shift beyond current habitat or extent of existing vegetation type, or fragment through lack of connectivity. In particular, the terrain, topography, land cover, and human settlement patterns within mountains create highly specific conditions which impact on the ability of species and ecosystems to adapt to climate change. Likewise, the velocity of change and the potential velocity of species or ecosystems to disperse in the landscape create highly specific adaptation capacity which varies both by species or ecosystem, and by very region- or site-specific considerations.

The highly differentiated and diverse micro-climatic conditions found in a mosaic of patterns across mountain landscapes means that there will be some resilience within mountain ecosystems to adapt to rapidly changing conditions, however, in general, mountains and mountain biodiversity are considered highly fragile and vulnerable to the projected change and spatial displacement of bioclimatic conditions. This set of fairly rapid and drastic change processes will increasingly impact upon the conservation effectiveness of the many protected areas and biodiversity reserves across the Asian Highlands region ( $\mathrm{Pu}$ et al, 2007; La Sorte and Jetz, 2010), as ecological conditions within these protected areas change beyond limits conducive for species currently found there. Impacts on specific vegetation types, particular species, or wildlife, are more difficult to predict, as the spatial distribution of life forms cannot be defined in purely biophysical terms (Barbour et al, 1987).

In general, however, it is possible to define the climatic envelopes of most types of vegetation, and to a large extent associated fauna, on the basis of correlations between their distribution, annual temperature, and precipitation (Holdridge, 1947, 1967; Whittaker, 1970; Leith, 1974; Box, 1981; Woodward, 1991). It is likely that the responses to changed conditions will be closely correlated with those more critical limiting factors (Woodward and Williams, 1987). Although species ranges will shift, the ability to survive, adapt or benefit from these changes is species- and site-specific, and depends on factors such as population dynamics, seed dispersal mechanisms, habitat fragmentation, and physiological adaptability (Corlett and Westcott, 2013). Improving our understanding of these responses, while maintaining as much habitat and landscape connectivity as possible, is imperative if conservation strategies and policies designed to meet these challenges are to be effective within the context of the rapidly changing bioclimatic conditions described by the results of this analysis.

Opportunities to anticipate, and to some extent mitigate these expected impacts may exist if the nature and magnitude of changing bioclimatic conditions can be better understood. Almost all sectors now need to consider the implications of climate and other associated environmental change. More specifically, climate change and adaptation has now become a widespread and urgent issue across the Asian Highlands region. The results of the analysis presented in this report provide an overview and a spatial mapping of trends and impacts on bioclimatic conditions across the region by 2050 .

In conclusion, we stress the need to incorporate a fundamental awareness of on-going and projected rapid climatic change on all levels of planning and policy. In response to anticipated effects of climate change, organizations at all levels and government agencies throughout the region, and the world, are developing "adaptation strategies" at various scales to facilitate the adjustment of human society and ecological systems to altered climate regimes. As reported in this analysis, the Asian Highlands region is, and will be, at the forefront of that change. 


\section{References}

Barbour, M., Burk, J., Pitts, W., Gilliam, F., 1987. Terrestrial Plant Ecology, 2nd ed. Benjamin/ Cummunings Publishing, Menlo Park, California.

Barnett, T.P., Adam, J.C., Lettenmaier, D.P., 2005. Potential impacts of a warming climate on water availability in snow-dominated regions. Nature 438, 303-309. doi:10.1038/nature04141

Beniston, M., 2003. Climatic change in mountain regions: a review of possible impacts. Climatic Change 59, 5-31.

Box, E., 1981. Macroclimate and plant forms: an introduction to predictive modeling in phytogeography. Junk, The Hague.

Chen, I.-C., Shiu, H.-J., Benedick, S., Holloway, J.D., Chey, V.K., Barlow, H.S., Hill, J.K., Thomas, C.D., 2009. Elevation increases in moth assemblages over 42 years on a tropical mountain. Proc. Natl. Acad. Sci. U.S.A. 106, 1479-1483. doi:10.1073/pnas.0809320106

Chettri, N., Shakya, B., Thapa, R., Sharma, E., 2008. Status of a protected area system in the Hindu Kush-Himalayas: An analysis of PA coverage. Int. J. of Biodiversity Sc., Ecosystems Services \& Man. 4, 164-178. doi:10.3843/Biodiv.4.3:4

Corlett, R.T., Westcott, D.A., 2013. Will plant movements keep up with climate change? Trends Ecol. Evol. (Amst.) 28, 482-488. doi:10.1016/j.tree.2013.04.003

Ebi, K.L., Woodruff, R., Hildebrand, A., Corvalan, C., 2007. Climate Change-related Health Impacts in the Hindu Kush-Himalayas. EcoHealth 4, 264-270. doi:10.1007/s10393-007-0119-z

Hijmans, R.J., Cameron, S.E., Parra, J.L., 2005. Very high resolution interpolated climate surfaces for global land areas. Int. J. Climatol. 25, 1965-1978.

Hijmans (2015) FutureClim: 30-seconds downscaled global climate model (GCM) data from CMIP5 (available at www.worldclim.org/future.htm)

Holdridge, L.R., 1967. Life zone ecology.

Holdridge, L.R., 1947. Determination of World Plant Formations From Simple Climatic Data. Science 105, 367-368. doi:10.1126/science.105.2727.367

Immerzeel, W.W., van Beek, L.P.H., Bierkens, M.F.P., 2010. Climate Change Will Affect the Asian Water Towers. Science 328, 1382-1385. doi:10.1126/science.1183188

Jarvis, A., Reuter, H., Nelson, A., 2008. Hole-filled SRTM for the globe - Version 4. Available

Immerzeel, W. W., Pellicciotti, F., \& Bierkens, M. (2013). Rising river flows throughout the twentyfirst century in two Himalayan glacierized watersheds. Nature Geoscience.online from the CGIARCSI SRTM 90m website: srtm.csi.cgiar.org.

La Sorte, F.A., Jetz, W., 2012. Tracking of climatic niche boundaries under recent climate change. J Anim Ecol. doi:10.1111/j.1365-2656.2012.01958.x

La Sorte, F.A., Jetz, W., 2010. Projected range contractions of montane biodiversity under global warming. Proc. Biol. Sci. 277, 3401-3410. doi:10.1098/rspb.2010.0612

Li, Z., Fox, J. M., 2012. Mapping rubber tree growth in mainland Southeast Asia using time-series MODIS 250 m NDVI and statistical data. Applied Geography, 32(2), 420-432.

Leith H (1974) Phenology and Seasonality Modeling. Springer-Verlag, Berlin 
Liu, X., 2000. Climatic warming in the Tibetan Plateau during recent decades. Int. J. Climatol.

Liu, X., Cheng, Z., Yan, L., Yin, Z.Y., 2009. Elevation dependency of recent and future minimum surface air temperature trends in the Tibetan Plateau and its surroundings. Global and Planetary Change 68, 164-174.

Maikhuri, R., Rao, K., Semwal, R., 2001. Changing scenario of Himalayan agroecosystems: loss of agrobiodiversity, an indicator of environmental change in Central Himalaya, India. The Environmentalist 21, 23-39. doi:10.1023/A:1010638104135

Meehl, G.A., Bony, S., 2011. Introduction to CMIP5. Clivar Exchanges 16, 2-5.

Metzger, M.J., Bunce, R.G.H., Jongman, R.H.G., Sayre, R., Trabucco, A., Zomer, R., 2013. A highresolution bioclimate map of the world: a unifying framework for global biodiversity research and monitoring. Global Ecology and Biogeography 22, 630-638. doi:10.1111/geb.12022

Mora, C., Frazier, A.G., Longman, R.J., Dacks, R.S., Walton, M.M., Tong, E.J., Sanchez, J.J., Kaiser, L.R., Stender, Y.O., Anderson, J.M., Ambrosino, C.M., Fernandez-Silva, I., Giuseffi, L.M., Giambelluca, T.W., 2013. The projected timing of climate departure from recent variability. Nature 502, 183-187. doi:10.1038/nature12540

Myers, N., Mittermeier, R.A., Mittermeier, C.G., da Fonseca, G.A., Kent, J., 2000. Biodiversity hotspots for conservation priorities. Nature 403, 853-858. doi:10.1038/35002501

Pu, Y.-S., Zhang, Z.-Y., Pu, L.-N., Hui, C.-M., 2007. Biodiversity and its fragility in Yunnan, China. J. of For. Res. 18, 39-47. doi:10.1007/s11676-007-0008-x

Ramirez-Villegas, J., Jarvis, A., 2010. Downscaling global circulation model outputs: the delta method decision and policy analysis. International Center for Tropical Agriculture, CIAT, Cali, Colombia.

Ramesh, K.V., Goswami, P., 2007. Reduction in temporal and spatial extent of the Indian summer monsoon. Geophys. Res. Lett. 34, L23704-. doi:10.1029/2007GL031613

Schild, A., 2008. ICIMOD's Position on Climate Change and Mountain Systems. Mountain Research and Development.

Sharma, E., Chettri, N., Oli, K.P., 2010. Mountain biodiversity conservation and management: a paradigm shift in policies and practices in the Hindu Kush-Himalayas. Ecol Res 25, 909-923. doi:10.1007/s11284-010-0747-6

Sharma, E., Chettri, N., Tse-ring, K., Shrestha, A.B., Jing, F., Mool, P., Eriksson, M., 2009. Climate change impacts and vulnerability in the Eastern Himalayas. ICIMOD, Kathmandu.

Shrestha, U.B., Gautam, S., Bawa, K.S., 2012. Widespread Climate Change in the Himalayas and Associated Changes in Local Ecosystems. PLoS ONE 7, e36741. doi:10.1371/journal.pone.0036741

Singh, S.P., Isabell, B.K., Karky, B.S., Sharma, E., 2011. Climate Change in the Hindu KushHimalayas: The State of Current Knowledge. ICIMOD, Kathmandu.

Thuiller, W., 2007. Biodiversity: climate change and the ecologist. Nature 448, 550-552. doi: $10.1038 / 448550 \mathrm{a}$

Tingley, M.W., Monahan, W.B., Beissinger, S.R., Moritz, C., 2009. Birds track their Grinnellian niche through a century of climate change. Proc. Natl. Acad. Sci. U.S.A. 106 Suppl 2, 19637-19643. doi:10.1073/pnas.0901562106

Trabucco, A., Zomer, R.J., Bossio, D.A., van Straaten, O., Verchot, L.V., 2008. Climate change mitigation through afforestation/reforestation: A global analysis of hydrologic impacts with four case studies. Agriculture Ecosystems and Environment 126, 81-97. doi:10.1016/j.agee.2008.01.015 
Vuuren, D.P., Edmonds, J., Kainuma, M., Riahi, K., Thomson, A., Hibbard, K., Hurtt, G.C., Kram, T., Krey, V., Lamarque, J.-F., Masui, T., Meinshausen, M., Nakicenovic, N., Smith, S.J., Rose, S.K., 2011. The representative concentration pathways: an overview. Climatic Change 109, 5-31. doi:10.1007/ s10584-011-0148-z

Whittaker R (1970) Communities and ecosystems. Macmillan Co., New York

Woodward, F., \& McKee, I. F. (1991). Vegetation and climate. Environment International, 17, 535546.

Woodward, F.I., Williams, B.G., 1987. Climate and plant distribution at global and local scales. Vegetatio 69, 189-197. doi:10.1007/BF00038700

Xu, J., Grumbine, R.E., SHRESTHA, A., Eriksson, M., YANG, X., Wang, Y., Wilkes, A., 2009a. The Melting Himalayas: Cascading Effects of Climate Change on Water, Biodiversity, and Livelihoods. Conservation Biology 23, 520-530. doi:10.1111/j.1523-1739.2009.01237.x

Xu, J., Shrestha, A., Eriksson, M., Braun, L., Severskiy, W.H.I.V., Young, G., 2009b. Climate change and its impacts on glaciers and water resource management in the Himalayan Region. Assessment of snow, glacier and water resources in Asia 44-54.

Xu, J., Vaidya, R., Eriksson, M., Hewitt, K., Jianchu, X., A. Shrestha, A., 2007a. The melting Himalayas: regional challenges and local impacts of climate change on mountain ecosystems and livelihoods. International Centre for Integrated Mountain Development (ICIMOD).

Xu, J., Yang, Y., Fox, J., 2007b. Forest transition, its causes and environmental consequences: empirical evidence from Yunnan of Southwest China. Tropical Ecology.

Zomer, R., Trabucco, A., Bossio, D., Verchot, L.V., 2008. Climate change mitigation: A spatial analysis of global land suitability for clean development mechanism afforestation and reforestation. Agriculture Ecosystems and Environment 67-80.

Zomer, R., Trabucco, A., Van Straaten, O., Bossio, D., 2006. Carbon, land and water: A global analysis of the hydrologic dimensions of climate change mitigation through afforestation/reforestation 101.

Zomer, R.J., Trabucco, A., Metzger, M.J., Wang, M., Oli, K.P., 2014. Projected climate change impacts on spatial distribution of bioclimatic zones and ecoregions within the Kailash Sacred Landscape of China, India, Nepal. Climatic Change 445-460. doi:10.2307/4555340?ref=no-x-route:6 49d99bd9d6bf67c5b4e18d2f1c48748

Zomer, R.J., Xu, J., Wang, M., Trabucco, A., Li, Z., 2015a. Projected impact of climate change on the effectiveness of the existing protected area network for biodiversity conservation within Yunnan Province, China. Biological Conservation 184, 335-345. doi:10.1016/j.biocon.2015.01.031

Zomer, R; Wang, M.; and Xu, J., 2015b. Projected climate change and impact on bioclimatic conditions in Central and South-Central Asia. ICRAF Working Paper 187. World Agroforestry Centre East and Central Asia, Kunming, China. pp 50. Doi: http://dx.doi.org/10.5716/WP14144.PDF 


\section{Appendix}

\section{Appendix 1: CIMP5 Earth System Models}

CIMP5 Earth System Models (ESM), downscaled to $\sim 1 \mathrm{~km}^{2}$ resolution, across four representative conservation pathways (RCP), representing a range of emission scenarios from lowest (RCP 2.6) to highest (RCP 8.5). Results from sixty-three ESM/RCP combinations were used in the analysis.

\begin{tabular}{|c|c|c|c|c|c|c|}
\hline CENTER & COUNTRY & CIMP5 - ESM & RCP 2.6 & RCP 4.5 & RCP 6.0 & RCP 8.5 \\
\hline $\begin{array}{l}\text { Commonwealth Scientific and Industrial Research Organization and Bureau of } \\
\text { Meteorology }\end{array}$ & Australia & ACCESS1-0 & & $\mathbf{x}$ & & $\mathbf{x}$ \\
\hline Beijing Climate Center, China Meteorological Administration & China & BCC-CSM1-1 & $\mathbf{x}$ & $\mathbf{x}$ & $\mathbf{x}$ & $\mathbf{x}$ \\
\hline National Center for Atmospheric Research & United States & CCSM4 & $\mathbf{x}$ & $\mathbf{x}$ & $\mathbf{x}$ & $\mathbf{x}$ \\
\hline National Science Foundation & United States & $\begin{array}{l}\text { CESM1-CAM5- } \\
\text { 1-FV2 }\end{array}$ & & $\mathbf{x}$ & & \\
\hline $\begin{array}{l}\text { Centre National de Recherches Meteorlogiques/Centre Europeen de Recherche et } \\
\text { Formation Avancee en Calcul Scientifique }\end{array}$ & France & CNRM-CM5 & $\mathbf{x}$ & $\mathbf{x}$ & & $\mathbf{x}$ \\
\hline NOAA Geophysical Fluid Dynamics Laboratory & United States & GFDL-CM3 & $\mathrm{x}$ & $\mathrm{x}$ & & $x$ \\
\hline NOAA Geophysical Fluid Dynamics Laboratory & United States & GFDL-ESM2G & $\mathbf{x}$ & $\mathbf{x}$ & $\mathrm{x}$ & \\
\hline NASA Goddard Institute for Space Studies & United States & GISS-E2-R & $\mathbf{x}$ & $\mathbf{x}$ & $\mathrm{x}$ & $\mathbf{x}$ \\
\hline Met Office Hadley Centre & UK & HadGEM2-AO & $\mathbf{x}$ & $\mathbf{x}$ & $\mathbf{x}$ & $\mathbf{x}$ \\
\hline Met Office Hadley Centre & UK & HadGEM2-CC & & $\mathbf{x}$ & & $\mathbf{x}$ \\
\hline Met Office Hadley Centre & UK & HadGEM2-ES & $\mathbf{x}$ & $\mathbf{x}$ & $\mathbf{x}$ & $\mathbf{x}$ \\
\hline Institute for Numerical Mathematics & Russia & INMCM4 & & $\mathbf{x}$ & & $\mathbf{x}$ \\
\hline Institut Pierre-Simon Laplace & France & IPSL-CM5A-LR & $\mathbf{x}$ & $\mathbf{x}$ & $\mathbf{x}$ & $\mathbf{x}$ \\
\hline Ocean Research Institute and National Institute for Environmental Studies & Japan & MIROC-ESM-CHEM & $\mathbf{x}$ & $\mathbf{x}$ & $\mathbf{x}$ & $\mathbf{x}$ \\
\hline Japan Agency for Marine-Earth Science and Technology & Japan & MIROC-ESM & $\mathbf{x}$ & $\mathbf{x}$ & $\mathbf{x}$ & $\mathbf{x}$ \\
\hline $\begin{array}{l}\text { Atmosphere and Ocean Research Institute (The University of Tokyo), National } \\
\text { Institute for Environmental Studies, and Japan Agency for Marine-Earth Science } \\
\text { and Technology }\end{array}$ & Japan & MIROC5 & $\mathbf{x}$ & $\mathbf{x}$ & $\mathbf{x}$ & $\mathbf{x}$ \\
\hline Max Planck Institut für Meteorologic & Germany & MPI-ESM-LR & $\mathbf{x}$ & $\mathbf{x}$ & & $\mathbf{x}$ \\
\hline Meteorological Research Institute & Japan & MRI-CGCM3 & $\mathbf{x}$ & $\mathbf{x}$ & $\mathbf{x}$ & $\mathbf{x}$ \\
\hline Norwegian Climate Centre & Norway & NorESM1-M & $x$ & $x$ & $\mathbf{x}$ & $\mathbf{x}$ \\
\hline
\end{tabular}




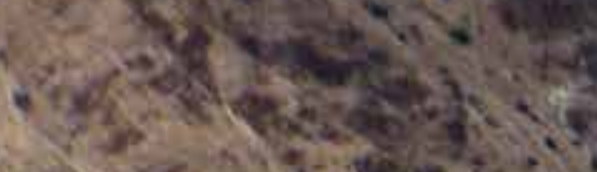
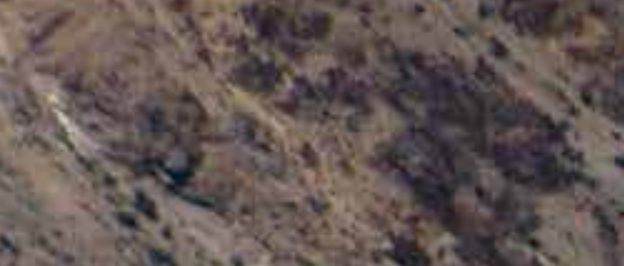

Y

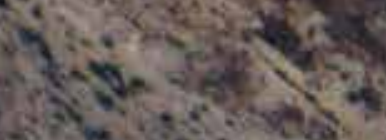

a. $24+5$

wer

is)

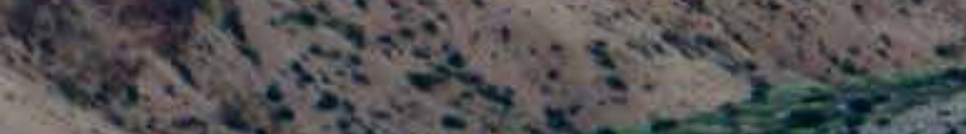

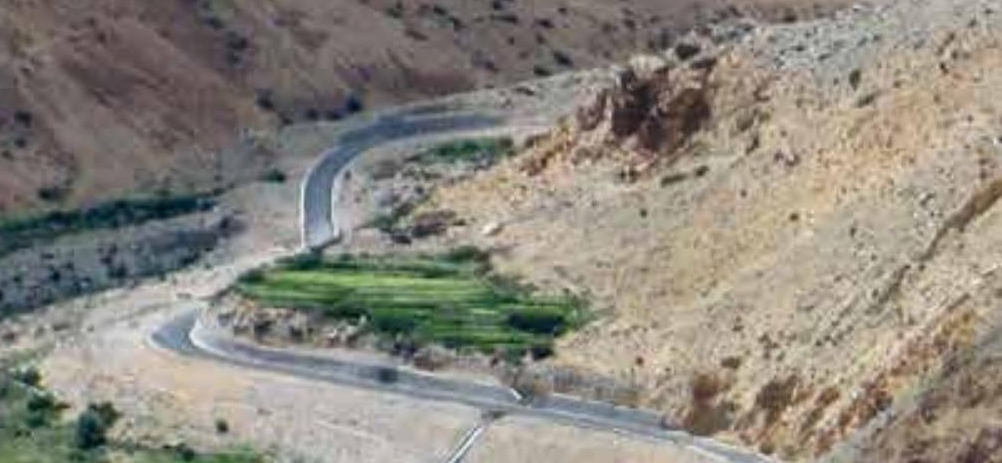

S.

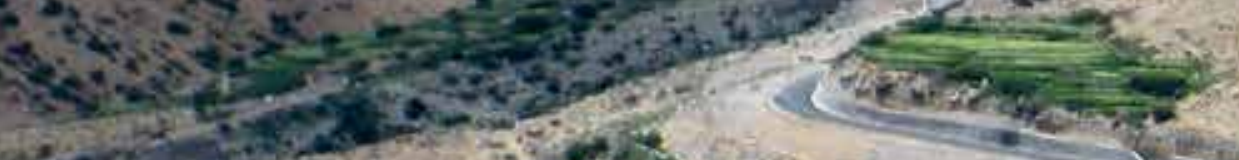

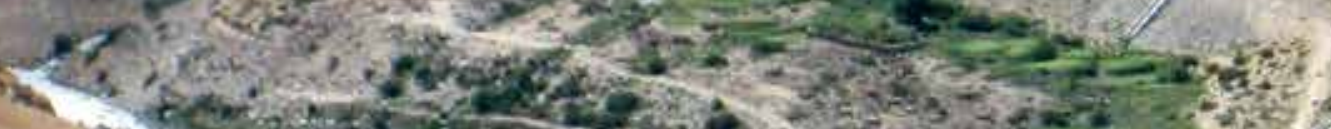

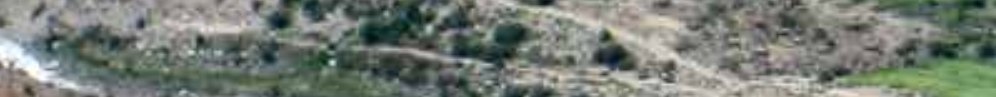

g.

तh

S.

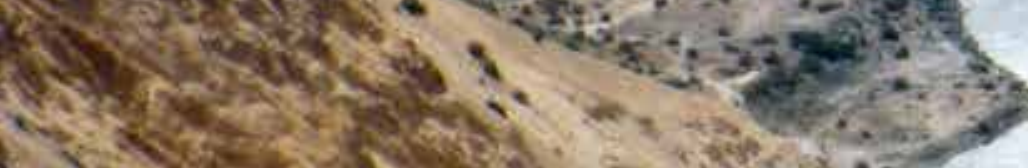

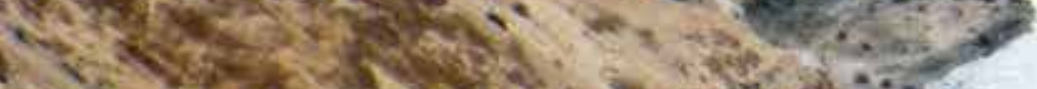

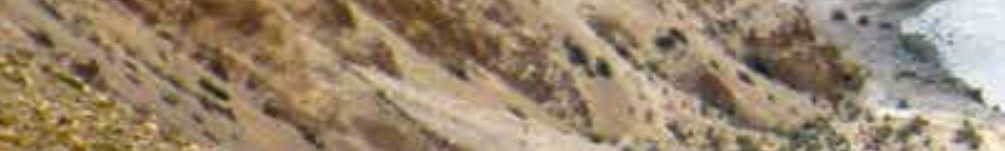

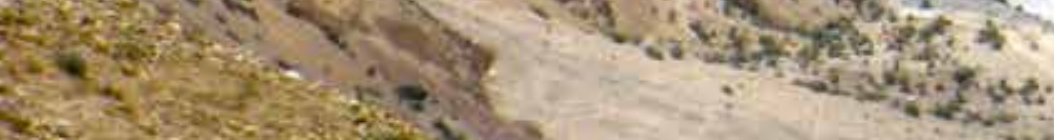

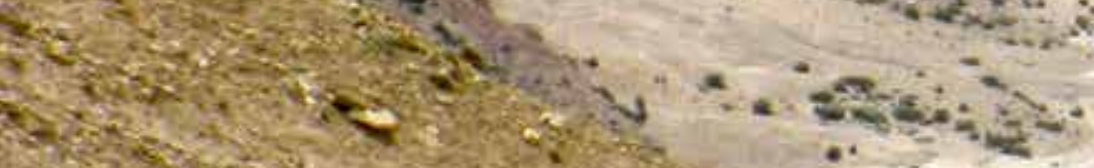

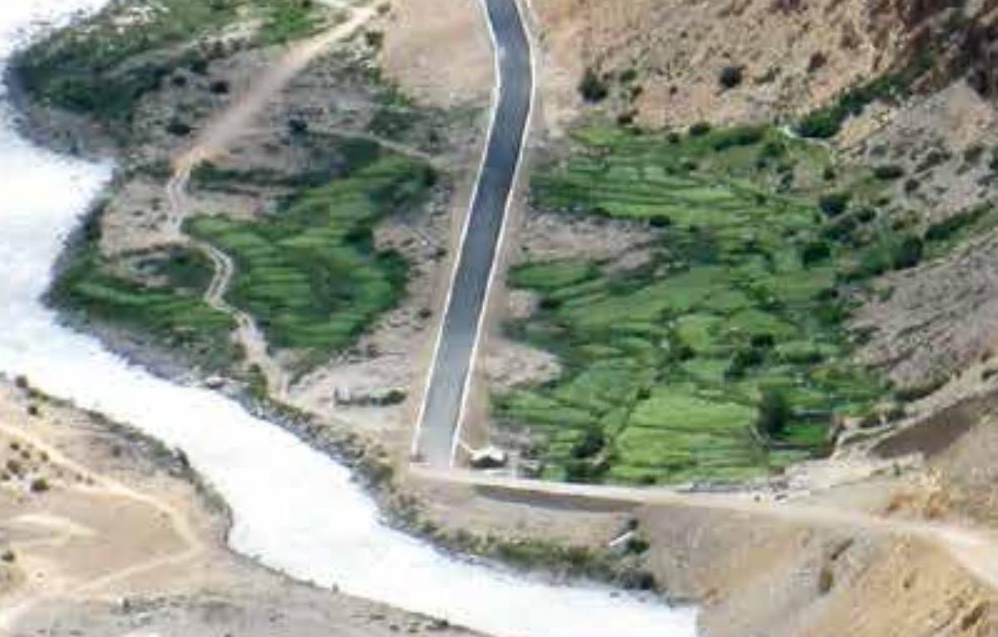

axis:

Q7.

nstis.

se

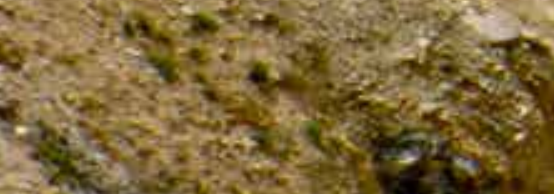

s.t.

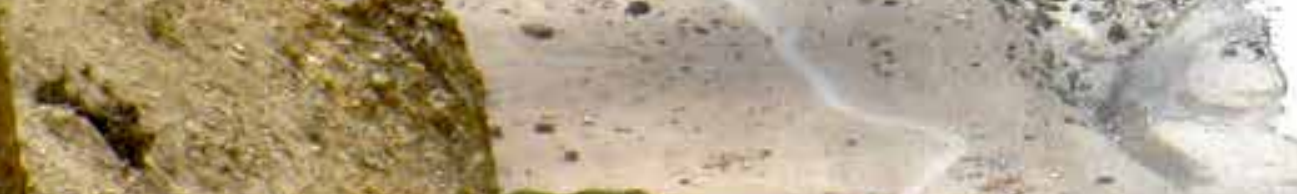

yet

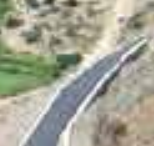

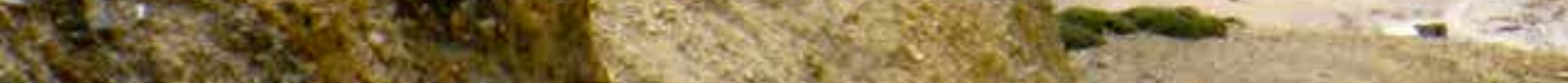

$t^{3}=x+2 x$

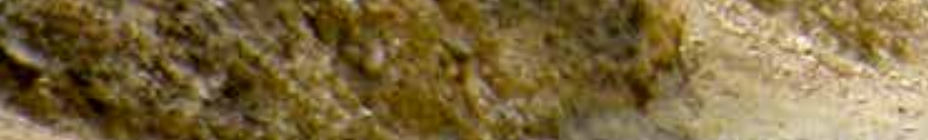
wastis 
The World Agroforestry Centre is an autonomous, non-profit research organization whose vision is a rural transformation in the developing world as smallholder households increase their use of trees in agricultural landscapes to improve food security, nutrition, income, health, shelter, social cohesion, energy resources and environmental sustainability. The Centre generates science-based knowledge about the diverse roles that trees play in agricultural landscapes, and uses its research to advance policies and practices, and their implementation that benefit the poor and the environment. It aims to ensure that all this is achieved by enhancing the quality of its science work, increasing operational efficiency, building and maintaining strong partnerships, accelerating the use and impact of its research, and promoting greater cohesion, interdependence and alignment within the organization.

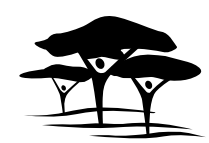

United Nations Avenue, Gigiri • PO Box 30677 • Nairobi, $00100 \cdot$ Kenya Telephone: +254207224000 or via USA +1 6508336645 Fax: +254207224001 or via USA +1 6508336646

Email: worldagroforestry@cgiar.org•www.worldagroforestry.org

East and Central Asia Regional Programme \% Kunming Institute of Botany • 3/F North Research Building Heilongtan • 650201 Kunming • Yunnan Province • P.R. China Telephone: +86-871-6522-3014 • Fax: +86-871-6522-3377 Email: icraf-eca@cgiar.org•www.worldagroforestry.org/eca 